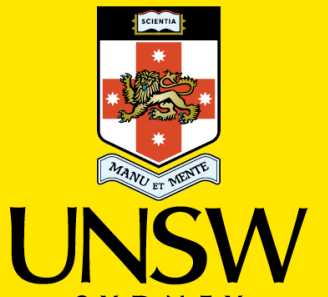

S Y D N Y
Australia's

Global

University
Business School / School of Economics

UNSW Business School Working Paper

UNSW Business School Research Paper No. 2017 ECON 17

Global Spillover Effects of US Uncertainty

Saroj Bhattarai

Arpita Chatterjee

Woong Wong Park 


\title{
Global Spillover Effects of US Uncertainty*
}

\author{
Saroj Bhattarai ${ }^{\dagger} \quad$ Arpita Chatterjee $\quad$ Woong Yong Park ${ }^{\ddagger}$
}

\begin{abstract}
We study spillover effects of US uncertainty fluctuations using panel data from fifteen emerging market economies (EMEs). A US uncertainty shock negatively affects EME stock prices and exchange rates, raises EME country spreads, and leads to capital outflows from them. Moreover, it decreases EME output, while increasing their consumer prices and net exports. The negative effects on output, exchange rates, and stock prices are weaker, but the effects on capital and trade flows stronger, for South American countries compared to other EMEs. We present a model of a small open economy that faces an external shock to interpret our findings.

Keywords: US Uncertainty; Emerging Market Economies; Small Open Economy Model; Capital Flows; Country Spread

JEL Classification: C33; E44; E52; E58; F32; F41
\end{abstract}

${ }^{*}$ First Version: September 2016. This version: October 2017.

${ }^{\dagger}$ University of Texas at Austin. 2225 Speedway, Stop C3100, University of Texas at Austin, Austin, TX 78712, U.S.A. Email: saroj.bhattarai@austin.utexas.edu.

${ }^{\ddagger}$ University of New South Wales. UNSW Business School, School of Economics, Sydney, NSW 2052, Australia. Email: arpita.chatterjee@unsw.edu.au.

${ }^{\S}$ Seoul National University and CAMA. Department of Economics, Seoul National University, 1 Gwanakro, Gwanak-gu, Seoul 08826, South Korea. Email: woongyong.park@snu.ac.kr. 


\section{Introduction}

What are the international spillover effects of fluctuations in US uncertainty? Given the recent integration of the emerging market economies (EMEs) to world financial markets, how does US financial uncertainty transmit to the financial sectors and the macroeconomy of these countries? If these spillovers are non-trivial, how can EMEs best cope with them? Specifically, does this cross-border transmission differ depending on the monetary policy stance of the EMEs?

These issues have received increased attention recently. Policy makers in EMEs and professional forecasters often cite increases in US and global uncertainty as a major reason for revising their economic forecasts downward as well as for an increase in the volatility of international capital flows. US uncertainty fluctuations in fact could have serious policy implications for EMEs beyond simple negative spillover effects on output. For instance, Rey (2013) highlights how uncertainty fluctuations in US financial markets, as measured by the Chicago Board of Options Exchange (CBOE) VIX index, tend to drive a global financial cycle and thereby, affect global asset prices and financial flows significantly. Rey $(2013,2015)$ argues that for many countries, especially periphery countries like EMEs, the traditional open-economy policy "trilemma" might have morphed into a "dilemma": countries cannot have both independent monetary policy and perfect capital mobility, even with flexible exchange rates. In fact, even the role and effectiveness of traditional monetary policy of EMEs in mitigating the macroeconomic and financial impact of fluctuations in US uncertainty is not fully understood.

We contribute to this topic on two main fronts. First, we measure empirically and study theoretically the spillover effects on EMEs of fluctuations in US financial uncertainty. Second, we study, again both empirically and theoretically, heterogeneity across EMEs with respect to transmission of this shock and monetary policy responses. ${ }^{1}$ Our results provide strong evidence that a rise in US financial uncertainty has substantial financial and macroeconomic spillover effects on EMEs. Moreover, we find that the nature of monetary policy response by EMEs can affect the cross-border transmission of the US uncertainty shock.

In our empirical framework, we estimate a monthly panel VAR for the following fifteen EMEs: Chile, Colombia, Brazil, India, Indonesia, Malaysia, Mexico, Peru, Philippines, Russia, South Africa, South Korea, Taiwan, Thailand, and Turkey. ${ }^{2}$ The panel VAR includes an

\footnotetext{
${ }^{1}$ We use the CBOE VIX index, which is the implied US stock market volatility, as the baseline proxy of US financial uncertainty since it is the most widely used indicator in the literature. In a robustness exercise, we use the US financial uncertainty measure estimated by Ludvigson, Ma, and Ng (2015).

${ }^{2}$ These countries are selected based on the classification of emerging economies by the IMF and Morgan Stanley. We do not include countries that experienced major economic crises during our sample period, such as Argentina and Venezuela, as well as countries that might actively manage their exchange rates, such as
} 
unanticipated component of US financial market uncertainty as an external shock so that the spillover effects of the fluctuations in US financial uncertainty can be traced out. In particular, we take the random coefficient approach to partially pool the cross-sectional information in the data and estimate average effects across EMEs of fluctuations in US uncertainty.

We estimate that unanticipated changes in US financial market uncertainty have significant financial and macroeconomic effects on the EMEs. An unanticipated increase in US uncertainty sharply depreciates the local currency of EMEs, leads to a decline in their local stock markets, increases long-term interest rate spreads (vis-à-vis the US), and is followed by capital outflows from them. These effects are statistically and economically significant. Specifically, on average across EMEs, a 1\% increase in US financial uncertainty leads to a $0.0035 \%$ point increase in the short-term interest rate, a $0.012 \%$ point increase in the long-term interest rate compared to the US, a $0.125 \%$ fall in the stock prices, a $0.045 \%$ depreciation of the local currency, and a $0.0175 \%$ point capital outflows relative to GDP. These are peak effects of US uncertainty fluctuations that occur 2-12 months after the impact. The effects on EME financial markets are uniformly adverse and significant for a time period of 2 years. These financial and macroeconomic effects are robust across a variety of specifications.

Importantly, we find that these financial effects transmit to the real economy as they are accompanied by significant contractionary macroeconomic effects. It is estimated that in response to a $1 \%$ increase in US financial market uncertainty, on average, output drops by $0.035 \%$ and net exports from these countries to the US rise by about $0.0022 \%$ point relative to GDP. Again, these are peak effects, which occur after a delay of 4-8 months. Consumer prices increase persistently and reach about $0.004 \%$ higher 24 months after the impact. These financial and macroeconomic influences on EMEs are potentially large as the standard deviation of unanticipated fluctuations in US uncertainty we estimate is about $14.4 \%$.

The effects on financial variables suggest that a US uncertainty shock triggers a "flight to safety/quality" phenomenon: Investors appear to pull capital out of the emerging markets that are perceived to be riskier than the US (despite the increase in uncertainty in the US), thus negatively affecting asset prices such as stock prices and exchange rates, while pushing up their cost of borrowing as country spreads vis-à-vis the US increase. The increase in net exports and decrease in capital inflows illustrates that one of the channels through which the effects of the US uncertainty shock transmits is via a reduction in aggregate spending. Combined with the increase in interest rate spreads faced by these countries, the effects

China. Countries in the Euro zone are also excluded since due to use of the Euro as a common currency, they might get affected differently from other EMEs. 
are thus qualitatively similar to those of a current account reversal or a sudden stop shock investigated in the literature. ${ }^{3}$ Moreover, consumer prices increase, which illustrates that the US uncertainty shock leads to a trade-off for central banks of these countries as it leads to output contraction and inflation simultaneously. These effects are thus similar to the effect of a negative supply shock in closed-economy models.

We also assess the heterogeneity in responses between South American and the rest of EMEs by allowing the effects of the US uncertainty shock to be different across these subgroups. The negative effects on output are found to be bigger and more persistent for the rest of EMEs than for the South American countries: output drops more than $0.04 \%$ in the rest of EMEs while it drops less than $0.02 \%$ in South American countries. On the other hand, the estimated effects are bigger and more persistent on capital and trade flows for South American countries compared to the rest of EMEs. The peak effect on capital outflows of a $1 \%$ increase in US uncertainty is estimated to be about $0.02 \%$ point relative to GDP in South America while it is about $0.01 \%$ in the rest of the countries. In addition, net exports increase by about $0.004 \%$ point relative to GDP at its peak in South American countries but only about $0.001 \%$ point in the rest of the emerging countries. Finally, the effects on stock prices and exchange rates are bigger, and especially more persistent, for South American countries. Thus, South American countries suffer less in terms of a decrease in output and asset prices but experience a larger reversal in capital flows and a larger increase in net exports.

It is intriguing that compared to South American countries, while the rest of the EMEs get affected much more negatively in terms of output (with similar effects in terms of consumer prices), their short-term interest rates do not decrease by more. Given a larger output response, the policy rates of the rest of EMEs can be considered "relatively high" and monetary policy "relatively tight." We conjecture that this is to stem capital outflows, but such an effect comes at the cost of a larger output contraction and larger drops in asset prices.

To help interpret our empirical findings and study possible transmission mechanisms, we present a simple two-good small open economy (SOE) model with capital accumulation that features financial and nominal frictions. The model can account qualitatively for our empirical findings: In the model, a negative external shock that increases the interest rate spread faced by the SOE produces responses of macroeconomic and financial variables that are consistent with our estimated responses. ${ }^{4}$ In particular, the increase in the country interest rate

\footnotetext{
${ }^{3}$ It is well-known that EMEs have quite countercyclical net exports/current account unconditionally, which we show here for a particular/identified external shock.

${ }^{4}$ We posit an external shock that increases the (level of) spread faced by the SOE, as it is consistent with our empirical findings. Thus we can interpret this shock as capturing fluctuations in the belief of external investors that lending to the SOE is risky (which in the empirical exercise is proxied by VIX). It can also capture some "flight to safety/quality" phenomenon.
} 
spread drives output as well as consumption and investment expenditures down. The driving force for these effects is the increased cost of financing consumption and investment due to a rise in the foreign interest rate. Given that the SOE cuts down on expenditure strongly, net exports increase in spite of the reduction in home production. A reduction in borrowing from the rest of the world gets reflected in an improvement in the current account. Lastly, the model generates implications for consumer prices and stock prices that are consistent with the empirical evidence.

The model also provides a possible explanation for the heterogeneity in macroeconomic and financial responses across countries by allowing differential endogenous responses of the monetary policy instrument to an increase in the foreign interest rate spread. We model monetary policy as a Taylor-type rule where the central bank possibly responds to the country interest rate spread in addition to the usual endogenous reaction of the home interest rate to inflation and the output gap. This reflects a desire on the part of policy to stem capital outflows. ${ }^{5}$ We show that in the case of such a response by central banks, capital flows are less volatile after the shock, but the response of output and asset prices is stronger. This is because such a policy is contractionary for macroeconomic activity, affecting output strongly. This variation in the monetary policy reaction function generates both a larger response of output and a smaller response of the current account, which is qualitatively consistent with the estimated response of the rest of EMEs. When the central bank does not respond to the country interest rate spread, however, a large capital outflow follows after the same shock while the response of output and asset prices is weaker. This is qualitatively similar to the estimated responses of South American countries.

While the theoretical exercise helps provide some grounding for our interpretation of the empirical results, especially those that pertain to the heterogeneous responses across subgroups of EMEs, we also present results from other validation exercises. First, we find that the spillover effects of a US monetary policy shock to EMEs are very similar to the ones of a US uncertainty shock to EMEs. ${ }^{6}$ This is the case for the aggregate results, which supports our hypothesis of transmission to EMEs through the foreign interest rate spread channel. Additionally, the heterogeneous responses across sub-groups of EMEs are also very similar, which provides support for possible heterogeneity in the systematic response of monetary

\footnotetext{
${ }^{5}$ Tracking the foreign interest rate and in particular conducting tight monetary policy to stem large movements in the exchange rate has been traditionally termed fear of floating of EMEs. Here, our model can be thought of as capturing a "fear of movements in external balance/capital flows" that also features tight monetary policy.

${ }^{6}$ These results on US monetary policy appeared in detail in Bhattarai, Chatterjee, and Park (2017b), which is now subsumed in this paper. As we describe in detail later, as our sample period contains the ZLB period for the U.S., we use a shadow interest rate as our measure of monetary policy. The panel VAR specification is exactly the same in this exercise.
} 
policy across EMEs to the foreign interest rate spread, irrespective of the shock. Second, using indices for capital control measures, we find that South American countries use capital controls to a lesser extent than the rest of EMEs. Thus, there is additional evidence that the rest of EMEs pay attention to capital flows to a greater extent, and possibly use both conventional interest rate policy as well as direct capital controls to counteract volatility in capital flows. Finally, through our reading of central bank minutes at important dates and with quantitative textual analysis, we also show that the rest of EMEs are quite concerned about the volatility of capital flows.

Related Literature Our paper is related to several strands of the literature. We build on the large body of work pioneered by Bloom (2009) that assesses the macroeconomic implications of fluctuations in uncertainty, especially changes in the expected volatility in the US stock market. Bloom (2014) is a recent survey in this literature. Rey (2013), which provides evidence for international implications of US uncertainty and constitutes key motivation for our paper, points out the correlation between US stock market volatility, as measured by VIX, and global asset prices and credit flows. Miranda-Agrippino and Rey (2015) provide further econometric evidence for the global financial cycle emphasized by Rey (2013). They first document the presence of a global factor that explains significant fraction of variation in asset returns across the world. Using a VAR approach, they next show that an identified US monetary policy shock not only has the standard effects on US and EU macroeconomic variables, but also affects global/cross-border credit and financial variables, as well as the global factor identified in the first exercise. This shows that US monetary policy might drive global financial conditions in an important way. Our theme is similar with a focus on macroeconomic and financial spillovers of US financial uncertainty, specifically to EMEs.

In terms of our empirical methodology, we use a random coefficients Bayesian panel VAR, which builds on Canova (2007) and Canova and Ciccarelli (2013). We develop a Gibbs sampling algorithm that allows us to estimate a high-dimensional panel VAR while allowing for shocks across the countries to be correlated. This approach allows us to make inference on the average effect across countries of an external shock, while allowing for heterogeneous country-specific effects. Our framework also allows for the average effect to be different across sub-groups of the countries.

In terms of theoretical modeling, we extend the classic one-good SOE business cycle model with an external financial shock, building on Uribe and Yue (2006) and Neumeyer and Perri (2005). We extend this framework to a two-good setup with nominal rigidities and monetary policy, where external borrowing is in terms of the foreign currency, and solve it non-linearly. The two-good extension allows us to assess implications for the exchange rate while the introduction of nominal price level determination allows for foreign currency debt, 
which is an important aspect of EME borrowing. Finally, introducing nominal rigidities enables us to consider realistically the dynamics of inflation and the role of monetary policy.

Regarding the focus of the paper, our work is related to papers that assess empirically the effects of US shocks on EMEs. Our empirical work has a similar theme as Canova (2005), which studies transmission of US shocks to Latin American countries and Mackowiak (2007), which studies the effects of US monetary policy shocks on EMEs. In Bhattarai, Chatterjee, and Park (2017a) we study the transmission of US unconventional monetary policy shocks on EMEs. Aizenman et al (2015) provides evidence of correlation of EME's policy rates and exchange rates with policy rates in four center countries: US, Euro area, Japan, and China. ${ }^{7}$

Even more closely related are Uribe and Yue (2006), who estimate the effects of foreign interest/interest spread shock on EMEs using an empirical VAR model, and Matsumoto (2011), Akinci (2013), and Carriere-Swallow and Cespedes (2013), who study effects of global financial conditions and/or VIX shocks on EMEs. Our paper is also related to Fink and Schüler (2015), which provides evidence on how US systemic financial stress shocks transmit to EMEs. These set of papers show that the macroeconomic effects of these shocks on EMEs are significant.

Overall, we contribute to this growing literature on the empirical front in terms of methodology and scope. Our method, instead of focusing on a single country estimation at a time or conducting fully pooled estimation, uses a partial pooling approach. This enables a joint estimation of an average/overall effect while allowing for heterogeneous effects across countries. We also estimate heterogeneous average effects across sub-groups of countries. This aspect of our empirical exercise led us to study how the differential response in monetary policy by the EMEs might change the transmission of the US uncertainty shock.

In terms of the scope of the empirical study, we study the effects on a large number of macroeconomic and financial variables jointly, including consumer prices, several asset prices, and capital flows, for a large number of EMEs. Thus, we build on and extend the important empirical findings of the previous literature. In particular, an inclusion of a comprehensive set of open economy variables such as exchange rates, capital flows, and trade flows as well as relative variables such as long-term country spreads allows us to study particular cross-border effects and transmission of US uncertainty. That is, the differential effects on EMEs relative to the US/world economy can be inferred. For instance, while US uncertainty is known to have contractionary domestic macroeconomic effects and both the previous literature and our results also show evidence for contractionary EME effects, we find that the US/rest of

\footnotetext{
${ }^{7}$ Some recent papers argue that spillovers of US shocks might be relevant even for advanced economics. For instance, Gerko and Rey (2017) document important international spillover effects of US monetary policy on the UK.
} 
the world actually experience capital inflows and exchange rate appreciation vis-à-vis EMEs. We use a theoretical model to interpret these empirical findings, both the aggregate as well as the sub-group ones. Finally, we show that the theoretical conclusions match the empirical results for both US financial uncertainty and monetary policy spillovers. It validates our modeling of these external shocks as a shock that raises the interest-rate spread faced by the EMEs and to which the EMEs' monetary policy reacts heterogeneously, which leads to heterogeneous responses across the EMEs.

\section{Data and empirical methodology}

In this section we explain the data and the methodology for empirical analysis. Our empirical study is executed in two steps. We first estimate a VAR for the US economy to extract unanticipated and exogenous fluctuations in uncertainty in US financial markets, which is referred to as a US uncertainty shock. This shock is then included as an external regressor in a panel VAR for the emerging market countries (EM panel VAR) to assess the spillover effects of the US uncertainty shock on these economies. Both the US VAR and the EM panel VAR are estimated using the Bayesian approach. The details of the Bayesian approach are explained in the online Appendix.

\subsection{US uncertainty shock}

For the US economy, a VAR model

$$
y_{t}=B_{1} y_{t-1}+B_{2} y_{t-2}+\cdots+B_{k} y_{t-k}+\varepsilon_{t},
$$

is used, where $y_{t}$ is an $m_{y} \times 1$ vector of endogenous variables and $\varepsilon_{t} \sim \mathbb{N}\left(0, I_{m_{y}}\right)$ with $E\left(\varepsilon_{t} \mid y_{t-j}: j \geq 1\right)=0$. The coefficient matrix $B_{j}$ for $j=0, \cdots, k$ is an $m_{y} \times m_{y}$ matrix. In the baseline specification, $y_{t}$ includes the following three variables: the CBOE VIX index as a proxy of US financial uncertainty, the industrial production (IP) index as a measure of output, and the consumer price index (CPI) as the price level. The baseline specification uses six lags of $y_{t}$ so $k=6$. In an extended specification, we consider a VAR with eight variables, similar to Bloom (2009). In a robustness exercise, we use the financial uncertainty measure estimated by Ludvigson, Ma, and Ng (2015), instead of VIX.

A shock to the VIX is estimated, which we refer to as the US uncertainty shock, in (1) after we remove the endogenous influences of lags of output and the price level on uncertainty. This is a reduced-form shock and thus we do not focus on impulse responses functions to this shock of the US economy. This is because our goal is to compute an unanticipated component 
of the uncertainty measure in a simple manner, in particular by removing predictability based on macroeconomic variables, that can be plugged into the EM panel VAR.

Different orthogonalization/ordering schemes to identify structural uncertainty shocks are used in the literature, for example in Bloom (2009) and Rey (2013). In an extension, we show that even if we orthogonalize the shock with a particular ordering, it is quite similar to the one we use in our baseline analysis. In a robustness exercise where we use the same variables as in Bloom (2009), we identify the uncertainty shock following the ordering of Bloom (2009) where VIX is ordered second after stock prices and estimate spillover effects of the uncertainty shock on EMEs.

Our approach of considering continuous fluctuations in VIX is different from the baseline approach of Bloom (2009). Bloom (2009) uses only very large movements in VIX that are associated with major political and economic events. ${ }^{8}$ We choose to use continuous fluctuations of the VIX index as our baseline measure of the uncertainty shock because of the concern on the relatively short sample period in the EM panel VAR, which might make it more sensitive to outliers. ${ }^{9}$ In our sample period, about four major fluctuations in the VIX shock are identified: the financial crisis in 2008-2009 and three European debt crisis events. If we were to follow Bloom (2009), our analysis would be closer to a case/narrative study on spillover effects of financial/debt crisis in advanced economies rather than estimating the effects of general uncertainty fluctuations. In fact we include dummy variables for these events in the EM panel VAR and so essentially exclude them in estimation to avoid the concern that our results are driven by financial crises outliers. Thus, we actually take a conservative approach in estimating the international spillover effects of US uncertainty shocks. In a robustness analysis however, we follow the large-change approach of Bloom (2009) and find very similar spillover results as our baseline results. ${ }^{10}$ Thus, if these four events are not excluded, the effects on the EMEs will be larger in general.

\subsection{EM panel VAR}

We now present in detail the baseline specification of the EM panel VAR in which the spillover effects of the US uncertainty shock on the EM countries are estimated. Then its various extensions and robustness exercises are described.

\footnotetext{
${ }^{8}$ This approach is also followed by Carriere-Swallow and Cespedes (2013).

${ }^{9}$ Bloom (2009) considers HP-filtered VIX index in a robustness exercise, which generates similar results to the baseline approach of his. Our method is closer to this approach. Gourio et al. (2013) is another paper using the same approach where they construct a measure of realized volatility using point-wise averages of several advanced economy volatility measures and then use that series in a VAR.

${ }^{10}$ As we describe later, this approach identifies three dates, which we use as dummy variables in the EM panel VAR.
} 


\subsubsection{Baseline specification}

After extracting the surprise component in US financial uncertainty from the US VAR (1), we assess its spillover effects on the EMEs by including it in a system of equations for their economies. Suppose that our sample includes $N$ countries indexed by $i=1,2, \cdots, N$. The dynamics of endogenous variables for country $i$ are then represented as

$$
z_{i, t}=\sum_{j=1}^{p} B_{i, j} z_{i, t-j}+\sum_{j=0}^{q} D_{i, j} \varepsilon_{V I X, t-j}+C_{i} x_{t}+u_{i, t}
$$

where $z_{i, t}$ is an $m_{z} \times 1$ vector of endogenous variables for country $i, \varepsilon_{V I X, t}$ is the median of the US uncertainty shock estimated in the US VAR, $x_{t}$ is an $m_{x} \times 1$ vector of exogenous variables including a constant term, dummy variables, and some world variables that are common across countries, and $u_{t}$ is an $m_{z} \times 1$ vector of the disturbance terms. ${ }^{11}$ The coefficient matrix $B_{i, j}$ for $j=1, \cdots, p$ is an $m_{z} \times m_{z}$ matrix, $D_{i, j}$ for $j=0, \cdots, q$ is an $m_{z} \times 1$ vector, and $C_{i}$ is an $m_{z} \times m_{x}$ matrix. It is assumed that for $\mathbf{u}_{t}=\left(u_{1, t}^{\prime}, \cdots, u_{N, t}^{\prime}\right)^{\prime}$,

$$
\mathbf{u}_{t} \mid \mathbf{z}_{t-1}, \cdots, \mathbf{z}_{t-p}, \varepsilon_{V I X, t}, \cdots, \varepsilon_{V I X, t-q}, x_{t} \sim \mathbb{N}\left(\mathbf{0}_{N m_{z} \times 1}, \boldsymbol{\Sigma}\right)
$$

where $\mathbf{z}_{t}=\left(z_{1, t}^{\prime}, \cdots, z_{N, t}^{\prime}\right)^{\prime}, \mathbf{0}_{N m_{z} \times 1}$ is an $N m_{z} \times 1$ vector of zeros, and $\boldsymbol{\Sigma}$ is an $N m_{z} \times N m_{z}$ positive definite matrix.

In the baseline specification, $z_{i, t}$ includes five financial variables and three macroeconomic variables. Specifically, we use short-term (policy) interest rates, long-term interest rate spreads of country $i$ with respect to the 10-year Treasury yield in the US, the aggregate stock price, the nominal effective exchange rate of the local currency, capital inflows to country $i$, industrial production as output, CPI as consumer prices, and net exports to the US relative to GDP. These constitute a core set of financial and macroeconomic variable for a small open economy. Note that we include the short-term (policy) rate to control for monetary policy reaction by these countries, which helps us determine the dynamics of the macroeconomic variables here. Three lags are included for the endogenous variables and the

\footnotetext{
${ }^{11}$ We note that since we use the median of the US uncertainty shock estimated in the US VAR and its lags as regressors in (2), our estimation of its effects is subject to the so-called generated regressor problem. As we show in Section 3, however, the US uncertainty shock is very tightly estimated and thus the uncertainty around the estimates of the shock is not big, which suggests that the generated regressor problem is not very severe. Ideally, we can estimate the effect of the US uncertainty shock in a panel VAR that includes both the US and the EM countries with a block exclusion restriction that the EM countries do not influence the US economy at all, adopting the small open economy benchmark for these EM economies. We prefer our two-step estimation because of the computational burden to estimate a large panel VAR model for both the US economy and the EM countries, which makes it practically difficult to estimate various alternative specifications and do robustness exercises. As another check on this issue, we also use the growth rate of VIX as a measure of US uncertainty shock in the EME panel VAR.
} 
uncertainty shock $(p=q=3)$.

Some of the EMEs in our sample are commodity exporters. As commodity exports and prices can potentially affect the business cycles of those countries, a proxy of the world demand for commodities and a price index of commodities are included in the vector of exogenous variables $x_{t}$ as control variables. In addition, we control for the world demand proxied by overall industrial production of the OECD countries. Dummy variables to control for the effect of the US financial and European debt crisis (September-Decemeber 2008, May 2010, and February and August 2011) are also included in $x_{t}$. In particular, (3) implies that these variables in $x_{t}$ are assumed exogenous to the system. This is because the EMEs in our sample can be plausibly considered as a small open economy. It is however likely that there are some other common factors that drive the business cycles of these countries. No restrictions on $\Sigma$ in (3) except that it is positive definite are imposed so that the disturbance terms $u_{i, t}$ 's are freely correlated across the EMEs and could capture potential effects of the other common factors.

Note that the coefficient matrices in (2) are allowed to be different across the individual EMEs. We allow for such dynamic heterogeneity since the EMEs in our sample are certainly not homogeneous. However, they are small open economies and thus their economies are likely to be affected in a similar way by common shocks. To account for potential common dynamics, and especially common effects of the US uncertainty shock, we take the random coefficient approach and assume that the distribution of the coefficient matrices in (2) are centered around the common mean. This approach also allows us to partially pool the crosscountry information and obtain the pooled estimator of the effects of the US uncertainty shock on the EMEs.

Specifically, the random coefficient approach is undertaken following Canova (2007) and Canova and Ciccarelli (2013). Let us collect the coefficient matrices in (2) as $B_{i}=$ $\left(\begin{array}{ccc}B_{i, 1} & \cdots & B_{i, p}\end{array}\right)^{\prime}$ and $D_{i}=\left(\begin{array}{ccc}D_{i, 0} & \cdots & D_{i, q}\end{array}\right)^{\prime}$ and let $\gamma_{i}=\operatorname{vec}\left(\begin{array}{ccc}B_{i}^{\prime} & D_{i}^{\prime} & C_{i}\end{array}\right)^{\prime}$. Note that the size of $\gamma_{i}$ is given as $m_{\gamma}=m_{z} m_{w}$ where $m_{w}=p m_{z}+(q+1)+m_{x}$ is the number of regressors in each equation. It is assumed that for $i=1, \cdots, N$,

$$
\gamma_{i}=\bar{\gamma}+v_{i}
$$

where $v_{i} \sim \mathbb{N}\left(\mathbf{0}_{m_{\gamma} \times 1}, \Sigma_{i} \otimes \underline{\Sigma}_{i}\right)$ with $\mathbf{0}_{m_{\gamma} \times 1}$ an $m_{\gamma} \times 1$ vector of zeros, $\Sigma_{i}$ an $m_{z} \times m_{z}$ matrix that is the $i$-th block on the diagonal of $\Sigma, \underline{\Sigma}_{i}$ an $m_{w} \times m_{w}$ positive definite matrix, and $E\left(v_{i} v_{j}^{\prime}\right)=\mathbf{0}_{m_{\gamma} \times m_{\gamma}}$ for $i \neq j$. The common mean $\bar{\gamma}$ in (4) turns out to be the weighted average of the country-specific coefficients $\gamma_{i}$ with their variances as weights in the posterior distribution conditional on $\gamma_{i}^{\prime}$ 's. For a particular value of $\bar{\gamma}$, the pooled estimates of the 
dynamics effects of the uncertainty shock $\varepsilon_{V I X, t}$ can be computed by tracing out the responses of $z_{i, t}$ to an increase in $\varepsilon_{V I X, t}$ over time with $\gamma_{i}$ replaced by $\bar{\gamma}$.

\subsubsection{Heterogeneity across subgroups of countries}

We also estimate the differential effects of the US uncertainty shock across two subgroups of the EMEs in our sample and assess heterogeneity across these two subgroups. Our baseline subgroup estimation consists of South American countries in one group and the rest of the EMEs in another. This choice is motivated by the close connections and linkages between the US and South American countries, as well as the existence of previous work that focuses on these countries, such as Canova (2005).

Specifically, the mean of the coefficients, $\bar{\gamma}$ in (4), is now different between two groups of the EMEs, denoted group 1 and 2. So the assumption for the random coefficient approach (4) is modified as follows: For $i=1, \cdots, N$,

$$
\gamma_{i}=\bar{\gamma}_{1} \times I_{1}(i)+\bar{\gamma}_{2} \times\left[1-I_{1}(i)\right]+v_{i}
$$

where $I_{1}(i)$ is an indicator function that takes on 1 if country $i$ is in group 1 and 0 otherwise, $v_{i} \sim \mathbb{N}\left(\mathbf{0}_{m_{\gamma} \times 1}, \Sigma_{i} \otimes \underline{\Sigma}_{i}\right)$. By comparing the impulse responses to the US uncertainty shock across these two subgroups, using $\bar{\gamma}_{1}$ and $\bar{\gamma}_{2}$, respectively, one can study whether these two groups were differentially sensitive to the US uncertainty shock. Note that, even with the heterogeneity in the mean of the coefficients, equations (2) of all the EMEs are jointly estimated with the disturbance terms $u_{i, t}$ 's still correlated across all the EMEs.

\subsubsection{Alternate specifications}

After estimating the baseline specification, we consider some alternate variables so that we can assess robustness of our empirical results and relate them to our theoretical model results. Due to the computational burden and sample size issues, we continue to use the baseline specification for the EM panel VAR that includes eight variables but replace one variable of the baseline specification with a new one at a time.

First, we consider different measures of economic activity. In the baseline specification, IP is included as a measure of economic activity, as it is the usual choice with monthly data. To assess the results based on a broader measure of activity as well as to help guide the theoretical results on measures of spending, we consider data on GDP, consumption, and investment, one variable at a time. Their quarterly observations are interpolated to get the monthly observations. Next, we use several alternate financial and open economy variables. In particular, we replace long-term interest rate spreads with a measure of long-term real 
Table 1: Baseline and alternative specifications of the EM panel VAR

\begin{tabular}{|c|c|c|}
\hline Specifications & & Endogenous variables \\
\hline Baseline & & $\begin{array}{l}\text { Short-term interest rates, long-term interest rate spreads with respect } \\
\text { to the } 10 \text {-year Treasury yield in the US, the aggregate stock price, } \\
\text { the nominal effective exchange rate of the local currency, capital } \\
\text { inflows, Industrial Production, CPI, and net exports to the US }\end{array}$ \\
\hline \multirow[t]{10}{*}{ Alternative } & & The same as the baseline specification except that \\
\hline & 1 & Industrial Production is replaced with GDP \\
\hline & 2 & Industrial Production is replaced with consumption \\
\hline & 3 & Industrial Production is replaced with investment \\
\hline & 4 & $\begin{array}{l}\text { Long-term interest rate spread is replaced with long-term real } \\
\text { interest rate spread }\end{array}$ \\
\hline & 5 & $\begin{array}{l}\text { Nominal effective exchange rate is replaced with real effective } \\
\text { exchange rate }\end{array}$ \\
\hline & 6 & Net exports to the US is replaced with net exports to the world \\
\hline & 7 & $\begin{array}{l}\text { Net exports to the US is replaced with net foreign asset position with } \\
\text { the US }\end{array}$ \\
\hline & 8 & $\begin{array}{l}\text { Capital inflows from the world is replaced with various capital inflow } \\
\text { measures from the US }\end{array}$ \\
\hline & 9 & CPI is replaced with the realized volatility of aggregate stock price \\
\hline
\end{tabular}

Notes: For each of the EMEs in the EM panel VAR the endogenous variables listed above, the US uncertainty shock with its lags, a proxy of the world demand for commodities, a price index of commodities, and the US financial crisis and European debt crisis dummy variables are included.

interest rate spreads. ${ }^{12}$ For open economy variables, we first replace the nominal effective exchange rate with the real effective exchange rate. We then use several alternate measures of external balance of the emerging market economies. We replace our baseline measure of net exports, which was to the US, with net exports to the rest of the world as well as net foreign asset position with the US. We then also use several capital inflow measures from the US, compared with our baseline measure which in principle also incorporates capital inflows from other countries. In particular, we use cumulated net foreign asset position of the US

\footnotetext{
${ }^{12}$ While using long-term real interest rates requires us to take a stance on how expected inflation is determined, which is why we use the nominal long-term interest rate spread in our baseline estimation, it is still worthwhile to check this specification as in the theoretical model, the relevant spread increase we will study as a shock will be in real terms.
} 
with these EMEs as well as the cumulated foreign asset position of the US with these EMEs. Finally, we include the realized volatility of EME stock price index in the panel VAR in order to control for both first and second moments of EM stock prices. ${ }^{13}$ This will also help establish further that the effects that we estimate are indeed that of an external uncertainty shock, as we would have directly controlled for domestic stock market uncertainty. In this specification, to keep number of variables the same as the baseline, we drop CPI. Table 1 presents all the specifications that we estimate.

\section{$2.3 \quad$ Data}

We use US data at the monthly frequency from January 1990 through November 2014. In addition to VIX, IP, and CPI included in the baseline specification, we also use data on an alternate financial uncertainty measure, as well as on a short-term interest rate as a measure of monetary policy, the S\&P 500 index, wages, hours, and employment in extended specifications for the US VAR. The data source for most of the US data is the FRED maintained by the St Louis Fed. The financial uncertainty measure is available from Ludvigson, Ma, and $\mathrm{Ng}$ (2015). For the period when the zero lower bound is binding, we use the shadow interest rate from Krippner (2016) as a measure of the short-term interest rate. As an alternative to it, we also use the 2-year Treasury yield.

Our sample includes fifteen important EMEs: Brazil, Chile, Colombia, India, Indonesia, Malaysia, Mexico, Peru, Philippines, Russian, South Africa, South Korea, Taiwan, Thailand, and Turkey. Our data for the EMEs is at the monthly frequency for the period from January 2004 through November 2014. We use data on IP, CPI, the trade-weighted effective nominal and real exchange rates, the aggregate stock price, long-term and short-term interest rates, long-term interest rate spreads with respect to the US 10-year Treasury yield, net exports to world and US, and capital inflows from the rest of the world. As an alternate measure of output, we also include data on gross domestic product (GDP), investment, and consumption. Moreover, for alternate external balance measures, we use data provided by Bertaut and Judson (2014), which is based on underlying data from US Treasury (TIC). In particular, from that data set, we use net foreign asset position and capital inflows from the US to the EMEs. Net exports and capital flows are normalized by the relevant nominal GDP. The data sources for the other EM country data include Datastream, Bloomberg, EPFR, BIS, IMF, and OECD.

A detailed data description is provided in the data Appendix. Lastly, we emphasize that the data is not pre-processed before estimation except that we interpolate quarterly nominal

\footnotetext{
${ }^{13}$ We use a realized volatility of the stock market for the EMEs as we do not have the required data on expected volatility.
} 


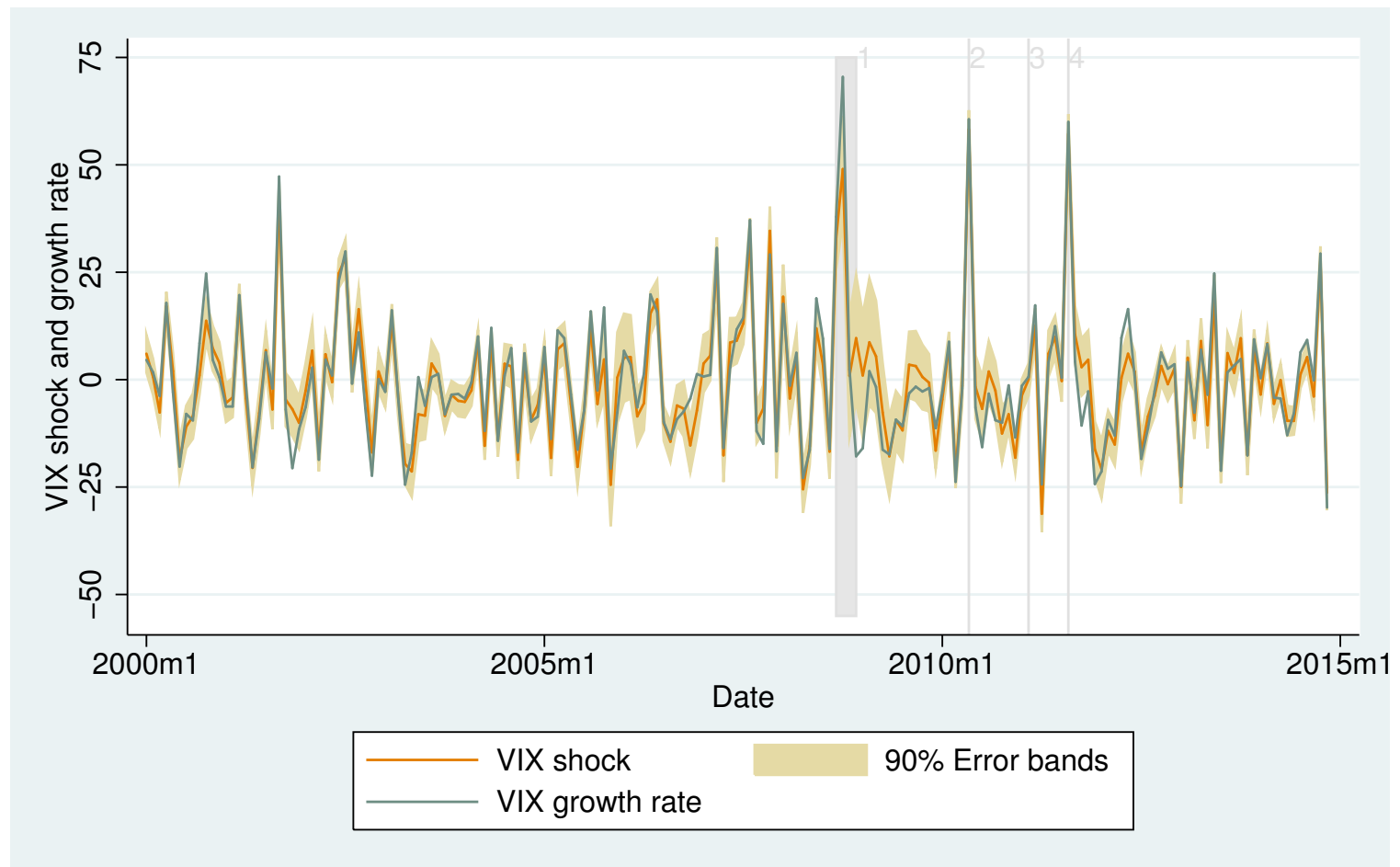

Figure 1: The estimated US uncertainty shock and the growth rate of VIX

Notes: The US uncertainty shock is 100 times the posterior median of the relevant shock in US VAR (1), which is presented together with $90 \%$ error bands. The growth rate of VIX is 100 times the first difference of the log of VIX. The vertical lines mark the financial crisis and the three major events of the Euro debt crisis: [1] September 2008 through December 2008 when Lehman Brothers collapsed and subsequently the financial markets were disturbed, [2] May 2010 when the Eurozone members and the IMF agreed on a large bailout package for Greece, [3] February 2011 when the Eurozone bailout fund, the European Stability Mechanism, was set up, and [4] August 2011 when the European Commission President Jose Manuel Barroso warned that the sovereign debt crisis was spreading beyond the periphery of the Eurozone.

GDP to monthly frequency to construct some ratios relative to GDP, and in an extension, interpolate quarterly real GDP, consumption, and investment into monthly series. The interpolation method is also described in the data Appendix. The variables are used in logs, in levels, or in ratios relative to GDP.

\section{Spillover effects of the US uncertainty shock}

We now present our results on the spillover effects of US financial uncertainty on the EMEs. We start with our measure of the US uncertainty shock and then proceed to present the effects on the EMEs. 


\subsection{US uncertainty shock}

Figure 1 presents the posterior median of the estimated US uncertainty shock, along with 90\% error bands. For comparison, in Figure 1 we also plot the growth rate of VIX, which is very similar to the shock we estimate. This shows that VIX contains a large unpredictable component. Finally, around some important events that had worldwide effects, such as the US financial and Euro debt crisis events that are marked by vertical lines in the figure, the US uncertainty shock takes quite large values. To ensure that our results are not driven by these outliers, we include dummy variables for these events in the EM panel VAR.

\subsection{Spillover effects}

We now present results on the uncertainty shock's spillover effects on the EMEs. The impulse responses presented in this section are the average effects of the US uncertainty shock across all the EMEs in the baseline panel VAR specifications and the average effects among South American countries and the rest of the EMEs, respectively, in the subgroup analysis. The average effects are computed using $\bar{\gamma}$ in (4) for the baseline specification and using $\bar{\gamma}_{1}$ and $\bar{\gamma}_{2}$ in (5) for the subgroup analysis.

\subsubsection{Benchmark specification}

We present results from our baseline specification in Figure 2. We start by describing the results on financial market variables as they provide the first channel of possible transmission to the EMEs. On average, following an increase in US financial uncertainty, short-term interest rates and long-term country spreads (compared to the 10-year Treasury yield in the US) of these countries increase persistently. In addition, stock prices declines and nominal exchange rates depreciate persistently. Finally, capital flows out of these countries. ${ }^{14}$

Specifically, on average across the EMEs, a $1 \%$ increase in US financial uncertainty leads to a $0.0035 \%$ point increase in the short-term interest rate, a $0.012 \%$ point increase in the long-term interest rate compared to the US, a $0.125 \%$ fall in the stock prices, a $0.045 \%$ depreciation of the local currency, and a $0.0175 \%$ point capital outflows relative to GDP. These are peak effects of the US uncertainty fluctuation that occur about 2-12 months after the impact. The effects on EME financial markets are uniformly adverse and significant during the entire time period of 2 years after the initial shock. The effects on financial variables suggest that a US uncertainty shock triggers a flight to safety/quality phenomenon as investors appear to pull capital out of these markets that are perceived to

\footnotetext{
${ }^{14}$ To be precise, our baseline measure is that of gross capital inflows. We use other measures of capital flows, including net measures, later in the paper.
} 
be risky compared to the US, thus negatively affecting asset prices such as stock prices and exchange rates, while increasing their cost of borrowing as country spreads (compared to the US) increase.
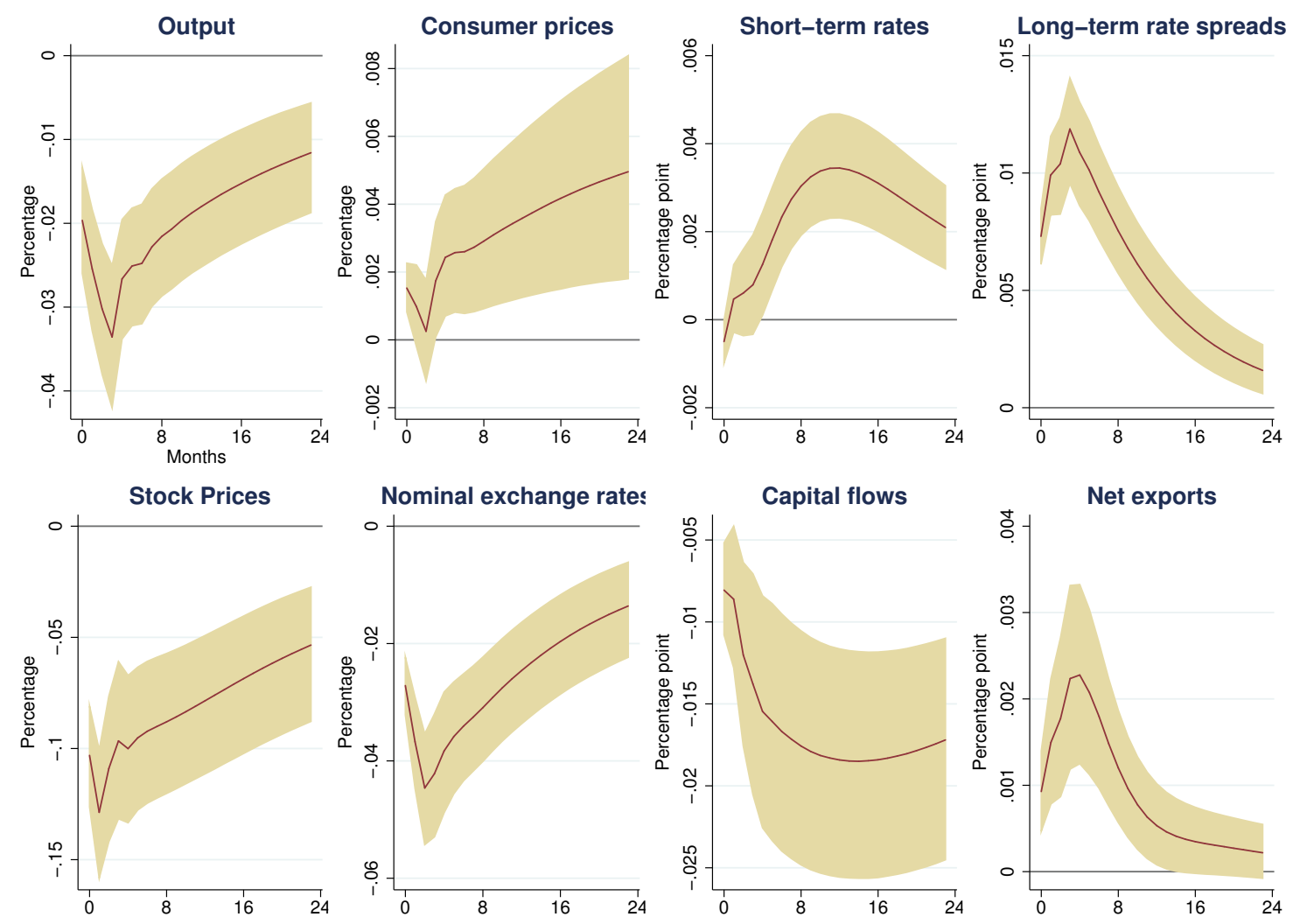

Figure 2: Impulse responses of the EM panel VAR to the US uncertainty shock: macroeconomic and financial variables

Notes: Each plot presents the posterior median of the impulse responses to a $1 \%$ increase in the US uncertainty shock along with the $90 \%$ error band in the baseline specification that includes the both macroeconomic and financial variables. Output is the industrial production and consumer prices are the CPI in each of the EM countries. Net exports are the ratio of the net exports from the EM countries to the US and GDP of the EM countries. The long-term rate spread is the spread between the 10-year Treasury yields in the US and the long-term interest rate in the EM countries. Both US and EM interest rates are nominal. The stock price is the MSCI. The nominal exchange rate is the effective exchange rate of the EM countries so a decrease in the exchange rate implies depreciation of the local currency. The capital flow is the ratio of the cumulative sum of the equity and bond inflows to GDP of the EM countries.

While the financial market effects are important, we are also interested in assessing the transmission to the real economy. Figure 2 shows that on average, an increase in US uncertainty had significant effects on the macroeconomy in addition to the financial market effects. Output of these countries drops while net exports increase. Moreover, consumer prices increase in EMEs. Specifically, we estimate that in response to a $1 \%$ increase in 
US financial market uncertainty, on average, output falls by $0.035 \%$ and net exports from these countries to the US rise by about $0.0022 \%$ point relative to GDP. Again, these are peak effects, which occur after a delay of 4-8 months. Consumer prices increase persistently and reach about $0.004 \%$ higher, 24 months after the impact. These effects on EMEs are economically large as the standard deviation of unanticipated fluctuations in estimated US financial uncertainty is about $14.4 \%$.

The decrease in output thus shows that increases in US financial uncertainty lead to a contractionary effect in EMEs. This is consistent with the concurrent financial market effects such as increases in long-term country spreads and decreases in stock prices. The increase in net exports and decrease in capital inflows illustrates that the effects of the US uncertainty shock transmits through these countries via a reduction in spending. ${ }^{15}$ Combined with an increase in the country spread, this is thus similar qualitatively to effects of a current account reversal or a sudden stop shock faced by these countries.

Finally, consumer prices increase, which we conjecture is due to both the exchange rate depreciation that affects the prices of home goods, as well as, a subsequent import price increase. ${ }^{16}$ It illustrates that the US uncertainty shock leads to a major trade-off for central banks of these countries as it leads to output contraction together with an increase in the price level. These effects are thus similar to the effect of a markup shock in closed-economy macroeconomic models.

\subsubsection{Subgroup analysis}

We now present results based on the subgroup analysis where we split the EMEs in our sample into two subgroups: South American countries that include Brazil, Chile, Colombia, Mexico and Peru, and the rest. Figure 3 shows that clear and meaningful heterogeneity is present in responses of both macroeconomic and financial variables. In particular, the negative effects on output, stock prices, and exchange rates are bigger and more persistent for the rest of EMEs compared to South American countries. For instance, the peak effects on output and exchange rates are more than double for the rest of EMEs and for all these variables, the effects are significantly more persistent for the rest of EMEs as well. Specifically, output drops less than $0.2 \%$ in South American countries while it drops more than $0.4 \%$ in the rest of EMEs.

\footnotetext{
${ }^{15}$ In an extension, using interpolated data, we in fact show that both consumption and investment of EMEs decline in response to a US VIX shock.

${ }^{16}$ For example, in the theoretical model, a real depreciation contributes to increase in marginal costs in home currency, which in turn lead to an increase in prices of home goods through the usual price-setting channels. Note that in an extension we show that the real effective exchange rate also depreciates for these countries, in a manner very similar to the depreciation here of the nominal effective exchange rate.
} 
On the other hand, the effects are bigger and more persistent on capital flows and net exports for South American countries compared to the rest of EMEs. In fact, the peak effects on capital flows and net exports are more than double for South American countries compared to rest of EMEs. The peak effect on capital outflows of a $1 \%$ increase in US financial market uncertainty is estimated to be about $0.002 \%$ relative to GDP in South American countries while it is about $0.001 \%$ in the rest of the emerging market countries. Also, net exports increases by about $0.004 \%$ point relative to GDP at its peak in South American countries but only about $0.001 \%$ point in the rest of EMEs. Thus, overall, South American countries suffer less in terms of output, stock prices and the exchange rate but there is a larger increase in net exports and a bigger reversal in capital flows.

Strikingly, the short-term (policy) rate of the rest of EMEs does not decrease by more compared to South American countries, even though the countries get affected much more negatively in terms of output (with similar effects in terms of consumer prices). Thus, the policy rates of the rest of EMEs can be considered to be "relatively high" and monetary policy "relatively more tight" given the larger negative response of output.

This heterogeneity in outcomes, especially the response of the short-term policy rates, then suggests an intriguing explanation that might be consistent with differential monetary policy reaction by these two groups of countries. It is well-known that many EMEs might be quite worried about sharp reversals in capital flows, even independently of the effects on output. ${ }^{17}$ Then, if the rest of EMEs are more concerned with capital outflows as a result of increased US uncertainty than South American countries, the central banks of these countries might keep their policy rates relatively high, in order to stem such capital outflows. This can be successful, but might come at the cost of larger drops in output as monetary policy will turn out to be unduly contractionary. This kind of trade-off is consistent with our empirical results above and guides the model we present in the next section where we introduce heterogeneity in monetary policy reaction function coefficients.

\footnotetext{
${ }^{17}$ For example, the Governor of South African Reserve Bank in a speech titled "Challenges to South African Monetary Policy in a World of Volatile Capital Flows" mentions:
}

The continued uncertainties in the global economy ... have contributed to periodic bouts of risk aversion, often resulting in a flight to so-called safe havens, despite the fact that the underlying fundamentals in the emerging markets have not changed. The problem ... is one of ... excessively volatile portfolio flows, which respond to the vagaries of global risk aversion. (Address to the Swiss Chamber Southern Africa, May 2012)

Later in the paper, we provide other relevant examples. 
Output
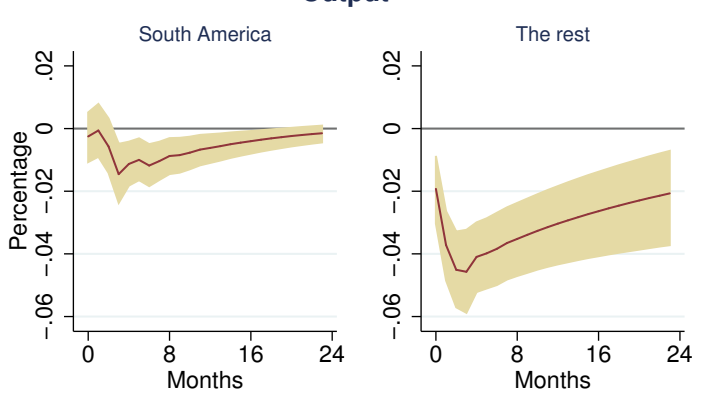

Short-term rates
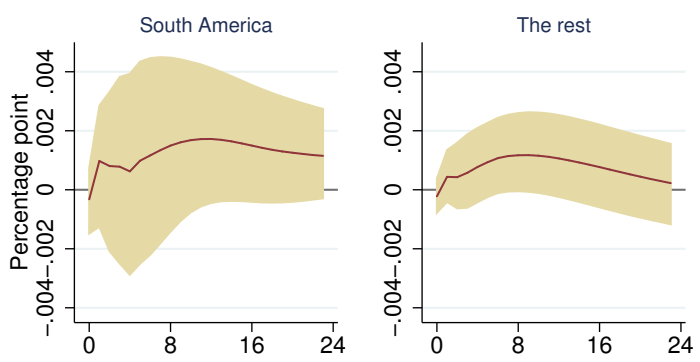

Stock prices
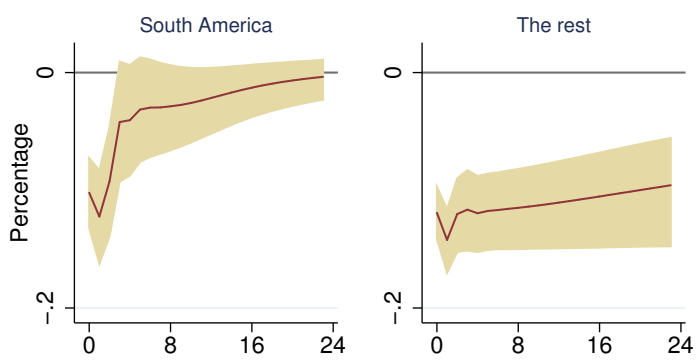

Capital flows
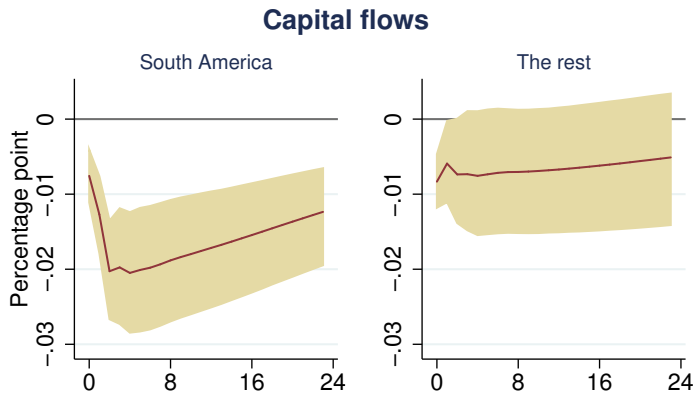

Consumer prices
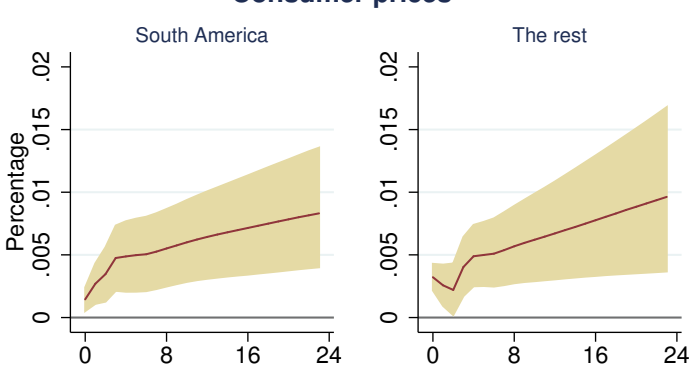

Long-term rate spreads
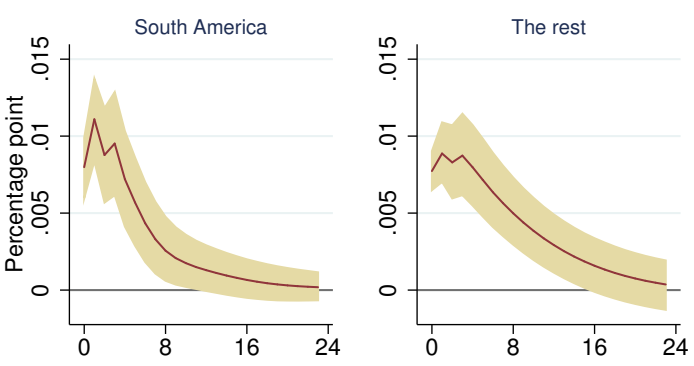

Nominal exchange rates
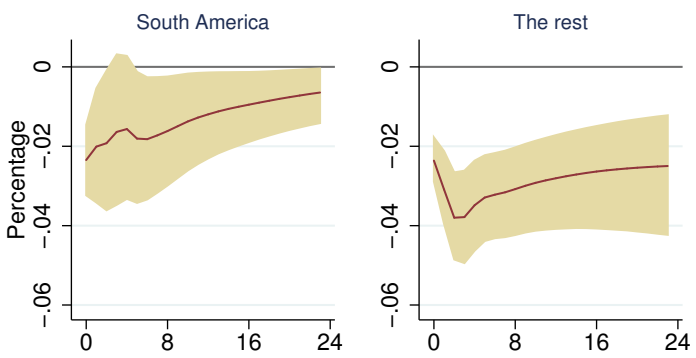

Net exports
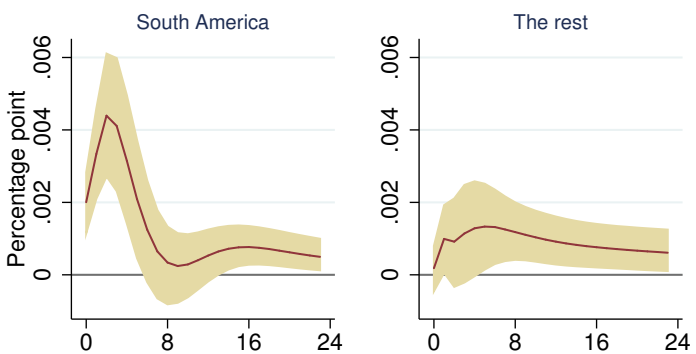

Figure 3: Impulse responses of the EM panel VAR to the US uncertainty shock: macroeconomic and financial variables; South America vs. the rest

Notes: Each plot presents the posterior median of the impulse responses to a $1 \%$ increase in the US uncertainty shock along with the $90 \%$ error bands in the specification for subgroup analysis that includes both the macroeconomic and financial variables. Subplots are arranged by variables and shown for two groups of countries: South America including Brazil, Chile, Colombia, Mexico, Malaysia, and Peru and the rest of the EM economies. See the notes in Figure 2. 


\subsubsection{Extensions and robustness}

We estimate several extensions to the baseline specification and do various robustness exercises. Our first set of extensions focus on effects of the baseline uncertainty shock on alternate measures of real economic activity and of open economy variables including measures of external balance. These specifications are outlined in Table 1 and their results are shown in Figures B.1 and B.2 of the Appendix. Figure B.1 shows that all these measures of economic activity and aggregate spending decline persistently when US uncertainty increases unexpectedly. The response of investment is bigger than GDP and consumption as expected. The first row of Figure B.2 shows that long-term real interest rate spreads increase, real exchange rates depreciate, and net exports to the world increase. In particular, note that the effects on the real exchange rates are essentially the same as those on the nominal exchange rates presented in Figure 2, which shows that nominal and real exchange rates are very strongly correlated in our sample. The second row of Figure B.2 shows that the net foreign asset position of the US, the cumulated net foreign asset position of the US, as well as the cumulated foreign asset position of the US with these EMEs all decreases. These variables are again based on US Treasury data (TIC) and the results are all consistent with net exports from the EMEs to the US increasing and capital inflows to the EMEs decreasing as we find in our baseline specification. Especially, the cumulated foreign asset position of the US is an alternative to our baseline measure for capital inflows from EPFR. As our final sensitivity analysis on the panel VAR, we estimate an eight variable system including realized EME stock price volatility (while dropping CPI) to analyze how robust our results are once we allow for EM stock price volatility to also respond endogenously to the US uncertainty shock. The baseline results are presented in Figure B.3. We find that our previous conclusions continue to hold. ${ }^{18}$

Next we conduct a series of robustness exercises for our measure of shock. First, we extend the US VAR to include more financial and real variables as in Bloom (2009)'s VAR with eight variables. We apply his identification scheme that orders VIX second after S\&P 500 Index. The results using this measure of US uncertainty shock are in Figure B.4. Second, in the three-variable US VAR, we impose a recursive identification scheme where VIX is ordered last and identify the uncertainty shock. It turns out that the identified shock is almost identical to the baseline series. So we do not report the result. Third, we simply use the growth rate of VIX as a measure of uncertainty shock in the EM panel VAR. This partly addresses the generated regressor problem that arises in our two-step estimation procedure.

\footnotetext{
${ }^{18}$ We also estimate a slight positive effect, after a delay, of US stock price uncertainty shock on EME stock price volatility itself. This is to be expected as in our baseline results we find a negative effect on the level of EME stock prices and typically, the first and second moments of stock prices are negatively correlated.
} 
The results are presented in Figure B.5. Fourth, in the three variable VAR specification, we replace VIX with the financial uncertainty measure of Ludvigson, Ma, and Ng (2015). The results are presented in Figure B.6. Lastly, we follow Bloom (2009) and identify only large movements in VIX as the US uncertainty shock. We find very similar spillover results as our baseline results. The results are presented in Figures B.7 in the Appendix.

We also check that our main results are not sensitive to lag length selection in the panel VAR. Results using four lags of the US uncertainty shock in the panel VAR are reported in Figure B. 8 for the baseline case and in Figure B.9 for the sub-group analysis in the Appendix. For the sub-group estimation, we have also checked our results on using other activity measures and other financial and open economy variables. As one example, we report results using long-term real rate spreads in Figure B.10 in the Appendix. ${ }^{19}$ Overall, all these exercises lead to similar results as our baseline specification.

As a final extension we consider a variance decomposition analysis. So far we have focused on transmission mechanisms as depicted by impulse responses of EME variables to a $1 \%$ US uncertainty shock. One natural question is how much does the US uncertainty shock contribute to explaining the variation in macroeconomic and financial variables in EMEs? To answer this question, we turn to a standard variance decomposition analysis. The appendix describes the method we use to compute the contribution of the shock at different horizons in explaining the forecast error variance. We start with the results based on all countries, which is in Table B.1, where for concreteness we focus on the five most salient variables. The US uncertainty shock explains a non-trivial fraction of the variation of these variables, for instance around $15 \%$ at the 3 month horizon for output and $20 \%$ at the 12 month horizon for long-term interest rate spreads. We then present results based on the sub-group estimation, in Table B.2 for South American countries and in Table B.3 for the rest of EMEs. Consistent with the impulse response results, they show that for South American countries, the US uncertainty shock explains relatively more the variation in capital flows compared to output while for the rest of EMEs, it explains relatively more the variation in output compared to capital flows.

\section{Model}

There are two countries, home and foreign, and two goods, one produced by each country, that are traded. The home country is a small open economy (SOE) while the foreign country is effectively a closed economy as home country variables have negligible effects on foreign

\footnotetext{
${ }^{19}$ To conserve space, we do not show all the results of the robustness exercises except those in Appendix but they are available upon request.
} 
variables. ${ }^{20}$ Monetary policy at home is determined by an interest rate feedback rule. The model is a two-good, nominal, foreign currency debt, sticky prices extension of the classic SOE business cycle model in Neumeyer and Perri (2005) and Uribe and Yue (2006). We now describe the model in detail. ${ }^{21}$

\subsection{Private sector}

We start with the description of the environment faced by households and firms in our model.

\subsubsection{Households}

A representative household at home maximizes expected discounted utility over the infinite horizon

$$
E_{0} \sum_{t=0}^{\infty} \beta^{t} U\left(c_{t}-\mu \tilde{c}_{t-1}, h_{t}\right),
$$

where $0<\beta<1$ is the discount factor, $0<\mu<1$ is the external habit formation parameter, $c_{t}$ is household consumption of the composite consumption good, $\tilde{c}_{t-1}$ is aggregate consumption that the household takes as given, and $h_{t}$ is hours supplied by the household. $E_{0}$ is the mathematical expectation operator conditional on period-0 information and $U\left(c_{t}-\mu \tilde{c}_{t-1}, h_{t}\right)$ is concave, twice continuously differentiable, and increasing in $c_{t}-\mu \tilde{c}_{t-1}$ and decreasing in $h_{t}$.

The composite consumption good $c_{t}$ is an aggregate of the home good, $c_{H, t}$, and the foreign good, $c_{F, t}$

$$
c_{t}=\left[(1-\chi)^{\frac{1}{\varepsilon}} c_{H, t}^{\frac{\varepsilon-1}{\varepsilon}}+\chi^{\frac{1}{\varepsilon}} c_{F, t}^{\frac{\varepsilon-1}{\varepsilon}}\right]^{\frac{\varepsilon}{\varepsilon-1}}
$$

where $\varepsilon>0$ is the elasticity of substitution between the goods and $0<\chi<1$ denotes the weight of the foreign good in the home consumption basket and therefore, also measures the degree of home bias. ${ }^{22}$ The home and foreign goods are, in turn, aggregates of a continuum of differentiated varieties indexed by $i \in[0,1]$. The consumption goods are thus defined as: $c_{H, t}=\left[\int_{0}^{1} c_{H, t}(i)^{\frac{\nu-1}{\nu}} d i\right]^{\frac{\nu}{\nu-1}}$ and $c_{F, t}=\left[\int_{0}^{1} c_{F, t}(i)^{\frac{\nu-1}{\nu}} d i\right]^{\frac{\nu}{\nu-1}}$, where $\nu>1$ is the elasticity of

\footnotetext{
${ }^{20}$ In terms of our empirical analysis, the home country is essentially an EME while the foreign country is the US.

${ }^{21}$ Note that the variables that are specific to the home and foreign country are subscripted with $H$ and $F$, respectively. Those variables that are defined in relation to the composite good of both home and foreign goods are denoted with an $*$ if they are relevant for the foreign country but without an $*$ if they are relevant for the home country.

${ }^{22}$ We will also refer to $\varepsilon>0$ as the trade elasticity. Moreover note that since the home country is small compared to the rest of the world, $\chi<1$ constitutes home bias in preferences.
} 
substitution among the varieties. The home and foreign investment goods are similar aggregates of the varieties as well. The composite investment good $i_{t}$ is defined as an aggregate of the home goods $i_{H, t}$, and foreign goods, $i_{F, t}: i_{t}=\left[(1-\chi)^{\frac{1}{\varepsilon}} i_{H, t}^{\frac{\varepsilon-1}{\varepsilon}}+\chi^{\frac{1}{\varepsilon}} i_{F, t}^{\frac{\varepsilon-1}{\varepsilon}}\right]^{\frac{\varepsilon}{\varepsilon-1}}$, in the same way as the composite consumption good.

Before presenting the flow budget constraint, it is useful to set some notation. We define the nominal price (in terms of the home currency) of the aggregate consumption and investment good as $p_{t}$ and the nominal prices (in terms of the home currency) of the home and foreign goods as $p_{H, t}$ and $p_{F, t}$ respectively. ${ }^{23}$ The household's flow budget constraint is then given by

$$
\begin{aligned}
& \text {, and } \\
& \qquad \frac{Q_{t}}{p_{t}^{*}} d_{t}^{*}+\frac{I_{t-1}}{\Pi_{t}} b_{t-1}=\frac{Q_{t}}{p_{t}^{*}} R_{t-1} d_{t-1}^{*}+b_{t}+\frac{Q_{t}}{p_{t}^{*}} \Psi\left(d_{t}^{*}\right)-w_{t} h_{t}-u_{t} k_{t}+c_{t}+i_{t}-\varphi_{t},
\end{aligned}
$$

where $d_{t}^{*}$ is the international debt position in terms of the foreign currency at the beginning of period $t+1, R_{t-1}$ is the gross nominal interest rate in foreign currency terms faced by households at the beginning of period $t$ for international borrowing, $w_{t}$ is real wages, $u_{t}$ is the real rental rate of capital, $k_{t}$ is the capital stock at the beginning of period $t$, and $\varphi_{t}$ is profits from home firms which are all held domestically. ${ }^{24}$

In addition, $Q_{t}$ is the real exchange rate and $p_{t}^{*}$ the foreign aggregate price level, which reflects the assumption that international borrowing and the real interest rate are in terms of the foreign currency. Here, we are using the conventional notation that $Q_{t} \equiv S_{t} p_{t}^{*} / p_{t}$, where $S_{t}$ is the nominal exchange rate between the home and foreign country, defined as the price of a unit of the foreign currency in terms of the home currency. Thus, an increase in $S_{t}$ is a depreciation of the home currency. Finally, $\Psi\left(d_{t}^{*}\right)$ denotes debt-adjustment costs faced by the households where $\Psi($.$) is a convex function, which induces stationarity of debt po-$ sitions and consumption in this incomplete market small open economy model. In addition to international borrowing, the household also can trade in domestic, one-period, non-state

\footnotetext{
${ }^{23}$ Similarly, we denote the nominal prices of home variety $i$ as $p_{H, t}(i)$ and of foreign varieties as $p_{F, t}(i)$. We can now derive $p_{t}$ as the minimum-expenditure price index as well as the appropriate demand functions, where the household minimizes total expenditure across the two goods: $p_{H, t} c_{H, t}+p_{F, t} c_{F, t}$. Next, the household also faces a static expenditure minimization problem over the differentiated varieties, where, the household minimizes expenditures : $\int_{0}^{1} c_{H, t}(i) p_{H, t}(i) d i$ and $\int_{0}^{1} c_{F, t}(i) p_{F, t}(i) d i$. From this problem, one can derive $p_{H, t}$ and $p_{F, t}$ as the minimum-expenditure price indices as well as the appropriate demand functions. Note that the expenditure minimization problem over the purchase of investment goods takes the same form as that over the consumption goods and thus there is a single aggregate price index in the economy. Moreover, similar expenditure minimization problems over varieties also apply for the investment good and are omitted for brevity. All the details are in the Appendix.

${ }^{24}$ Note that the flow budget constraint is written in terms of real values, where the deflator is the common price level of the aggregate consumption and investment baskets. Also international borrowing/lending is through a one-period non-state contingent real bond.
} 
contingent nominal bonds (in home currency terms). ${ }^{25} b_{t}$ is domestic bond holdings, expressed in real terms $b_{t}=B_{t} / p_{t}$, at the beginning of period $t+1, I_{t-1}$ is the gross nominal interest rate faced by households at the beginning of period $t$, and $\Pi_{t} \equiv p_{t} / p_{t-1}$ is gross inflation. The household is also subject to a no-Ponzi game condition.

The capital accumulation equation is given by

$$
k_{t+1}=(1-\delta) k_{t}+k_{t} \Phi\left(\frac{i_{t}}{k_{t}}\right),
$$

where $k_{t+1}$ is the capital stock at the beginning of period $t+1$ and $0<\delta<1$ is the rate of depreciation of the capital stock . Here, $\Phi\left(i_{t} / k_{t}\right)$ represents investment adjustment cost where $\Phi($.$) is an increasing concave function. { }^{26}$

The problem faced by the foreign country household is the same as above, but since the home country is a small open economy, the home good will have a negligible weight on the foreign consumption basket. Thus, we have $p_{F, t}^{*}=p_{t}^{*}$ where $p_{F, t}^{*}$ is the foreign currency price of the foreign goods. Moreover, as we explain more later, from the perspective of the home country, the sum of foreign aggregate consumption and investment, $y_{t}^{*}=c_{t}^{*}+i_{t}^{*}$, evolves exogenously.

\subsubsection{Firms}

At home there are a continuum of monopolistically competitive firms that produce differentiated varieties. The firms are of measure 1 and indexed by $i \in[0,1]$. Firm $i$ produces output $y_{t}$ using labor and capital as inputs, $y_{t}(i)=F\left(k_{t}(i), h_{t}(i)\right)$, where the production function $F($.$) is constant returns to scale, concave, and increasing in k_{t}(i)$ and $h_{t}(i)$. Firms rent capital and hire labor in perfectly competitive factor markets. There is a working capital requirement that firms need to hold non-interest bearing assets, $\kappa_{t}(i)$, to finance a fraction of wage bill each period

$$
\kappa_{t}(i) \geq \eta w_{t} h_{t}(i)
$$

where $\eta \geq 0$. Thus $\kappa_{t}(i)$ has the interpretation of working capital held by the firm and (10) represents the financial friction on the firm side in a simple formulation.

Firm $i$ sets prices $p_{H, t}(i)$ for its goods. We introduce nominal rigidities following Rotemberg (1983). Thus, firms face a cost of adjusting prices given by $d\left(p_{H, t}(i) / p_{H, t-1}(i)\right)$ where $d($.$) is a convex function. Moreover, the demand function for variety i$ is derived from the

\footnotetext{
${ }^{25}$ We introduce this asset to introduce a nominal interest rate, which is the monetary policy instrument in the model.

${ }^{26}$ Capital adjustment costs serve to temper the fluctuations in the small open economy's investment in response to interest rate spread or foreign interest rate shocks.
} 
cost-minimization problem of the household over differentiated varieties discussed in the Appendix and given by $\frac{y_{t}(i)}{y_{t}}=\left(\frac{p_{H, t}(i)}{p_{H, t}}\right)^{-\nu}$, where $y_{t}$ is aggregate world demand that is taken as given by the firms. As we emphasize below, there is no price discrimination between home and foreign markets in the model.

In addition to the non-interest bearing assets $\kappa_{t}(i)$, the balance sheet of the firm has one-period interest bearing liabilities, denoted by $d_{t}^{f}(i)$. These one-period riskless liabilities bear gross interest rate $R_{t}^{d}$ in terms of price of the home good. Defining the net liabilities of the firm as $a_{t}(i) \equiv R_{t}^{d} d_{t}^{f}(i)-\frac{p_{t}}{p_{H, t}} \kappa_{t}(i)$ gives a law of motion for $a_{t}(i)$ as

$$
\begin{aligned}
\frac{a_{t}(i)}{R_{t}^{d}}= & a_{t-1}(i)-\frac{p_{H, t}(i)}{p_{H, t}} F\left(k_{t}(i), h_{t}(i)\right)+d\left(\frac{p_{H, t}(i)}{p_{H, t-1}(i)}\right)+\frac{p_{t}}{p_{H, t}}\left[w_{t} h_{t}(i)+u_{t} k_{t}(i)+\varphi_{t}(i)\right] \\
& +\frac{p_{t}}{p_{H, t}} \kappa_{t}(i)\left(1-\frac{1}{R_{t}^{d}}\right)+\left(\frac{p_{t-1}}{p_{H, t-1}}-\frac{p_{t}}{p_{H, t}}\right) \kappa_{t-1}(i)
\end{aligned}
$$

where $\varphi_{t}(i)$ is profits of the firm. The firm is also subject to a no-Ponzi game condition.

We assume that the home firm is owned by the home household. The firm then maximizes expected discounted profits over the infinite horizon

$$
E_{0} \sum_{t=0}^{\infty} \rho_{0, t} \varphi_{t}(i)
$$

where the discounting is done using the stochastic discount factor of the home household $\rho_{0, t}=\beta^{t} \frac{U_{c}\left(c_{t}-\mu \tilde{c}_{t-1}, h_{t}\right)}{U_{c}\left(c_{0}-\mu \tilde{c}-1, h_{0}\right)}$. As is standard, we will focus on a symmetric equilibria where all firms choose the same price and produce the same amount of output.

\subsection{International pricing and market clearing}

There is no international price discrimination in the model and thus the law of one price holds. As a good sells at the same price, once converted in the same currency, both at home and abroad, we have $p_{H, t}=S_{t} p_{H, t}^{*}$ and $p_{F, t}=S_{t} p_{F, t}^{*}$. We also define the terms of trade $\varsigma_{t} \equiv p_{F, t} / p_{H, t}$ and a relative price $r_{t} \equiv p_{t} / p_{H, t}$. Then, we have $\varsigma_{t}=\frac{p_{F, t}}{p_{H, t}}=\frac{p_{F, t}^{*}}{p_{H, t}^{*}}=\frac{p_{t}^{*}}{p_{H, t}^{*}}$, where the last equality follows as $p_{F, t}^{*}=p_{t}^{*}$.

The goods, factor, and bonds markets clear in equilibrium. ${ }^{27}$ In particular, the social resource constraint, at the variety level, is given by

$$
y_{t}(i)=c_{H, t}(i)+i_{H, t}(i)+c_{H, t}^{*}(i)+i_{H, t}^{*}(i)+d\left(\frac{p_{H, t}(i)}{p_{H, t-1}(i)}\right)
$$

\footnotetext{
${ }^{27}$ Our notation already imposes that factor markets clear in equilibrium.
} 
where we incorporate the resource cost of adjusting prices. The foreign demand for the home good $c_{H, t}^{*}(i)+i_{H, t}^{*}(i)$ will in equilibrium be a function of the terms of trade and foreign aggregate demand $y_{t}^{*}=c_{t}^{*}+i_{t}^{*}$, as we show later in detail in the Appendix while discussing all the optimality conditions. Finally, we assume a zero net supply of the home nominal bond, $B_{t}=0$.

\subsection{Monetary policy}

Monetary policy in the home country is determined according to an interest-rate feedback rule

$$
\beta I_{t}=\left[\beta I_{t-1}\right]^{\rho_{I}}\left[\left(\frac{\Pi_{t}}{\Pi}\right)^{\phi_{\pi}}\left(\frac{y_{t}}{y_{t-1}}\right)^{\phi_{y}}\left(\beta R_{t}\right)^{\phi_{R I}}\right]^{\left(1-\rho_{I}\right)},
$$

where $\rho_{I} \geq 0$ is the interest-rate smoothing parameter, $\phi_{\pi} \geq 0, \phi_{y} \geq 0$, and $\phi_{R I} \geq 0$ are feedback parameters, and $\Pi$ is the steady state value of gross inflation. Thus, the nominal interest rate responds, as is standard, to inflation and output growth, but also could additionally, to the international borrowing/lending rate. ${ }^{28}$ The latter aspect of the monetary policy rule will be used to interpret the heterogeneity across countries that we find in the empirical results and reflects a concern that some central banks might have in keeping the home nominal interest rate close to the foreign interest rate, in order for instance to stem rapid movements of capital flows. ${ }^{29}$

\subsection{Exogenous processes}

We define the interest rate spread $R_{t}^{S} \equiv R_{t}-R_{t}^{*}$ as the difference between the domestic household international borrowing rate and foreign interest rate and posit an ARMA $(1,3)$ process for $R_{t}^{S}$

$$
R_{t}^{S}=\rho_{S} R_{t-1}^{S}+\exp \left(\sigma_{0}\right) \varepsilon_{R^{S}, t},+\exp \left(\sigma_{1}\right) \varepsilon_{R^{S}, t-1}+\exp \left(\sigma_{2}\right) \varepsilon_{R^{S}, t-2}+\exp \left(\sigma_{3}\right) \varepsilon_{R^{S}, t-3},
$$

\footnotetext{
${ }^{28}$ Using output or output growth in the feedback rule leads to very similar results.

${ }^{29}$ In the past, tracking the foreign interest rate to stem large movements in the exchange rate has been termed "fear of floating," of EMEs. Here, our model can be thought of as capturing a "fear of movements in external balance" of EMEs. Simply changing the relative weight on output vs. inflation, without introducing a concern explicitly for the foreign rate, is another possible way to introduce heterogeneity. This approach however, does not capture the notion of "fear of capital flows" that we think is important in the data. We nevertheless explored this approach as well, and found that it does not lead to any discernable differences in the results across countries. Finally, in a very different context, Taylor (2007) explores monetary policy rules of this kind for the US and Europe, where interest rate feedback rule contains a feedback to foreign interest rate, and finds some suggestive evidence that this term might matter.
} 
where $\varepsilon_{R^{S}, t}, \varepsilon_{R^{S}, t-1}, \varepsilon_{R^{S}, t-2}, \varepsilon_{R^{S}, t-3} \sim N(0,1)$ and $\exp \left(\sigma_{0}\right), \exp \left(\sigma_{1}\right), \exp \left(\sigma_{2}\right), \exp \left(\sigma_{3}\right)>0$. We posit this more general process to match the hump-shaped response of country spread that we estimate empirically. Thus, this spread measure is the theoretical counterpart to our empirical measure of country spread. This will be the baseline shock, as a proxy for the empirical US uncertainty shock. ${ }^{30}$

In the baseline, we do not consider time varying volatility in the interest rate spread process. In an extension, we consider a stochastic volatility process by making $\sigma_{0}$ timevarying as

$$
\sigma_{t}-\sigma=\rho_{\sigma}\left(\sigma_{t-1}-\sigma\right)+\varepsilon_{\sigma, t}
$$

where $\varepsilon_{\sigma} \sim N(0,1)$. We then explore macroeconomic implications of a pure second-moment shock that does not change the level of the spread $R_{t}^{s} \cdot{ }^{31}$ Finally, we assume that foreign output and prices evolve exogenously following $\mathrm{AR}(1)$ processes in terms of deviations from their respective deterministic steady-states. Thus, we have

$$
y_{t}^{*}-y^{*}=\rho_{y^{*}}\left(y_{t-1}^{*}-y^{*}\right)+\varepsilon_{y, t}^{*} \text { and } p_{t}^{*}-p^{*}=\rho_{p^{*}}\left(p_{t-1}^{*}-p^{*}\right)+\varepsilon_{p, t}^{*}
$$

In particular, in an extension, we will explore implications of a negative foreign output/demand shock, as that could be another proxy for the empirical US uncertainty shock.

\subsection{Results}

We formally define in the online appendix the equilibrium in our economy and discuss the aggregate optimality and feasibility conditions that characterize it. We present in detail in the online appendix, the non-linear, aggregate equilibrium conditions of the model that determine the dynamics of the seventeen endogenous aggregate variables $\left\{d_{t}, w_{t}, h_{t}, u_{t}, k_{t}\right.$, $\left.c_{t}, i_{t}, R_{t}^{d}, y_{t}, \tilde{c}_{t}, \varphi_{t}, \varsigma_{t}, \Pi_{t}, \Pi_{H, t}, b_{t}, I_{t}, \xi_{t}\right\}$. The economic interpretation of these equilibrium conditions is also relegated to the online appendix.

We here define three variables for later use in the model simulations and results. Net exports as a ratio of output is given by $\frac{n x_{t}}{y_{t}}=\frac{y_{t}-r_{t}\left[c_{t}+i_{t}+\frac{Q_{t}}{p_{t}^{*}} \Psi\left(d_{t}^{*}\right)\right]}{y_{t}}$ while the current account as a ratio of output is given by $\frac{c a_{t}}{y_{t}}=-r_{t}\left(\frac{Q_{t}}{p_{t}^{*}} d_{t}^{*}-\frac{Q_{t}}{p_{t}^{*}} d_{t-1}^{*}\right)$. Finally, to compare with the empirical results, we price a stock as a claim to the (future) stream of firm profits using the

\footnotetext{
${ }^{30}$ Also, note that we assume a common steady state for $R_{t}$ and $R_{t}^{*}$ and that since we will not model a process for $R_{t}^{*}$ separately, we can consider the shock to spread as a shock to the international borrowing rate $R_{t}$. We will therefore use them interchangeably.

${ }^{31} \mathrm{We}$ adopt this framework of time-varying volatility in the external shock process from FernandezVillaverde et al (2011).
} 
stochastic discount factor of the home household. Thus the stock price is given by the usual asset pricing recursion $\Omega_{t}=E_{t}\left[\frac{\rho_{t+1}}{\rho_{t}}\left(\Omega_{t+1}+\varphi_{t+1}\right)\right]$.

We solve the model non-linearly, where in period 0 , an unexpected shock to the interest rate spread, $\varepsilon_{R^{s}}$, hits the economy, and then the economy evolves deterministically thereafter. ${ }^{32}$ As we discussed before, we interpret this shock as proxying for the foreign uncertainty shock in our empirical exercise. Thus, it is used to roughly capture the belief of external investors that lending to the SOE is risky. It can also capture some "flight to safety/quality" phenomenon.

\subsubsection{Functional forms and parameterization}

We use the same functional forms for utility, production function, and real adjustment costs as in Uribe and Yue (2006) and a standard specification for price-adjustment costs

$$
\begin{gathered}
U(c-\mu \tilde{c}, h)=\frac{\left[c-\mu \tilde{c}-\omega^{-1} h^{\omega}\right]^{1-\gamma}-1}{1-\gamma}, F(k, h)=k^{\alpha} h^{1-\alpha}, \\
\Phi(x)=x-\frac{\phi}{2}(x-\delta)^{2}, \Psi(d)=\frac{\psi}{2}\left(d_{t}^{*}-\bar{d}\right), d\left(\Pi_{H}\right)=\frac{d_{1}}{2}\left(\Pi_{H}-\bar{\Pi}_{H}\right)^{2} .
\end{gathered}
$$

For the parameters common to Uribe and Yue (2006), we use the same values as theirs. Thus, our goal here is simply to assess model dynamics taking the calibration as given from the previous literature. ${ }^{33}$

Note however that our model is calibrated to the monthly frequency and some parameters are modified accordingly. Then for the new parameters in our model, we conduct detailed comparative statics. The numerical values for parameters common with Uribe and Yue (2006) we use in simulation of our model are given below in Table 2. We note that as in Uribe and Yue (2006), we calibrate the debt-adjustment function parameter, $\bar{d}$, to achieve a steady-state net exports to GDP ratio of 0.02 . Then we consider three alternate values for the home-bias, trade elasticity, and price-adjustment costs parameters: $\chi=0.3,0.35,0.4$, $\varepsilon=0.7,1.5,4$, and $d_{1}=35,50,75$. Our baseline choices are $\chi=0.35, \varepsilon=1.5$, and $d_{1}=35$. This parameterization implies a moderate trade elasticity and quite flexible prices. For the elasticity of substitution across differentiated varieties, we use a standard value of 7 .

\footnotetext{
${ }^{32}$ We use a non-linear solver to compute this perfect foresight solution. In an extension, when we consider a second-moment shock to the interest rate spread, we use a third-order perturbation solution method. For conciseness, we do not show explicitly results on the foreign output and price shock later in the paper. In the Appendix, we report results on the effects of a negative foreign output shock.

${ }^{33}$ We do not thus attempt a impulse response matching exercise as in Uribe and Yue (2006) and want to simply assess some qualitative predictions of the model.
} 
Table 2: Parameterization of the model based on Uribe and Yue (2006)

\begin{tabular}{cccc}
\hline Parameter & Value & Parameter & Value \\
\hline \hline$\mu$ & 0.204 & $\omega$ & 1.455 \\
$\delta$ & $0.025 / 3$ & $\gamma$ & 2 \\
$\beta$ & 0.99 & $\phi$ & 72.8 \\
$\alpha$ & 0.32 & $\psi$ & 0.00042 \\
$\frac{\bar{d}}{y}$ & 1.37 & $\eta$ & 1.2 \\
\hline
\end{tabular}

We use parameters for the shock process such that it matches exactly the dynamics of the interest rate spread we estimate empirically in Figure 2. For the monetary policy reaction function, as baseline, we consider the usual Taylor rule parameter values: $\rho_{I}=0.8$, $\phi_{\pi}=1.5$, and $\phi_{y}=0.5 / 12$. Finally, in a model variant to interpret the heterogeneous responses across different sub-groups of countries that we estimate empirically in Figure 3, we allow a response in the monetary policy reaction function directly to the foreign interest rate spread: $\phi_{R I}=0.5 / 12 .^{34}$

\subsubsection{Impulse responses}

We now present impulse responses when an unexpected shock $\varepsilon_{R^{S}, t}$ hits the economy in the initial period, when it is in the deterministic steady-state. ${ }^{35}$ The baseline impulse responses from the model are shown in Figure 4, which are all qualitatively consistent with our empirical impulse responses in Figure 2. When the cost of borrowing in international market increases, it generates contractionary macroeconomic effects as is the case empirically. Consumption, investment, and output all decrease in the small open economy. Consumption and investment decline for, by now well understood, mechanisms inherent even in classic onegood SOE models like Neumeyer and Perri (2005) and Uribe and Yue (2006). The major mechanism is an increased cost of borrowing, and thus of financing spending, which drives lower consumption as well as investment. Because of the working capital constraint, investment gets additionally negatively affected in the model as wage bill increases with increased interest rates. Output of the home good declines following this reduction in spending.

\footnotetext{
${ }^{34}$ In this case, since the shock is persistent, we remove the interest rate smoothing component of the Taylor rule. We use the same value for this coefficient as the output coefficient for ease of comparison.

${ }^{35}$ The deterministic steady-state of our model is relatively straightforward to derive and the details are in the online Appendix. We note some properties of the steady-state later in the paper in the Appendix. Also, note again that our model frequency is monthly, the same frequency as in the empirical section, and for direct comparison with the empirical results, we annualize the responses of the interest rate variables.
} 

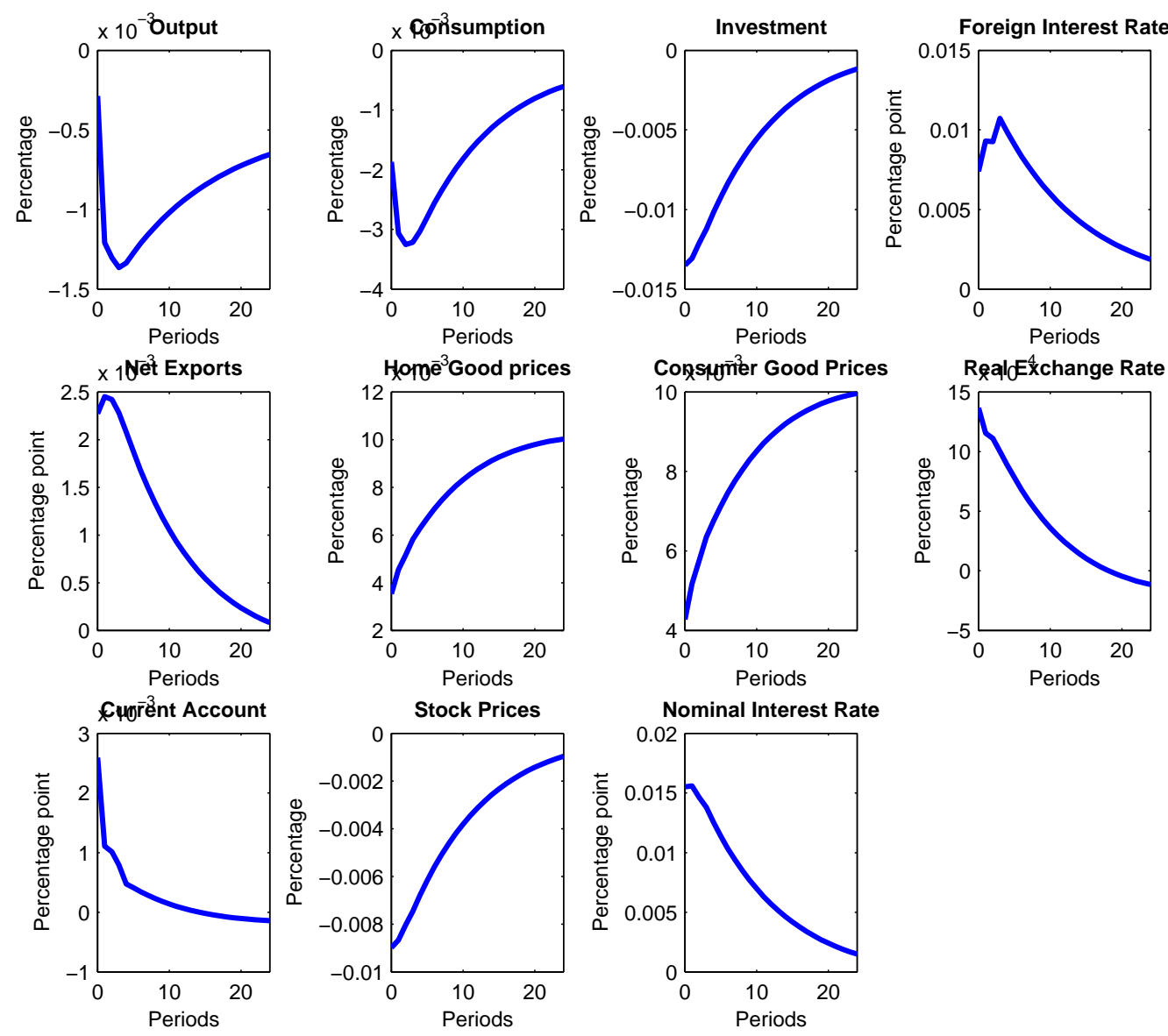

Figure 4: Impulse responses of the small open economy model to a shock to the foreign interest rate spread

Notes: These non-linear impulse responses are those computed when an unexpected foreign interest rate (spread) shock hits the economy in the initial period and then the economy evolves deterministically thereafter. The economy is in the deterministic steady-state initially and the response of the variables are presented in terms of $\%$ or $\%$ points deviation from the steady-state. The economy transitions back to the deterministic steady-state in the long-run. The choice of model parameter values, including the size and persistence of the shock, is described in the text.

In our two-good model, there are additional implications for prices that are consistent with our empirical results, which in turn also affect dynamics of macroeconomic quantities. First, because of decreased demand, through the market-clearing condition for home goods, a clear prediction is that the real exchange rate depreciates. ${ }^{36}$ That is, the relative price

\footnotetext{
${ }^{36}$ Note that in the model, as is the convention, our notation is such that an increase in the exchange rate constitutes a depreciation. Here we focus on the real exchange rate as the nominal exchange rate is non-stationary in the model, but empirically, as we show in the Appendix, the response of the real exchange rate in the EM VAR is basically identical to the nominal exchange rate.
} 
of the home good must decline in equilibrium as demand for the good falls strongly. The decline in output, together with a fall in relative price of the home good, leads to a fall in firm profits and thereby, stock prices.

Moreover, associated with the decrease in aggregate demand is also an increase in net exports (as a ratio of GDP), as spending contracts more compared to output. Compared to a one-good model, in our two-good model, the contraction in spending gets additionally magnified as the relative price of the home good declines (or equivalently the real exchange rate depreciates). Thus, net exports is persistently positive for a long period of time following the shock. Finally, as a reflection of the reduction in debt of the SOE following this shock, there is a positive current account balance (as a ratio of GDP). ${ }^{37}$ These are consistent with the empirical responses in Figure 2 where net exports increase while capital inflows decline in the EMEs.

Next, again as is consistent with our empirical responses, goods prices increase. In particular, in the model, both consumer and home good prices increases. What is the mechanism? Because of nominal rigidities and forward looking behavior of price-setting firms, in our model, home good inflation is determined by the path of (expected future) marginal costs faced by the home firms. Importantly, the relevant marginal cost is in terms of the home good price. Thus, while components of the marginal cost such as real wages and rental rate of capital decline initially given the large drop in macroeconomic aggregates, because of the real exchange rate depreciation, the marginal cost in terms of the home good prices actually increases. ${ }^{38}$ This then leads to an increase in home goods prices. Given the home bias in consumption, consumer good prices are influenced strongly by home good prices. This then translates also into consumer good prices increasing in the model by a very similar amount.

To help interpret the heterogeneity in responses across sub-groups of countries that we find empirically, we now consider a case where the central bank, in addition to inflation and output, also responds to the foreign interest rate. This is meant to capture an inclination on the part of some central banks to keep the home interest rate at a similar level as the foreign interest rate, in order to avoid large swings in capital flows. The impulse responses from this variation in the model are shown in Figure 5. It is clear that because of such policy, which turns out to be contractionary, output and consumption, and by more limited amount also investment, decline by more. ${ }^{39}$ In addition, while the differential effects are smaller, the

\footnotetext{
${ }^{37} \mathrm{As}$ is to be expected, the cyclicality of current account can depend on the persistence of the external shock. In our model, the current account is countercyclical for a persistent enough shock.

${ }^{38}$ Note that even though the foreign interest rate increases, in equilibrium, because of the large fall in output, the rental rate of capital actually declines for the initial periods. It later however increases above steady-state.

${ }^{39}$ Note that as the monetary policy instrument tracks the foreign interest rate/spread, the dynamics of the
} 
decline in stock prices is also larger.
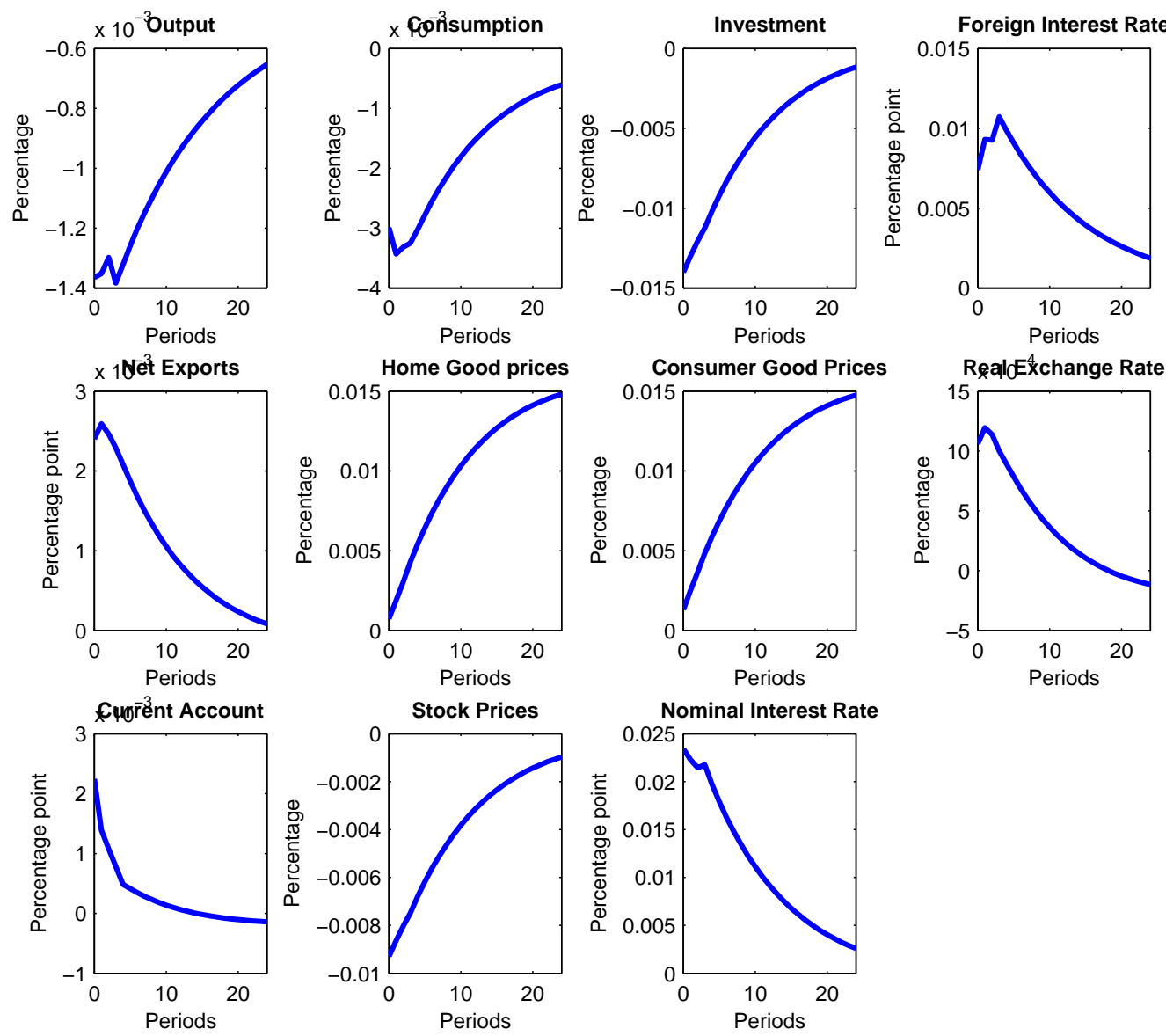

Figure 5: Impulse responses of the small open economy model to a shock to the foreign interest rate spread when the central bank reaction function includes the shock

Notes: Compared to the baseline in 4, the central bank interest rate reaction function now also includes a feedback to the foreign interest rate. Also, see the notes in Figure 4.

On the other hand, the response of current account is lower. ${ }^{40}$ Thus the small open economy limits the capital outflows from it to the rest of the world as a result of such a policy. Thus, at least qualitatively, for many variables, this is consistent with the heterogeneity in responses we find in Figure 3, where in particular, South American countries suffer less in terms of output and stock prices but there is a larger increase in current account following nominal interest rate and some other variables such as output have a very similar dynamics, with somewhat humped shape response and minor non-monotonicity in the first few periods.

${ }^{40}$ Note that some of the differences across the figures, such as those in stock prices, are small. But our point here is just qualitative. We can make the differences larger by increasing the weight on the foreign interest rate in the monetary policy reaction function. 
a US uncertainty shock. Our model based interpretation for this heterogeneity then is that it can arise if the rest of EMEs, compared to South American countries, put a larger weight in the monetary policy reaction function to the foreign interest rate.

\subsubsection{Extensions and robustness}

We consider several model extensions and robustness exercises. The results are reported in the Appendix. The most important extension we consider is one where we introduce a second-moment shock to the foreign interest rate process. We then compute the responses of the model variables to a purely second-moment shock, that is, one where we hold the first-moment shock at its steady-state. We use a third-order accurate perturbation solution method to compute the stochastic equilibrium. Figure B.11 shows the results and while the response of most variables are similar qualitatively to our baseline, with magnitudes being smaller, by definition, this shock does not lead to an increase in the level of foreign interest rate spread. This increase in the level of country spread is a robust feature of the VIX shock on EMEs, which we have shown in the empirical section.

For the baseline first-moment shock to the foreign interest rate spread case, we show in the Appendix in Figures B.12 and B.13, results we obtain when we use a greater level of price stickiness $\left(d_{1}=50\right)$ and a lower trade elasticity $(\varepsilon=0.9)$ respectively.

Finally, we also consider a negative foreign income/output shock as a possible proxy for the US uncertainty shock. The results are reported in Figure B.14. Since such a shock constitutes an exogenous drop in demand for the SOE produced good, it does generate a drop in the SOE output and also, consumption and investment. But a counterfactual prediction is that net exports decrease, which is also a direct result of the drop in demand for the SOE produced home good.

\section{Discussion and external evidence}

We have so far presented our empirical results, with several robustness exercises, and used a theoretical model to help interpret them. In particular, we have used the model to assess the transmission of an external shock to a SOE, as well as to help assess possible reasons for the heterogeneous results across groups of EMEs. We now present some evidence, external to the baseline empirical and theoretical approach, to provide additional validity to our results and interpretation. 


\subsection{US monetary policy spillovers}

We now discuss results based on spillovers to EMEs of the standard US monetary policy shock. ${ }^{41}$ Since our sample period includes the zero lower bound for the US, we use a shadow interest rate computed by Krippner (2016) for this period as a measure of monetary policy. The identification of a US monetary policy is standard, where we use a recursive identification method by ordering the shadow interest rate last. ${ }^{42}$ Additionally, for the panel VAR exercise, the specification is identical to the one we have used above except that the US monetary policy shock is considered as an external shock instead of a US uncertainty shock. ${ }^{43}$

We do this exercise for several reasons. First, we want to assess whether our interpretation that the transmission to EMEs of an external shock mainly goes through the foreign interest rate spread channel has validity with a different shock. Second, we will be able to check on whether there is heterogeneity in responses across subgroups of EMEs to foreign interest rate spread shocks. Third, if we find heterogeneity, we can check if it manifests itself in terms of differential responses of the short-term monetary policy rate in order to counter excess volatility in capital flows.

We present results from our baseline specification in Figure B.15 in the Appendix. We find that unanticipated US monetary policy changes have significant financial and macroeconomic spillover effects on EMEs. On average, following an exogenous increase in US shortterm interest rates, EME short-term interest rates and especially, EME long-term country spreads (EME long-term government yield compared to the 10-year US Treasury yield) increase persistently. In addition, stock prices decline and nominal exchange rates depreciate persistently. Finally, capital flows out of these countries. Importantly, we find that these financial effects are accompanied by significant contractionary macroeconomic effects. The US monetary policy shock transmits to the real economy of EMEs: output of these countries drops while net exports increase.

These results thus lend validity to our model based interpretation that transmission of foreign shocks to EMEs appear to operate through the country spread channel. Additionally, similar to the US uncertainty shock, in a period of financial integration and flexible exchange rate regimes, central banks of EME countries face a non-trivial trade-off in the face of a US monetary policy shock as well, especially with the drop in output occurring together with

\footnotetext{
${ }^{41}$ These results appeared in much more detail in Bhattarai, Chatterjee, and Park (2017b).

${ }^{42}$ The monthly US VAR has five variables: the industrial production (IP) index as a measure of output, PCE index as a measure of consumption, the PCE deflator as a measure of consumer prices, CRB BLS spot price index as a measure of commodity prices, and a short-term interest rate as the measure of monetary policy instrument. In the baseline specification we use six lags. The sample period is Jan 1984-Nov 2015 and we use a Bayesian approach to estimation. For more details please see the Appendix.

${ }^{43} \mathrm{Ha}$ and So (2017) also find that US monetary policy plays an important role in monetary transmission in SOE interest rates, presumably hampering the effectiveness of domestic monetary policy.
} 
an increase in capital outflows. If our hypothesis that central banks of different EMEs might respond differentially to such a trade-off is correct, then we should observe similar heterogeneous responses in our sub-group estimation here as well.

Figure B.16 in the appendix presents results based on the subgroup analysis where we split the EMEs in our sample into two subgroups as before: South American countries that include Brazil, Chile, Colombia, Mexico and Peru, and the rest of emerging market countries. Strikingly, we uncover a pattern of heterogeneity that very closely echoes our earlier results in the context of the US financial uncertainty shock. In particular, the negative effects on output and exchange rates are bigger and more persistent for the rest of EMEs compared to South American countries. On the other hand, the effects are bigger and more persistent on capital flows and net exports for South American countries compared to the rest of EMEs. In fact, the effects on net exports are significant only for South American countries.

Most importantly, the short-term (policy) rate of the rest of EMEs not only does not decrease by more compared to South American countries, despite that the countries get affected much more negatively in terms of output (with insignificant effects in terms of consumer prices), it in fact is significantly positively affected. Moreover, the positive response of the policy rate is statistically significant only for the rest of EMEs. Thus, the policy rates of the rest of EMEs can be considered too high and monetary policy tight, given the negative response of output. In other words, faced with a non-trivial trade-off between output and external balance, even for this different US shock, South American countries appear to focus more on output stabilization while the rest of EMEs more on external balance stabilization. Thus, our empirical results here provide supporting evidence in favor of "fear of capital flows" in the rest of the EMEs and associated heterogeneity in monetary policy as captured in different Taylor-rule type formulations.

\subsection{Capital flow controls}

We have interpreted the heterogeneity in responses across sub-groups as coming from heterogeneity in how monetary policy responds to the trade-off of negative effects on output accompanied by increase in capital outflows. In particular, we find evidence in our empirical exercises consistent with the rest of EMEs showing more concern for capital flows compared to output.

There is some external evidence consistent with our interpretation of a higher significance attached to external balance stabilization among Asian economies. For instance, SEACEN, the research network of Asian central banks has established since 2000 an expert group on capital flows whose "main objectives are: to develop a regional framework to promote in- 
formation sharing on capital flows among members; and to draw up concrete and practical proposals that members can implement individually or collectively to enhance the management of capital flows." Asian countries are the majority in the group of other EMEs in our sample.

Moreover, if these capital flow concerns are more paramount for the rest of EMEs compared to South American EMEs, then it should be reflected in other, non-monetary policy choices as well. In particular, the rest of EMEs are expected to use direct capital flow restrictions measures more extensively. Capital flow control indices computed by Fernandez et al (2015) show that it is indeed the case: South American EMEs have higher capital mobility (or less restrictive capital control policies) compared to the rest of EMEs in our sample. The results based on these indices are reported in Table B.4 in the Appendix.

\subsection{Analysis of EME central bank minutes}

We now turn to minutes and statements from monetary policy committee meetings of various EME central banks. Overall, this narrative analysis reveals a picture of perennial fear of capital flows. Moreover, in some instances, considerations for financial stability and associated fear of flows led to changes in monetary policy decisions, despite domestic output and inflation stabilization objectives demanding a different course of policy action. In this section we provide some evidence documenting this phenomenon.

We first provide quote-based examples of several countries in the group of rest of EMEs (India, South Africa, and Turkey) where these concerns led to tight monetary policy and an example of Peru which is in the South American EMEs group, where these concerns were deemed secondary to domestic stabilization. For example, the Reserve Bank of India (RBI) decided to maintain their policy rate constant despite decline in output and inflation after the international monetary policy uncertainty and related capital outflows in May, 2013:

On monetary policy measures, four of the seven Members recommended maintenance of status quo in the policy repo rate. In their view, though growth and inflation are projected to move down, we still have to guard against high inflation expectations that can destabilize the momentum of the economy. Moreover, the external front is fragile and warrants that we do not do anything that can send wrong signals about our discounting the possibility of capital outflows (Minutes of Monetary Policy Technical Advisory Committee Meetings, RBI, July 2013).

In a similar instance, the Reserve Bank of South Africa (RBS) raised its policy rate despite economic slowdown out of concerns for external financial market uncertainty: 
Since the previous meeting of the Monetary Policy Committee the global environment has been dominated by heightened uncertainty relating to the debt crisis in Greece and the sharp decline in equity prices in China. While the tail risks from these events appear to have dissipated somewhat, uncertainties still remain. At the same time, the risks associated with financial market volatility related to the timing of the first increase in the US policy rate persist. Domestically, the growth outlook remains weak, as both the supply and demand sides remain constrained amid declining business and consumer confidence. The MPC has therefore decided ... the repurchase rate will increase by 25 basis points to 6 per cent per annum with effect from Friday 24 July 2015 (Monetary Policy Committee, RBS, July 2015).

Perhaps the most prominent example of this "fear of capital flows" is the Central Bank of Republic of Turkey (CBRT) law that explicitly includes financial stability together with inflation targeting in their monetary policy framework. In November 2016, despite a decline in aggregate economic activity and a fall in inflation, CBRT undertook substantial monetary tightening to take precautions for the enhancement of the stability in the financial system and to mitigate capital outflows:

In sum, the slowdown in aggregate demand contributes to the fall in inflation. However, the recent exchange rate movements resulting from increased global uncertainty and high volatility limit the improvement in inflation outlook.... The increased global uncertainty driven by the US presidential election send emerging financial markets into turbulence, inducing portfolio outflows... The Committee decided to implement monetary tightening (Monetary Policy Committee, CBRT, Nov 2016). .

However, this "fear of capital flows" is not a homogeneous concern among the EMEs. For example, facing similar external considerations, the Board of the Central Reserve Bank of Peru (CRBP) approved to maintain the monetary policy interest rate in their November 2016 meeting:

This decision is consistent with an inflation forecast in which inflation is gradually converging to 2.0 percent in the monetary policy horizon and takes into account that: i) 12 month inflation expectations are within the target range; ii) The effects of the rise in the prices of some food products and fuels on the rate of inflation in September and October have been transitory, so inflation is expected to converge soon to the inflation target range; iii) Local economic activity has 
been growing at a rate close to its potential growth level, and iv) The global economy continues showing mixed signals of recovery in production and employment, as well as increased uncertainty in international financial markets. In this scenario, the Peruvian economy maintains sound fundamentals (Monetary Policy Notes, CRBP, Nov 2016).

Thus, there indeed is heterogeneity across EME central banks in terms of the degree of attention and importance they assign to volatility of capital flows and how they tailor monetary policy in response to these concerns. This is consistent with our interpretation of our empirical results based on sub-group estimation.

Next, given these somewhat stark differences in policy actions between Turkey and Peru facing very similar domestic and external considerations, we take a further step by analyzing the entire text of monetary policy meeting minutes of Turkey and Peru from 2006-2016. This exercise provides a more rigorous narrative evidence in support of our hypothesis. In particular, we measure capital flow concerns as the number of times monetary policy minutes contain words in the group \{capital flow, capital outflow, international capital market, international market\} and contrast this to the output stabilization concern measured as word count in the group \{output, economic activity, employment, unemployment . Because both central banks are currently official inflation targeting central banks, naturally they are concerned with price stabilization. Hence, we decide to use output stabilization as the appropriate scale to compare with for capital flow sentiment. As Figures B.17 and B.18 in the Appendix confirm, a pervasive fear of capital flows for Turkey can be traced, which forms a striking contrast with Peru where capital flow concerns are generally rarely mentioned, and in fact, not mentioned at all after the US financial crisis.

\section{Conclusion}

We study empirically the spillover effects on emerging market economies (EMEs) of fluctuations in US uncertainty. We find that an unanticipated change in US financial uncertainty has significant financial and macroeconomic effects on the EMEs. An unanticipated increase in US uncertainty, on average, sharply depreciates the local currency of the EMEs, leads to a decline in their local stock markets, increases long-term interest rate spreads, and capital flows out from them. Moreover, we find that these financial effects transmit to the real economy as they are accompanied by large and persistent macroeconomic effects. We estimate a significant drop in output, a rise in consumer prices, and a rise in net exports from these countries in response to a rise in US uncertainty. 
We find economically meaningful heterogeneity in responses among the fifteen EMEs. In particular, the negative effects on output, stock prices, and exchange rates are bigger and more persistent for the rest of EMEs compared to South American countries. On the other hand, the effects are bigger and more persistent on capital and trade flows for South American countries compared to the rest of EMEs. We find that the short-term (policy) rate of the non-South American EMEs stays relatively high, given the large negative macroeconomic effects, thereby suggesting that the monetary policy response can play a critical role in the transmission of the external US uncertainty shock.

We present a two-good small open economy (SOE) model with financial and nominal frictions that can help interpret our empirical findings. A negative external shock that increases the interest rate spread faced by the SOE produces responses of macroeconomic and financial variables that are consistent with our estimated responses. Moreover, the model provides a possible explanation for the heterogeneity in responses across countries depending on the endogenous response of the monetary policy instrument to the increase in interest rate spread. We corroborate our theoretical mechanisms further in an application to US monetary policy spillovers. This validates our modeling of external shock as raising the interest rate spread faced by a SOE and establishes the possibility of differential "fear of capital flows" and associated heterogeneity in EME monetary policy response as an important channel to alter spillover effects of such external shocks.

In future work, it will be worthwhile to explore if the spillovers effects of US uncertainty we estimate are also important for advanced small open economies, such as Canada, Australia, Sweden, Norway, and Switzerland. Moreover, it will be interesting to consider a model with global financial intermediaries and investors that can provide an even deeper understanding of how US financial uncertainty propagates to the financial and macroeconomic sectors of EMEs. In doing so, we can build on existing work such as Caballero and Krishnamurthy (2001) that features a richer set of collateral constraints, Caballero and Krishnamurthy (2008) that models a flight to quality episode, and Calvo, Izquierdo, and Talvi (2006) that features sudden stops in emerging market economy models. In terms of modeling, it might also be fruitful to directly model an uncertainty shock in a foreign country. For example, we can develop a general equilibrium global economy with countries of different sizes where an increase in expected volatility in the stock markets of a large economy can be considered directly. Also, a more comprehensive analysis of the EME central bank minutes to capture the "fear of capital flows", following analysis of FOMC statements like Lucca and Trebbi (2011) and Feroli et al (2017), is part of our future research. 


\section{Acknowledgments}

We thank Nick Bloom, Oli Coibion, Martin Uribe, Kei-Mu Yi, Inkoo Lee, Deokwoo Nam, Taebong Kim, and seminar and conference participants at the Federal Reserve Bank of Dallas, the Bank of Korea, University of New South Wales, the 17th KEA International Conference, Hong Kong Institute for Monetary Research, KIPF, the 2017 Econometric Society Winter Meetings, Stanford Institute for Theoretical Economics Conference on Macroeconomics of Uncertainty and Volatility, 2017 Asian Meeting of the Econometric Society, Reserve Bank of India, Indian Institute of Technology Delhi and Kanpur, University of Queensland, 2017 Australasian Macroeconomic Society, University of Auckland, and the Fourth Annual Conference of the IAAE for helpful comments and suggestions. We thank Choongryul Yang and Shreeyesh Menon for superb research assistance. This paper was partly written while Bhattarai was a research fellow of the Hong Kong Institute for Monetary Research. Bhattarai is grateful to the Institute for its hospitality during the resident visit period. Park gratefully acknowledges the financial support from the Housing and Commercial Bank Economic Research Fund for Institute of Economic Research at Seoul National University and from the Creative-Pioneering Researchers Program through Seoul National University. 


\section{References}

[1] Aizenman, Joshua, Menzie Chinn, and Hiro Ito (2015), "Monetary Policy Spillovers and the Trilemma in the New Normal: Periphery Country Sensitivity to Core Country Conditions," working paper.

[2] Akinci, Ozge (2013), "Global Financial Conditions, Country Spreads and Macroeconomic Fluctuations in Emerging Countries," Journal of International Economics, 91, 358-371.

[3] Bertaut, Carol, and Ruth Judson (2014), "Estimating U.S. Cross-Border Securities Positions: New Data and New Methods," working paper.

[4] Bhattarai, Saroj, Arpita Chatterjee, and Woong Yong Park (2017a), "Effects of US Quantitative Easing on Emerging Market Economies," working paper.

[5] Bhattarai, Saroj, Arpita Chatterjee, and Woong Yong Park (2017b), "US Monetary Policy Spillovers," HKIMR working paper, No. 17/2017.

[6] Bloom, Nicholas (2009), "The Impact of Uncertainty Shocks," Econometrica, 77, 623685.

[7] Bloom, Nicholas (2014), "Fluctuations in Uncertainty," Journal of Economic Perspectives, 28, 153-176.

[8] Caballero, Ricardo, and Arvind Krishnamurthy (2001), "International and Domestic Collateral Constraints in a Model of Emerging Market Crises," Journal of Monetary Economics, 48, 513-548.

[9] Caballero, Ricardo, and Arvind Krishnamurthy (2008), "Collective Risk Management in a Flight to Quality Episode," Journal of Finance, 63, 2195-2230.

[10] Calvo, Guillermo A., Alejandro Izquierdo, and Ernesto Talvi (2006), "Sudden Stops and Phoenix Miracles in Emerging Markets," American Economic Review, 96, 405-410.

[11] Canova, Fabio (2005), "The Transmission of US Shocks to Latin America," Journal of Applied Econometrics, 20, 229-251.

[12] Canova, Fabio (2007), Methods for Applied Macroeconomic Research, Princeton, NJ: Princeton University Press. 
[13] Canova, Fabio, and Matteo Ciccarelli (2013), "Panel Vector Autoregressive Models: A Survey," in VAR Models in Macroeconomics-New Developments and Applications: Essays in Honor of Christopher A. Sims. London, Uk: Emerald Group Publishing Limited.

[14] Carriere-Swallow, and Luis Felipe Cespedes (2013), "The Impact of Uncertainty Shocks in Emerging Economies," Journal of International Economics, 90, 316-325.

[15] Cushman, David O., and Tao Zha (1997), "Identifying Monetary Policy in a Small Open Economy Under Flexible Exchange Rates," Journal of Monetary Economics, 39, 433-448.

[16] Fernandez, Andres, Michael W. Klein, Alessandro Rebucci, Martin Schindler, and Martin Uribe (2015), "Capital Control Measures: A New Dataset," working paper.

[17] Fernandez-Villaverde, Jesus, Pablo Guerron-Quintana, Juan F. Rubio-Ramirez, and Martin Uribe (2011), "Risk Matters: The Real Effects of Volatility Shocks," American Economic Review, 101, 2530-2561.

[18] Feroli, Michael, David Greenlaw, Peter Hooper, Frederic Mishkin, and Amir Sufi (2017), "Language after Liftoff: Fed Communication Away from the Zero Lower Bound," working paper.

[19] Gerko, Elena, and Helene Rey (2017), "Monetary Policy in the Capitals of Capital," working paper.

[20] Gourio, Francois, Michael Siemer, and Adrien Verdelhan (2013), "International Risk Cycles," Journal of International Economics, 89, 471-484.

[21] Ha, Jongrim, and Inhwan So (2017), "Which Monetary Shocks Matter in Small Open Economies? Evidence from SVARs," Bank of Korea working paper no. 2017-2.

[22] Ireland, Peter N. (2000), "Interest Rates, Inflation, and Federal Reserve Policy since 1980," Journal of Money, Credit, and Banking, 32, 416-34.

[23] Krippner, Leo (2016), "Measures of Monetary Policy," working paper.

[24] Lucca, David, and Francesco Trebbi (2011), "Measuring Central Bank Communication: An Automated Approach with Application to FOMC Statements," working paper.

[25] Ludvigson, Sydney, Sai Ma, and Serena Ng (2015), "Uncertainty and Business Cycles: Exogenous Impulse or Endogenous Response?" working paper. 
[26] Mackowiak, Bartosz (2007), "External Shocks, U.S. Monetary Policy and Macroeconomic Fluctuations in Emerging Markets," Journal of Monetary Economics, 54, 25122520 .

[27] Matsumoto, Akito (2011), "Global Liquidity: Availability of Funds for Safe and Risky Assets," working paper.

[28] Miranda-Agrippino, Silvia, and Helene Rey (2015), "World Asset Markets and the Global Financial Cycle", working paper.

[29] Neumeyer, Pablo A., and Fabrizio Perri (2005), "Business Cycles in Emerging Economies: The Role of Interest Rates," Journal of Monetary Economics, 52, 345-380.

[30] Rey, Helene (2013), "Dilemma not Trilemma: The Global Financial Cycle and Monetary Policy Independence," Proceedings of the Jackson Hole Economic Policy Symposium.

[31] Rey, Helene (2015), "International Channels of Transmission of Monetary Policy and the Mundellian Trilemma," working paper.

[32] Sims, Christopher A., and Tao Zha (1998), "Bayesian Methods for Dynamic Multivariate Models," International Economic Review, 39, 949-968.

[33] Taylor, John B. (2007), "Globalization and Monetary Policy: Missions Impossible," working paper.

[34] Uribe, Martin, and Vivian Z. Yue (2006), "Country Spreads and Emerging Countries: Who Drives Whom?" Journal of International Economics, 69, 6-36. 


\section{A Data description}

See the data Appendix for the complete list of the data with detailed descriptions and their sources. It also explains how quarterly GDP, consumption, and investment series are interpolated to monthly series for the US and the emerging market countries. For the latter countries, monthly GDP is used to normalize capital flows and net exports.

\section{B Extensions and robustness}

\section{B.1 Empirical results}

Figure B.1 presents the spillover effects on the alternative measures of economic activity and aggregate spending in EMEs where to conserve space we only present the responses of the alternative measures. GDP, consumption, and investment all respond negatively to the uncertainty shock with investment responding most strongly. Figure B.2 in the first row, reports the spillover effects of the US uncertainty shock on long-term real interest rate spreads, real effective exchange rates, and net exports to the world and in the second row, reports the spillover effects on alternate measures of external balance and capital flows that use TIC data. Again, to conserve space we only present the responses of the alternate variables. Figure B.3 presents our baseline macro and financial variables' impulse responses in a specification which allows for an endogenous response of EM stock price volatility to the US uncertainty shock. 

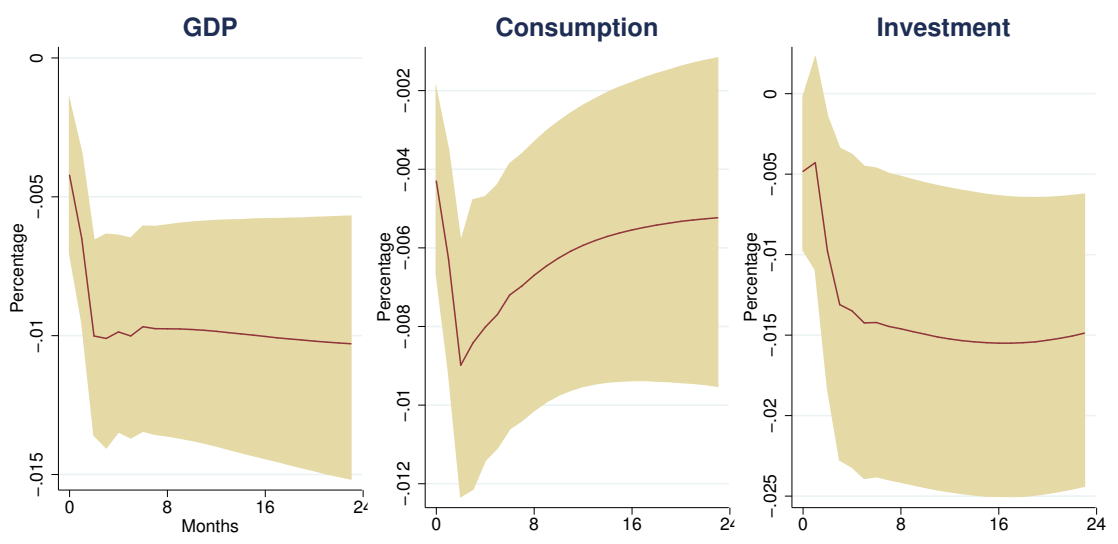

Figure B.1: Impulse responses of the EM panel VAR to the US uncertainty shock: other macroeconomic activity variables

Notes: Each plot presents the posterior median of the impulse responses to a $1 \%$ increase in the US uncertainty shock along with the $90 \%$ error bands in an alternative specification that includes GDP, consumption and investment as a measure of economic activity. The EM panel VAR includes the baseline seven variables except IP plus an alternative measure of economic activity but only the impulse response of the different measures of economic activity is displayed. Quarterly data on GDP, consumption and investment is interpolated into monthly observations. For the details, see the Data Appendix. 

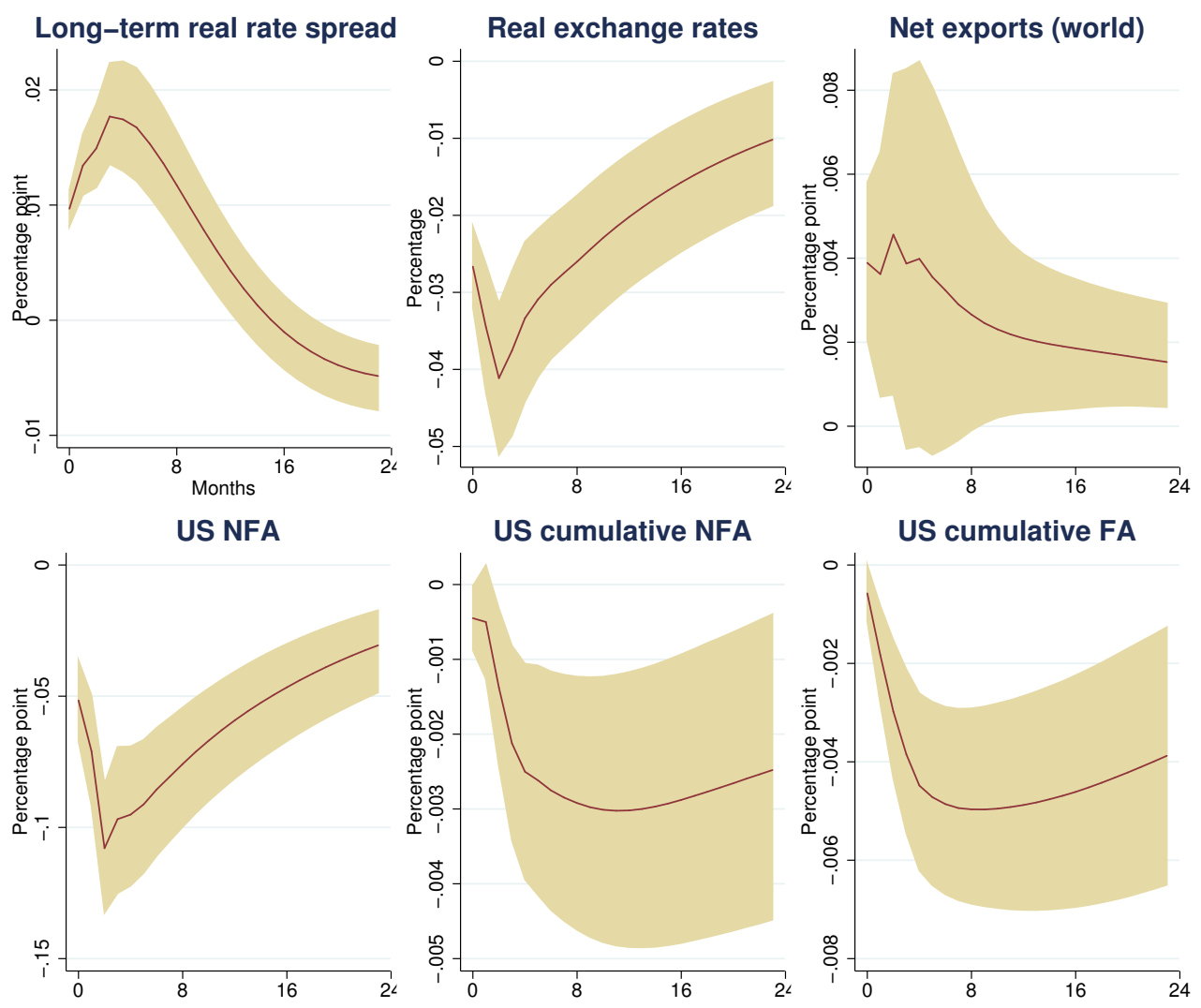

Figure B.2: Impulse responses of the EM panel VAR to the US uncertainty shock: other open economy and financial variables

Notes: Each plot presents the posterior median of the impulse responses to a $1 \%$ increase in the US uncertainty shock along with the $90 \%$ error bands in alternative specifications. In the first row, these are where the long-term nominal interest rate is replaced with the long-term real interest rate, the nominal effective exchange rate is replaced with the real effective exchange rate, and the net exports to the US is replaced with the net exports to the world, respectively. In the second row, these are where net exports to the US is replaced with net foreign asset position of the US on the EMEs, capital flows is replaced with cumulated net foreign asset position of the US on the EMEs, and capital flows is replaced with cumulated US foreign asset positions. Only the impulse response of the alternative variables is displayed. For the details, see the Data Appendix. 

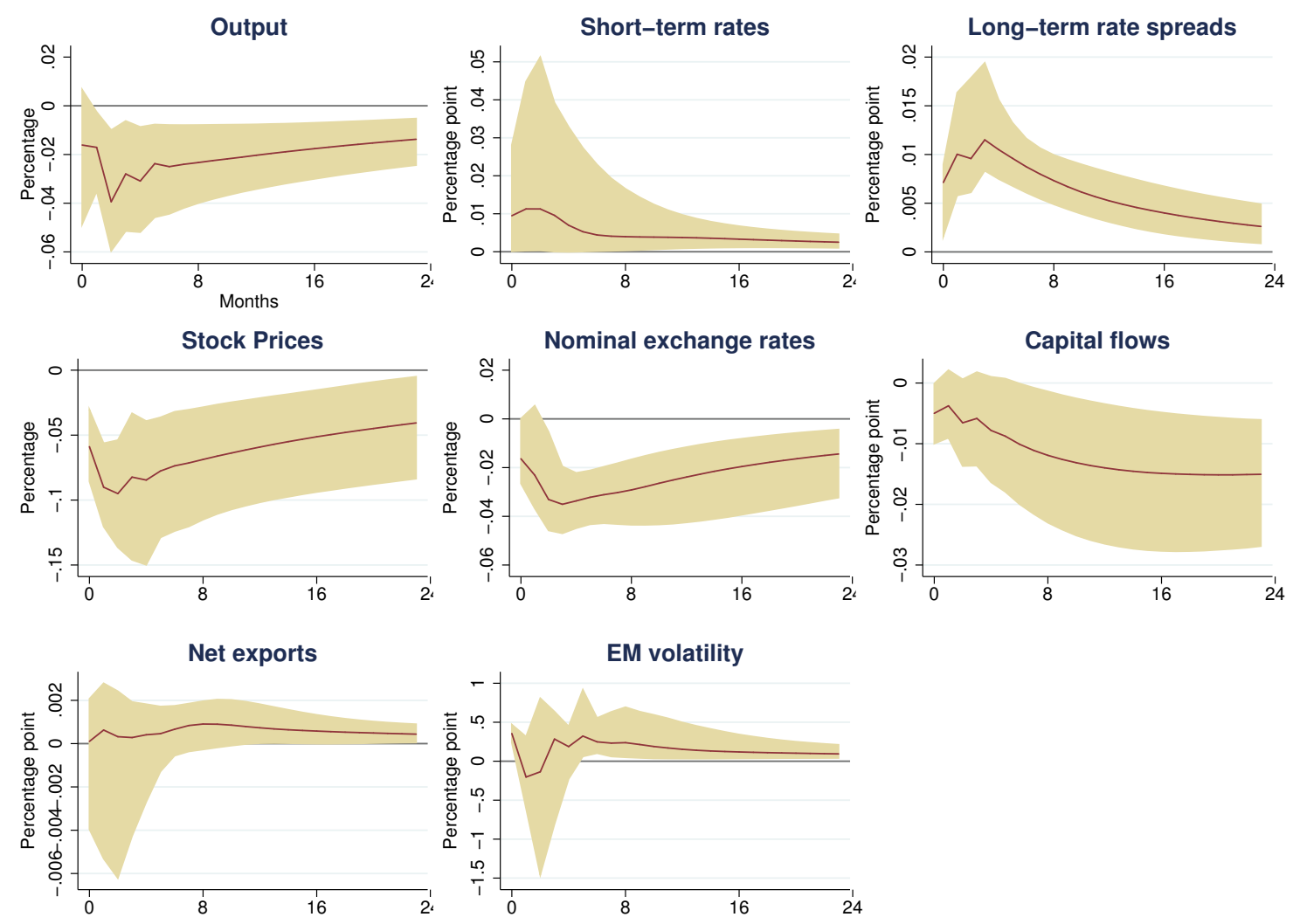

Figure B.3: Impulse responses of the EM panel VAR to the US uncertainty shock: controlling for EM MSCI volatility

Notes: Each plot presents the posterior median of the impulse responses to a $1 \%$ increase in the US uncertainty shock along with the $90 \%$ error bands in alternative specifications. We display the full set of impulse responses of the 8 variable system for each EM where we add realized EM MSCI volatility and drop CPI from the panel VAR. For the details, see the Data Appendix.

We do some robustness exercises on our measure of shock. First, the US VAR is extended to include eight total variables, as in Bloom (2009). We then identify US VIX shock by ordering VIX second, after S\&P 500. This is the order used in Bloom (2009). The results are presented in Figure B.4. Second, we compare the baseline reduced-form shock to the identified shock from the orthogonalization scheme that orders VIX last. The identified shock is very similar to the baseline shock. The largest difference between the two shock series is less than 0.03 while the standard deviation of the two shock series is about 1.05 . We do not present the orthogonalized shock since it is hardly distinguishable from the reduced-form shock. Note again that the shock series from ordering VIX first would be identical to our baseline series. Third, we simply use the growth rate of VIX as a measure of uncertainty shock in the EME panel VAR. This partly addresses the generated regressor problem that arises in our two-step estimation procedure. The results are presented in Figure B.5. Fourth, in 
the three variable VAR specification, we replace VIX with the financial uncertainty measure of Ludvigson, Ma, and $\mathrm{Ng}$ (2015). The results are presented in Figure B.6.
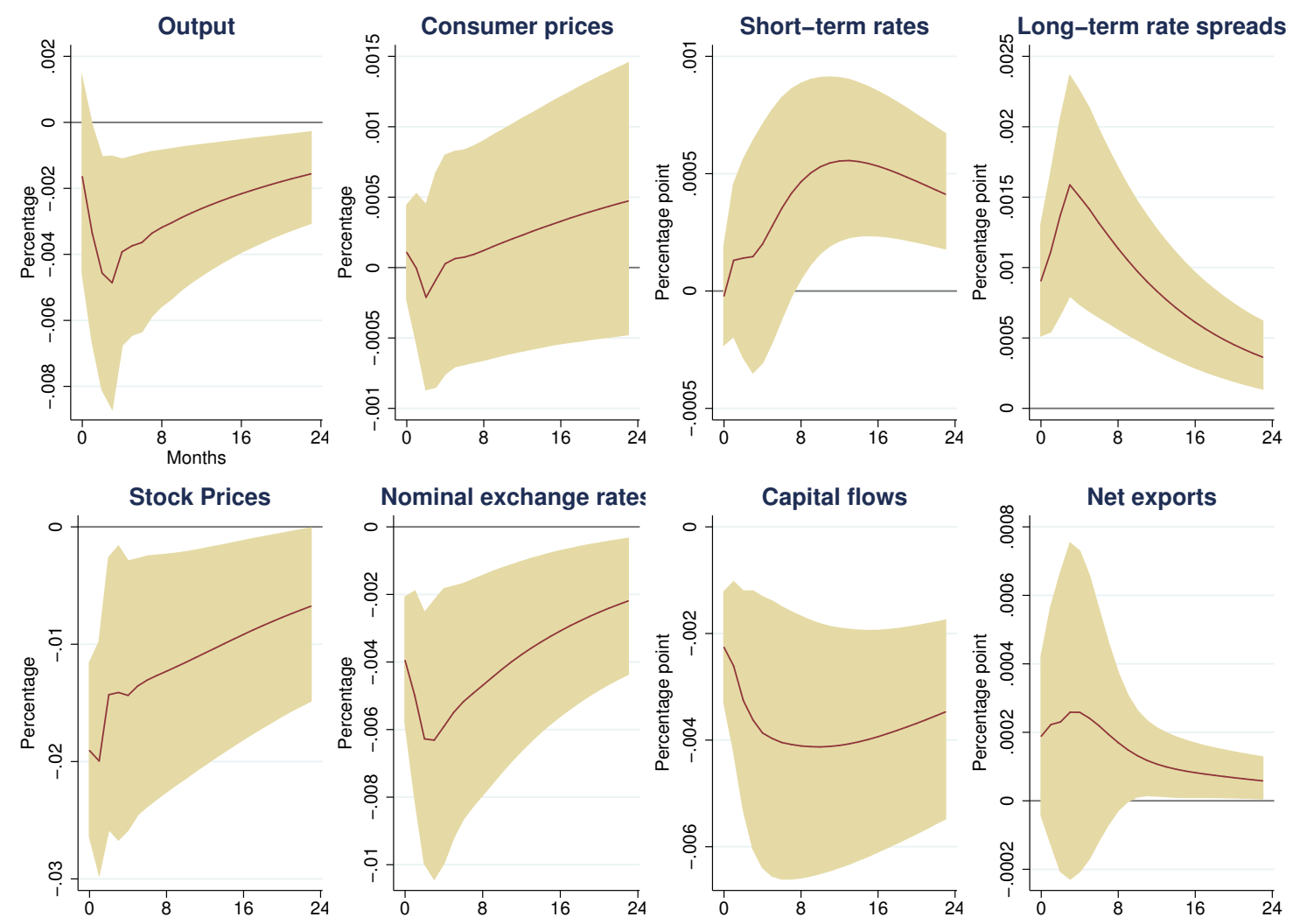

Figure B.4: Impulse responses of the EM panel VAR to the US uncertainty shock: macroeconomic and financial variables

Notes: Each plot presents the posterior median of the impulse responses to a $1 \%$ increase in the US uncertainty shock along with the $90 \%$ error band in the baseline specification that includes the both macroeconomic and financial variables. The US uncertainty shock is an identified shock in a eight variable US VAR specification where the identification scheme follows Bloom (2009). See notes in Figure 2. 

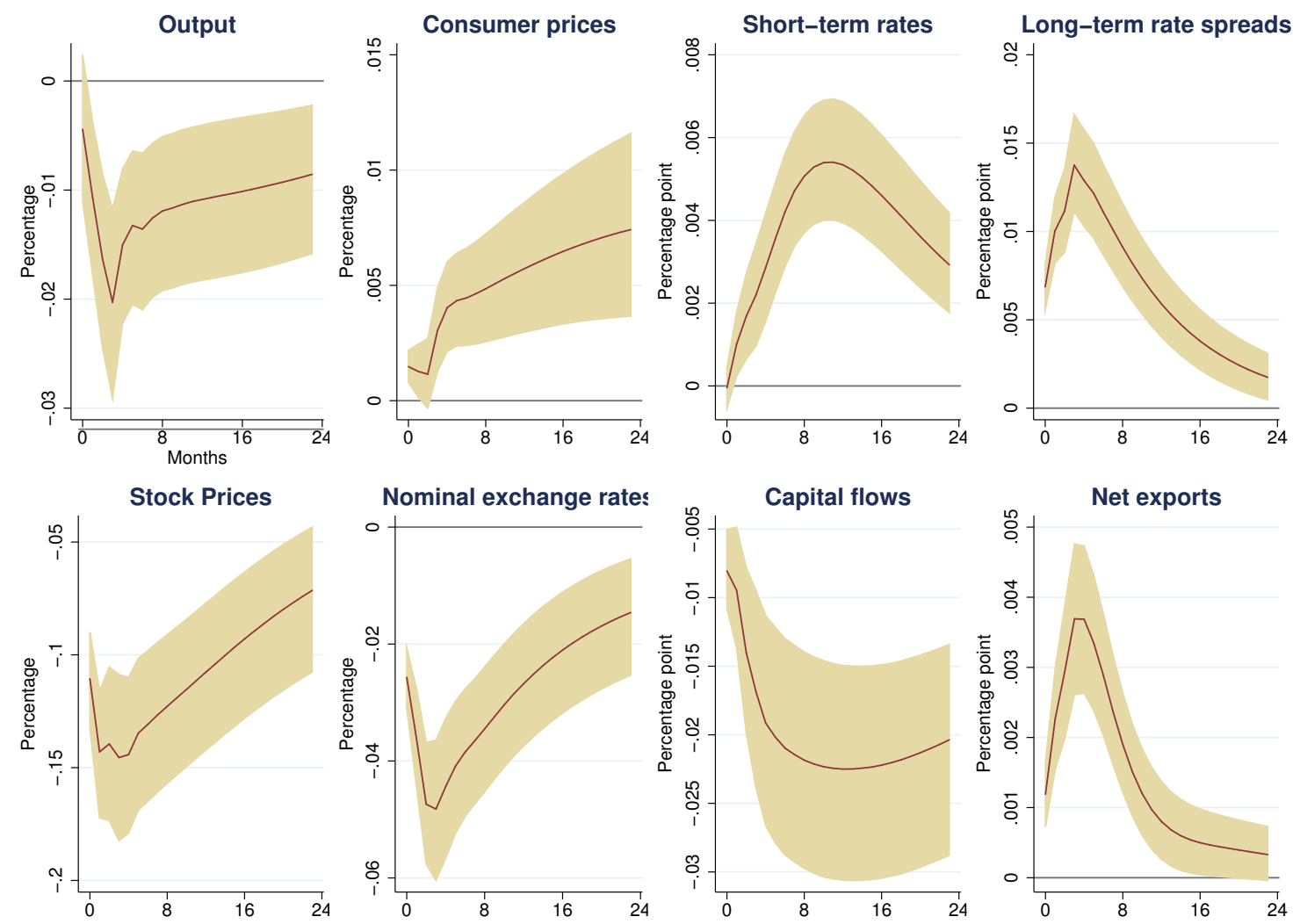

Figure B.5: Impulse responses of the EM panel VAR to the US uncertainty shock: macroeconomic and financial variables

Notes: Each plot presents the posterior median of the impulse responses to a $1 \%$ increase in the US uncertainty shock along with the $90 \%$ error band in the baseline specification that includes the both macroeconomic and financial variables. The US uncertainty shock is simply the growth rate of VIX. See notes in Figure 2. 

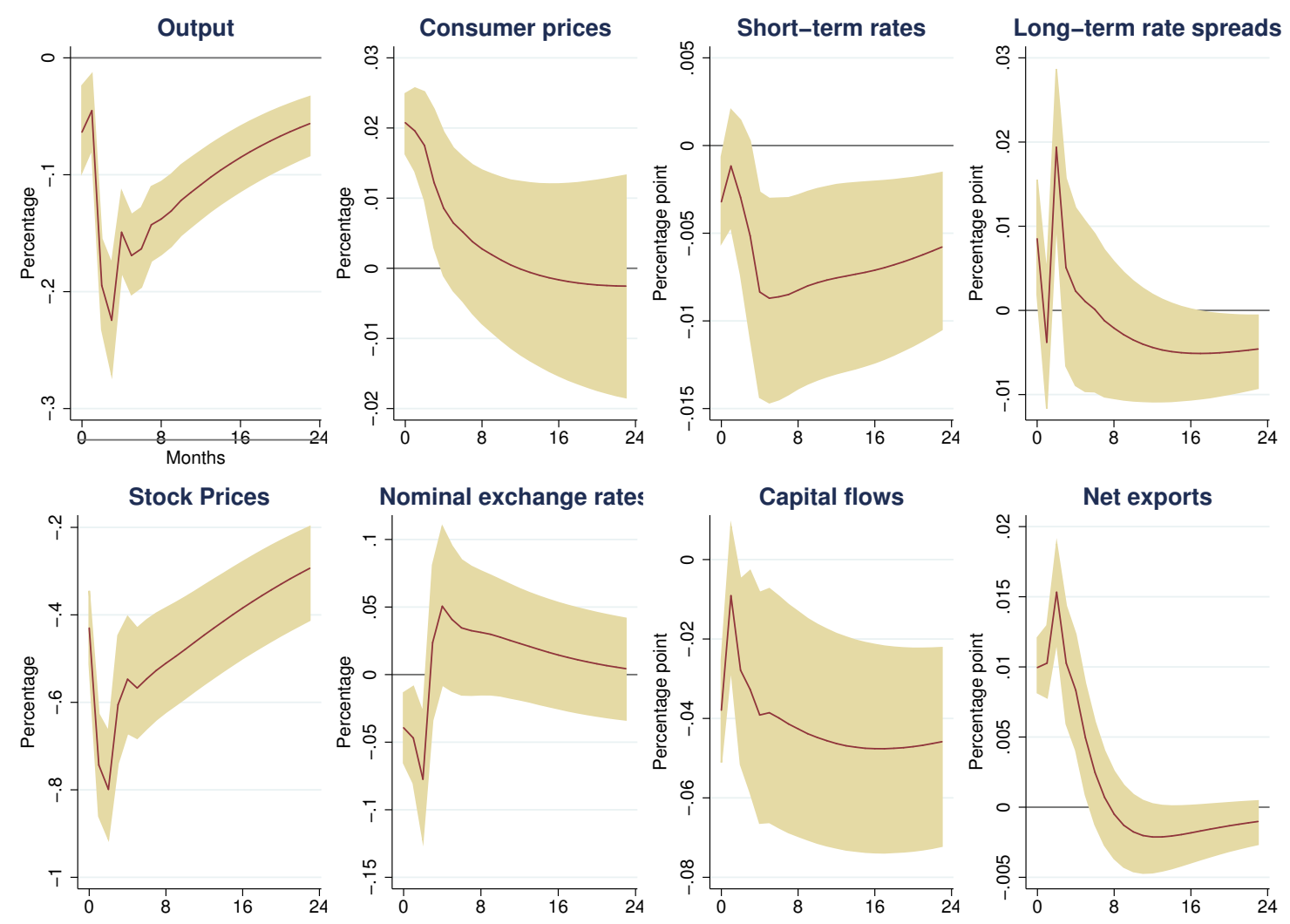

Figure B.6: Impulse responses of the EM panel VAR to the US uncertainty shock: macroeconomic and financial variables

Notes: Each plot presents the posterior median of the impulse responses to a $1 \%$ increase in the US uncertainty shock along with the $90 \%$ error band in the baseline specification that includes the both macroeconomic and financial variables. The US uncertainty shock is computed from a three variable US VAR specification, like the baseline specification, but uses the financial uncertainty measure of Ludvigson, Ng, and Ma (2015), instead of the VIX. See notes in Figure 2.

Fifth, we follow Bloom (2009) and identify only large movements in VIX as the US uncertainty shock. We first remove the persistent trend in log VIX using HP filter and then we create a dummy variable that takes on 1 in those periods where HP-filtered VIX is more than one standard deviation above the mean of the same series and 0 otherwise. This dummy variable is used in the panel VAR as a measure of the US uncertainty shock. Bloom (2009) identified a shock as one more than 1.65 standard deviations above the mean but we lowered the bar because of the relatively short sample period. If such large shocks are identified for multiple consecutive periods, we choose the period where HP-filtered VIX is greatest among those periods. Specifically, the following six periods are identified when the US uncertainty shock hits: September 2001, September 2002, February 2003, November 2008, May 2010, and September 2011. The results are presented in Figure B.7. 

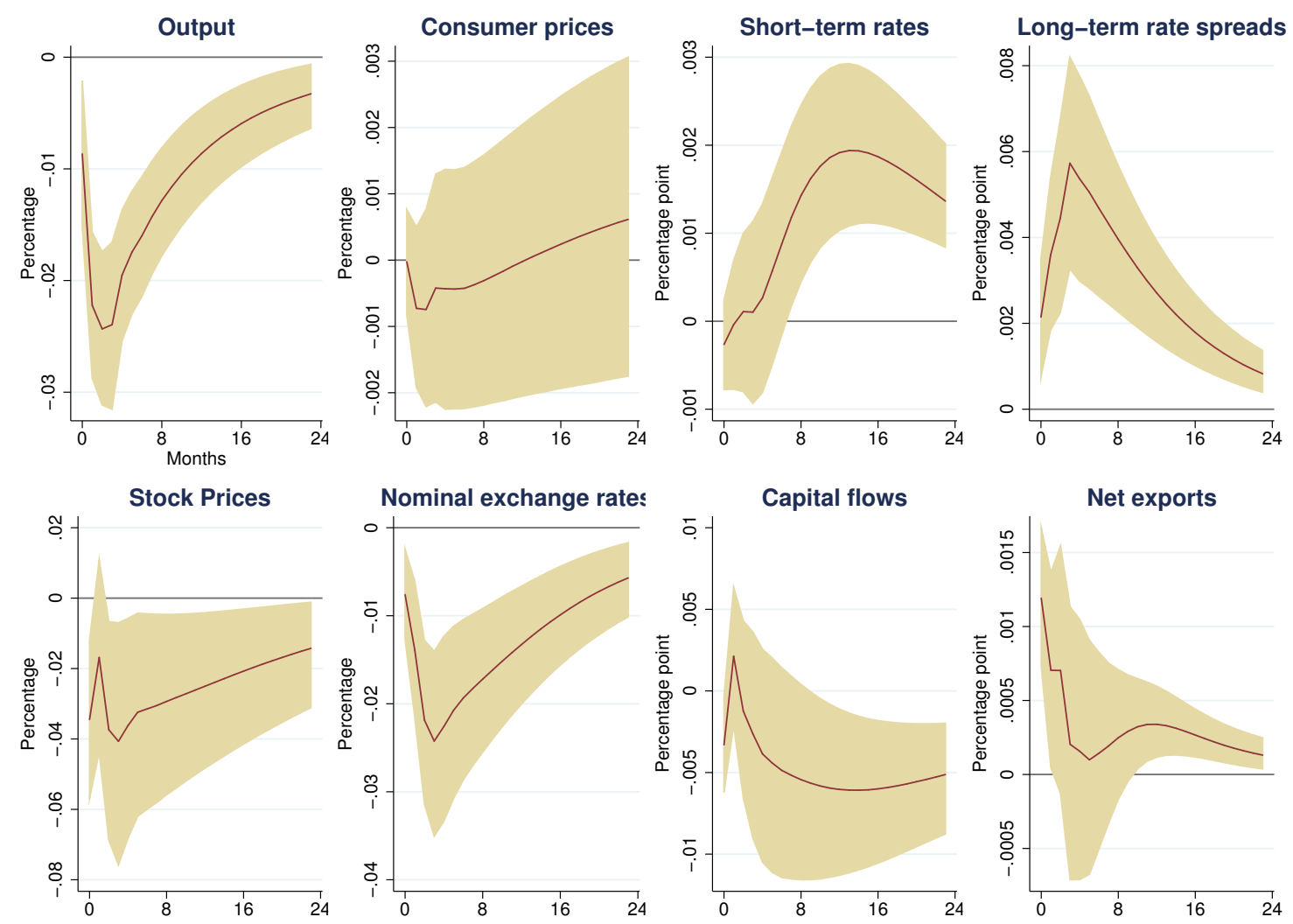

Figure B.7: Impulse responses of the EM panel VAR to the US uncertainty shock: macroeconomic and financial variables

Notes: Each plot presents the posterior median of the impulse responses to a $1 \%$ increase in the US uncertainty shock along with the $90 \%$ error band in the baseline specification that includes the both macroeconomic and financial variables. The US uncertainty shock is computed as large movements in VIX following Bloom (2009).

Next, we check that our main results are not sensitive to lag length selection in the panel VAR. Results using four lags of the US uncertainty shock in the panel VAR are reported in Figure B.8 and B.9. The results with five and six lags of the US uncertainty shock show similar responses and are available upon request. 

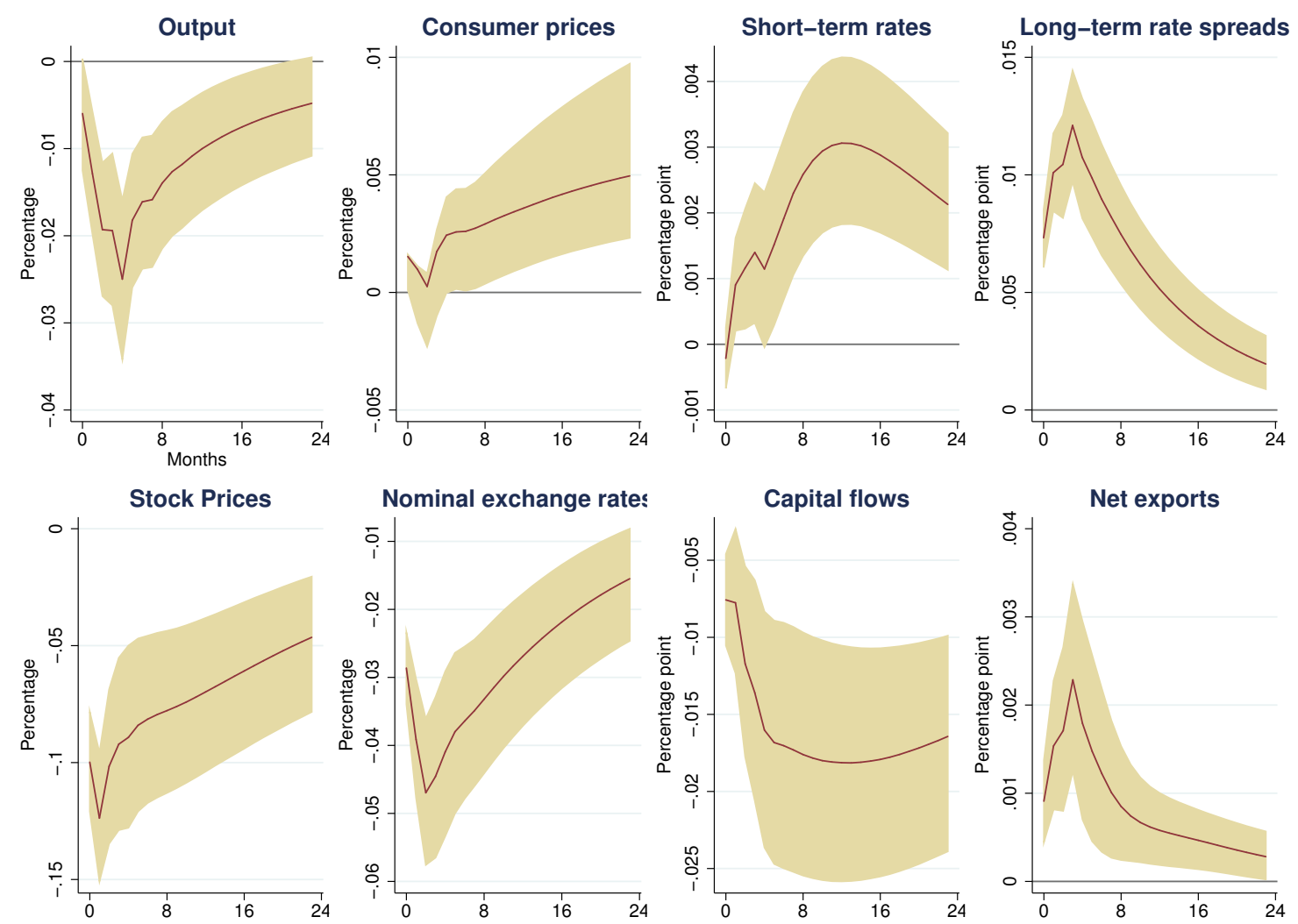

Figure B.8: Impulse responses of the EM panel VAR to the US uncertainty shock: with four lags of the US uncertainty shock

Notes: Each plot presents the posterior median of the impulse responses to a $1 \%$ increase in the US uncertainty shock along with the $90 \%$ error band in the baseline specification that includes the both macroeconomic and financial variables. Four lags of the US uncertainty shock are included. See notes in Figure 2. 
Output
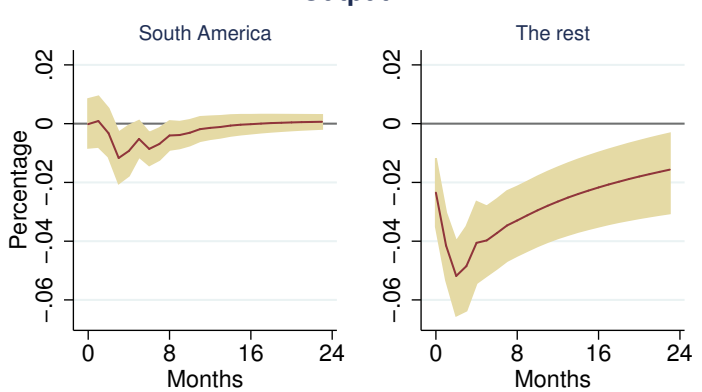

Short-term rates
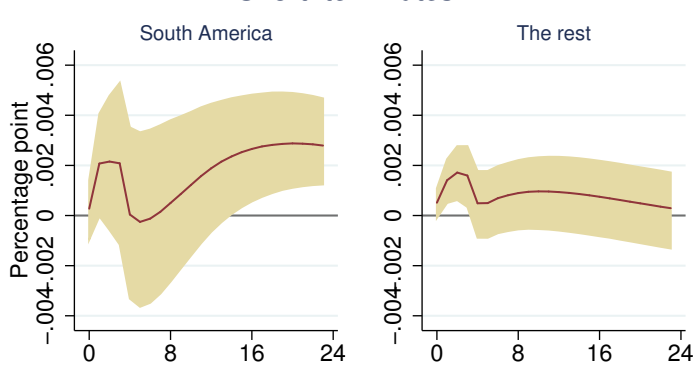

Stock prices
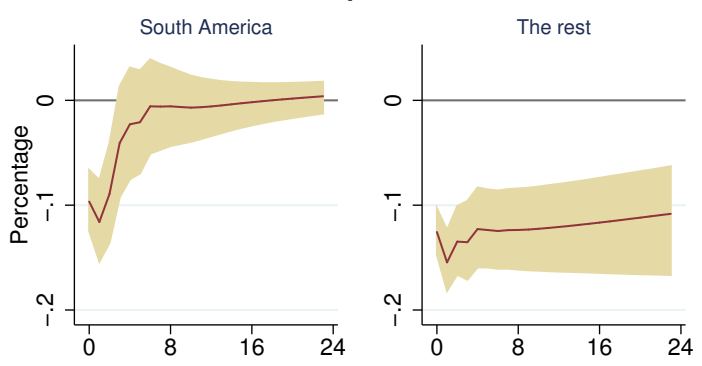

Capital flows
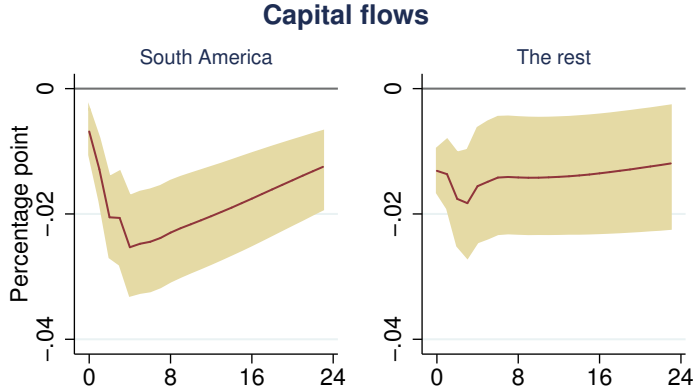

Consumer prices
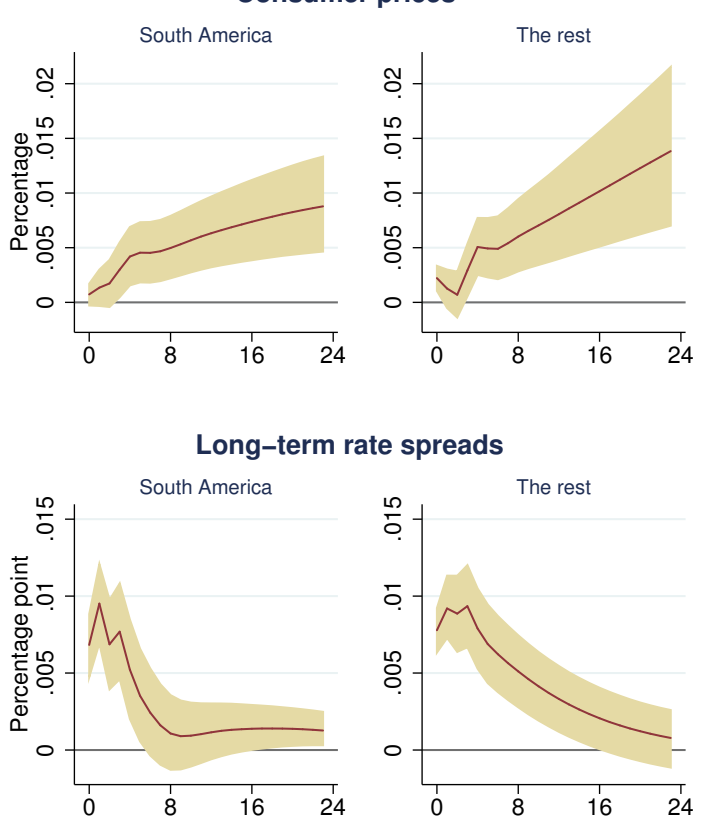

Nominal exchange rates
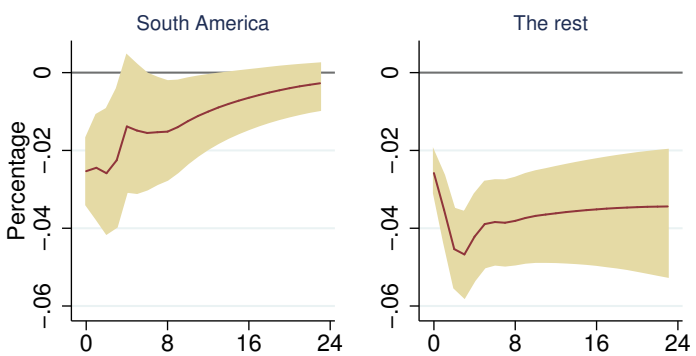

Net exports
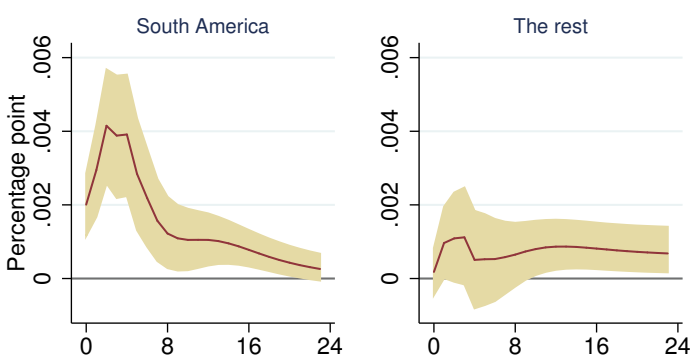

Figure B.9: Impulse responses of the EM panel VAR to the US uncertainty shock: macroeconomic and financial variables; South America vs. the rest; with four lags of the US uncertainty shock

Notes: Each plot presents the posterior median of the impulse responses to a $1 \%$ increase in the US uncertainty shock along with the $90 \%$ error band in the specification for subgroup analysis that includes both the macroeconomic and financial variables. Four lags of the US uncertainty shock are included. Subplots are arranged by variables and shown for two groups of countries: South America including Brazil, Chile, Colombia, Mexico, Malaysia, and Peru and the rest of the EM economies. See the notes in Figure 2. 
For the sub-group estimation, we have also checked our results on using other activity measures and other financial and open economy variables. As one example, we report results using long-term real rate spreads in Figure B.10.
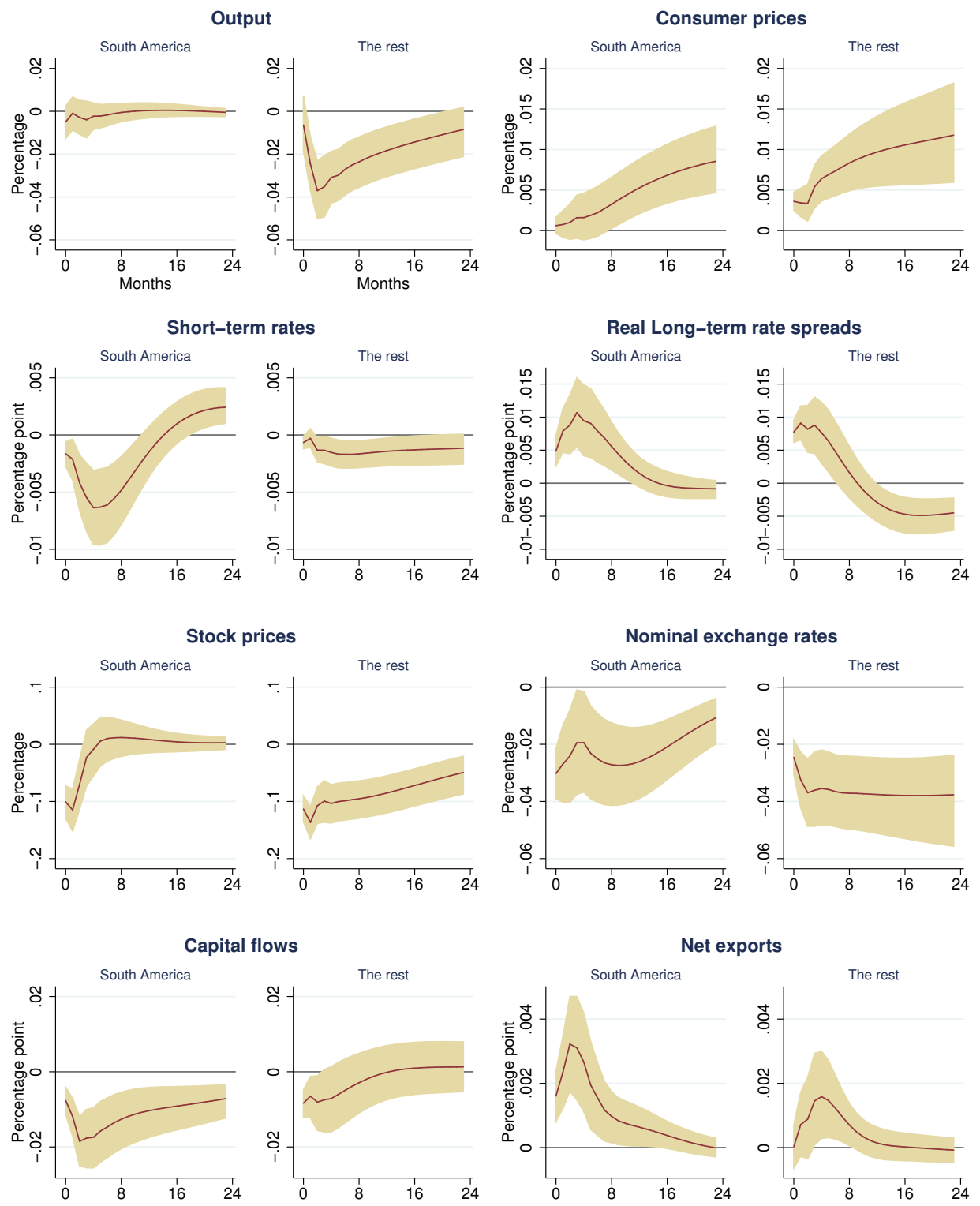

Figure B.10: Impulse responses of the EM panel VAR to the US uncertainty shock: macroeconomic and financial variables; South America vs. the rest; with real long-term rate spreads

Notes: Each plot presents the posterior median of the impulse responses to a $1 \%$ increase in the US uncertainty shock along with the $90 \%$ error band in the specification for subgroup analysis that includes both the macroeconomic and financial variables. Nominal long-term interest rate spreads are replaced with real longterm interest rate spreads. Subplots are arranged by variables and shown for two groups of countries: South America including Brazil, Chile, Colombia, Mexico, Malaysia, and Peru and the rest of the EM economies. See the notes in Figure 2. 
We now present the contribution of the US uncertainty shock in the $h$-period ahead forecast error variance of the EME variables. The method used to compute these variance decomposition results is described above in the Appendix.

Table B.1: Forecast error variance decomposition (\%)

\begin{tabular}{cccccc}
\hline Horizon & Output & Short rate & LR spread & Exch Rate & Cap Flows \\
\hline \hline 1 & 1.74 & 0.37 & 10.67 & 7.49 & 2.70 \\
3 & 15.02 & 0.63 & 14.89 & 12.18 & 3.39 \\
12 & 11.62 & 6.35 & 20.04 & 13.49 & 8.63 \\
24 & 11.11 & 9.59 & 12.52 & 12.43 & 12.76 \\
\hline
\end{tabular}

Notes: Forecast error variance decomposition at different horizons in the specification for all EMEs that includes financial and macroeconomic variables. See the Appendix for details on the method used to compute these variance decomposition results.

Table B.2: Forecast error variance decomposition for South American EMEs (\%)

\begin{tabular}{cccccc}
\hline Horizon & Output & Short rate & LR spread & Exch Rate & Cap Flows \\
\hline \hline 1 & 0.48 & 0.28 & 6.55 & 4.39 & 2.71 \\
3 & 9.79 & 0.97 & 8.88 & 4.37 & 13.88 \\
12 & 12.07 & 5.42 & 6.56 & 8.77 & 17.75 \\
24 & 10.85 & 6.05 & 5.27 & 12.96 & 18.91 \\
\hline
\end{tabular}

Notes: Forecast error variance decomposition at different horizons for South American EMEs in the sub group specification that includes financial and macroeconomic variables. See the Appendix for details on the method used to compute these variance decomposition results.

Table B.3: Forecast error variance decomposition for Rest of EMEs (\%)

\begin{tabular}{cccccc}
\hline Horizon & Output & Short rate & LR spread & Exch Rate & Cap Flows \\
\hline \hline 1 & 1.72 & 0.40 & 15.16 & 6.70 & 2.91 \\
3 & 14.71 & 1.46 & 14.37 & 11.71 & 1.96 \\
12 & 13.24 & 5.54 & 13.07 & 12.77 & 3.52 \\
24 & 11.00 & 9.88 & 12.93 & 13.97 & 6.84 \\
\hline
\end{tabular}

Notes: Forecast error variance decomposition at different horizons for rest of EMEs in the sub group specification that includes financial and macroeconomic variables. See the Appendix for details on the method used to compute these variance decomposition results.

\section{B.2 Theoretical model and results}

In this section we present details of the theoretical model as well as the results from the various extensions that we discuss in the main text. 


\section{B.2.1 Maximization problems}

We present formally the maximization problems of the household and firms. We start first with the two static expenditure minimization problems. The household chooses $\left\{c_{H, t}, c_{F, t}\right\}_{t=0}^{\infty}$ to minimize $p_{H, t} c_{H, t}+p_{F, t} c_{F, t}$ subject to

$$
\left[(1-\chi)^{\frac{1}{\varepsilon}} c_{H, t}^{\frac{\varepsilon-1}{\varepsilon}}+\chi^{\frac{1}{\varepsilon}} c_{F, t}^{\frac{\varepsilon-1}{\varepsilon}}\right]^{\frac{\varepsilon}{\varepsilon-1}} \geq c_{t}
$$

while taking as exogenously given $\left\{p_{H, t}, p_{F, t}\right\}_{t=0}^{\infty}$. Then, the shadow price on (B.17) is equal to $p_{t}$, the home currency nominal price of the aggregate consumption good. The demand functions take standard forms. Next, the household chooses $\left\{c_{H, t}(i)\right\}_{t=0}^{\infty}$ to minimize $\int_{0}^{1} c_{H, t}(i) p_{H, t}(i) d i$ subject to

$$
\left[\int_{0}^{1} c_{H, t}(i)^{\frac{\nu-1}{\nu}} d i\right]^{\frac{\nu}{\nu-1}} \geq c_{H, t}
$$

while taking as exogenously given $\left\{p_{H, t}(i)\right\}_{t=0}^{\infty}$. Then, the shadow price on (B.18) is equal to $p_{H, t}$, the home currency nominal price of the home consumption good. The demand functions take standard forms. Similar expenditure minimization problems also apply for the foreign consumption goods and the investment good.

Given the two first-stage, static expenditure minimization problems discussed above, the problem of the home household then is to choose $\left\{c_{t}, h_{t}, d_{t}^{*}, b_{t}, k_{t+1}, i_{t}\right\}_{t=0}^{\infty}$ to maximize (6) subject to a sequence of constraints (8) and (9), while taking as exogenously given initial wealth, initial capital stock, and $\left\{\Pi_{t}, \varphi_{t}, R_{t-1}, \tilde{c}_{t-1}, w_{t}, u_{t}, Q_{t}, I_{t-1}, p_{t}^{*}\right\}_{t=0}^{\infty}$.

Now we move to the maximization problem of the firms. The problem of firm $i$ at home is to choose $\left\{a_{t}(i), h_{t}(i), k_{t}(i), p_{H, t}(i)\right\}_{t=0}^{\infty}$ to maximize (12) subject to a sequence of constraints (10) and (11), the production function, and the demand curve, while taking as exogenously given initial net liabilities, non-interest bearing assets, and $\left\{\frac{p_{t-1}}{p_{H, t-1}}, R_{t-1}^{d}, p_{H, t}, y_{t}, \rho_{0, t}, w_{t}, u_{t}\right\}_{t=0}^{\infty}$.

\section{B.2.2 Equilibrium}

We next define the equilibrium in our economy and discuss the aggregate optimality and feasibility conditions that characterize it. We briefly also discuss the steady-state of the model.

An equilibrium is a collection of allocations (of goods varieties and aggregates) for the household, $\left\{c_{H, t}(i), c_{F, t}(i), i_{H, t}(i), i_{F, t}(i), c_{t}, \tilde{c}_{t-1}, h_{t}, d_{t}^{*}, b_{t}, k_{t+1}, i_{t}\right\}_{t=0}^{\infty}$, allocations and goods prices for the firms $\left\{a_{t}(i), h_{t}(i), k_{t}(i), p_{H, t}(i)\right\}_{t=0}^{\infty}$, a sequence of aggregate prices $\left\{S_{t}\right.$, $\left.p_{H, t}, p_{F, t}, p_{t}, R_{t}, w_{t}, u_{t}, \rho_{0, t}, R_{t}^{d}\right\}_{t=0}^{\infty}$ and output $\left\{y_{t}\right\}_{t=0}^{\infty}$, and monetary policy instrument $\left\{I_{t}\right\}_{t=0}^{\infty}$ such that 
(i) Given prices and monetary policy, the allocations are such that they satisfy the maximization problems of the household,

(ii) Given aggregate prices, aggregate output, and monetary policy, the goods prices and allocations are such that they satisfy the maximization problem of the firms,

(iii) The allocations and goods prices across firms are symmetric,

(iv) Individual and aggregate consumption is equal,

(v) The nominal interest rate is determined by the monetary policy rule, and

(vi) Goods, factor, and bonds markets clear,

given the initial capital stock, consumption, household debt, firm net asset position, firm non-interest bearing asset, relative price, aggregate price, interest rates, and an exogenous process for $\left\{R_{t}^{s}, y_{t}^{*}, p_{t}^{*}, \sigma_{t}\right\}_{t=0}^{\infty}$.

We present in detail in the Online Appendix, the non-linear, aggregate equilibrium conditions of the model that determine the dynamics of the seventeen endogenous aggregate variables $\left\{d_{t}, w_{t}, h_{t}, u_{t}, k_{t}, c_{t}, i_{t}, R_{t}^{d}, y_{t}, \tilde{c}_{t}, \varphi_{t}, \varsigma_{t}, \Pi_{t}, \Pi_{H, t}, b_{t}, I_{t}, \xi_{t}\right\}$. The economic interpretation of these equilibrium conditions is also relegated to the Online Appendix. We only focus on an equilibrium where $R_{t-1}^{d}$ is strictly positive. This means that the working capital constraint (10) will always bind. It is assumed that the firms start with no net liabilities.

While the details of the deterministic steady-state are in the online Appendix, it is nevertheless useful to note some properties of the steady-state as for our non-linear impulse responses, we will start the economy in the deterministic steady-state and the economy will transition back to this same steady-state in the long run. First, as is well known, given the debt adjustment cost function, $\bar{d}$ pins down the steady-state external debt of this economy. Moreover, we pick a zero net inflation steady-state. Then, the interest rates are equal to $\frac{1}{\beta}: I=R^{d}=R=\frac{1}{\beta}$. We also normalize the terms-of-trade $\varsigma$ in steady-state to be $1 .{ }^{44}$ Together, this implies that all relative prices and exchange rates are also1 in the steady state. The investment to capital stock ratio is equal to $\delta$, which implies $u=\frac{1}{\beta}-(1-\delta)$, and $w=\left[\left(\frac{\varepsilon-1}{\varepsilon}\right)(1-\alpha)^{1-\alpha} \alpha^{\alpha} u^{-\alpha}\right]^{\frac{1}{1-\alpha}}(1+\eta(1-\beta))^{-1}$. Finally, given these solutions for factor prices and the investment to capital stock ratio, variables in levels such as hours, consumption, output, investment, and capital in steady-state can be derived.

\section{B.2.3 Results of extensions}

We now consider a second-moment shock to the foreign interest rate and compute the responses of the model variables to a purely second-moment shock, that is, one where we hold the first-moment shock at its steady-state. We use a third-order accurate perturbation

\footnotetext{
${ }^{44}$ We have this freedom, given that we choose the steady-state of foreign demand to be consistent with the market clearing condition for goods.
} 
solution method to compute the stochastic equilibrium. For the parameterization of the second-moment shock, we use estimates in Fernandez-Villaverde et al (2011) for Brazil and use a simple $\mathrm{AR}(1)$ process for the interest rate shock as opposed to an $\operatorname{ARMA}(1,3)$, so that it is easily comparable to the literature. Figure B.11 shows the results.
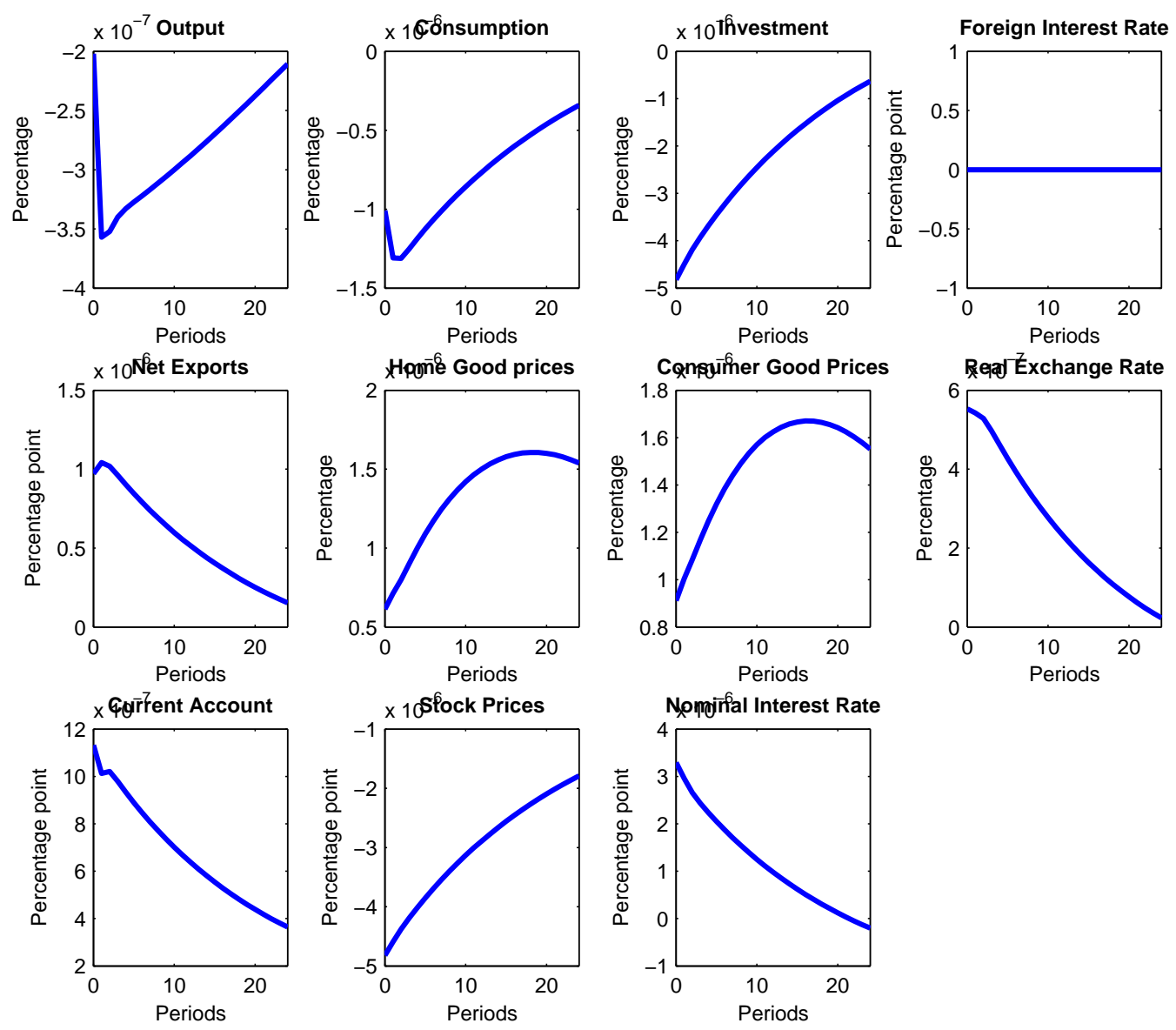

Figure B.11: Impulse responses of the small open economy model to a shock to the volatility of the foreign interest rate spread

Notes: These are non-linear impulse responses to a second-moment shock (volatility shock) to the foreign interest rate spread. The solution method is a third-order perturbation.

For the baseline case, we show in Figures B.12 and B.13, results when we use a greater level of price stickiness $\left(d_{1}=50\right)$ and a lower trade elasticity $(\varepsilon=0.9)$ respectively. Finally, we also consider a negative foreign income/output shock as a possible proxy for the US uncertainty shock. We use the same parameters for the size of this shock as the baseline interest rate spread shock and for persistence use a random walk specification that is common in business cycle studies. The results are reported in Figure B.14. 

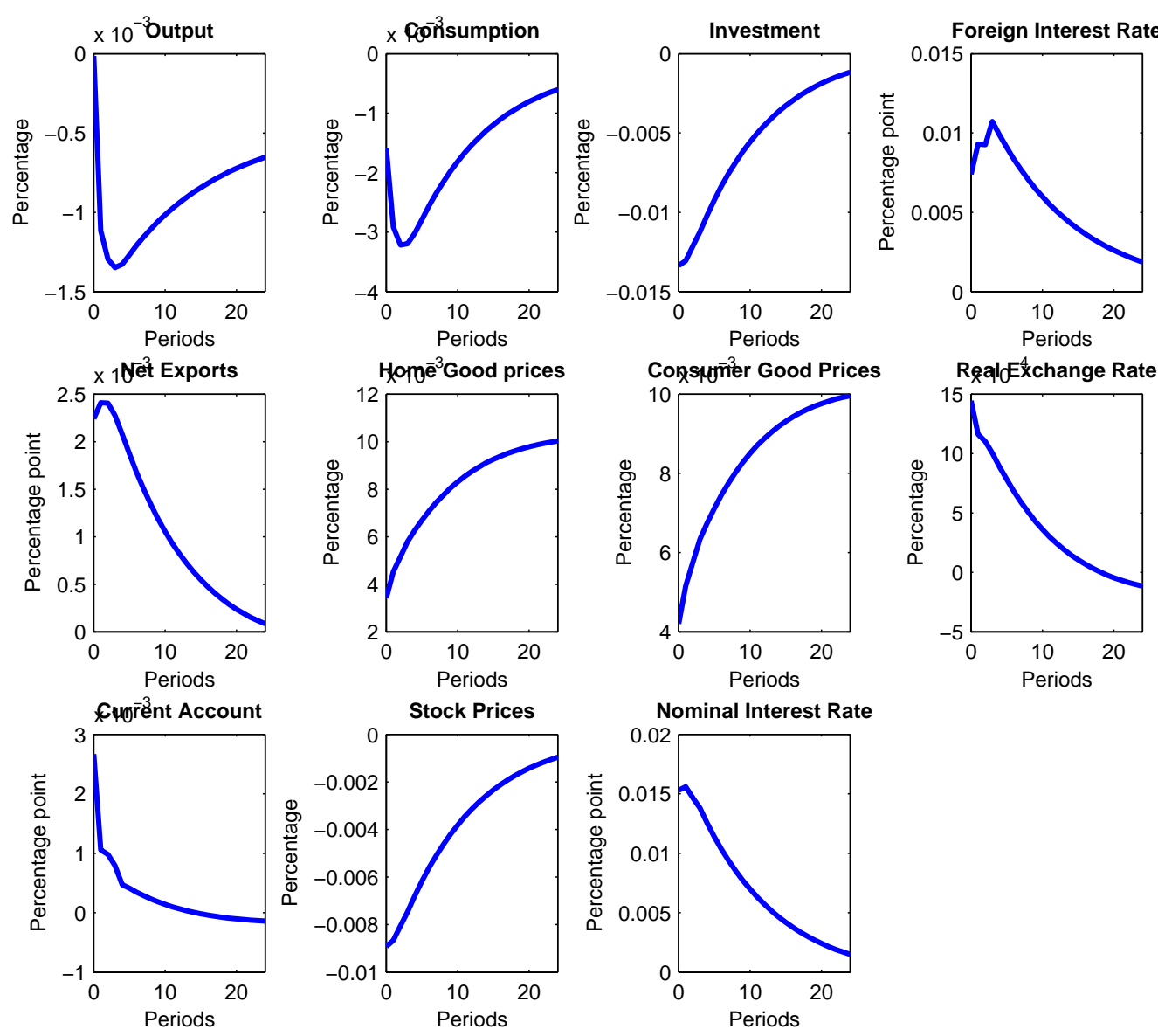

Figure B.12: Impulse responses of the small open economy model to a shock to the foreign interest rate spread with stronger nominal rigidities than baseline

Notes: Compared to the baseline in Figure 4, prices are more sticky. Also, see the notes in Figure 4. 

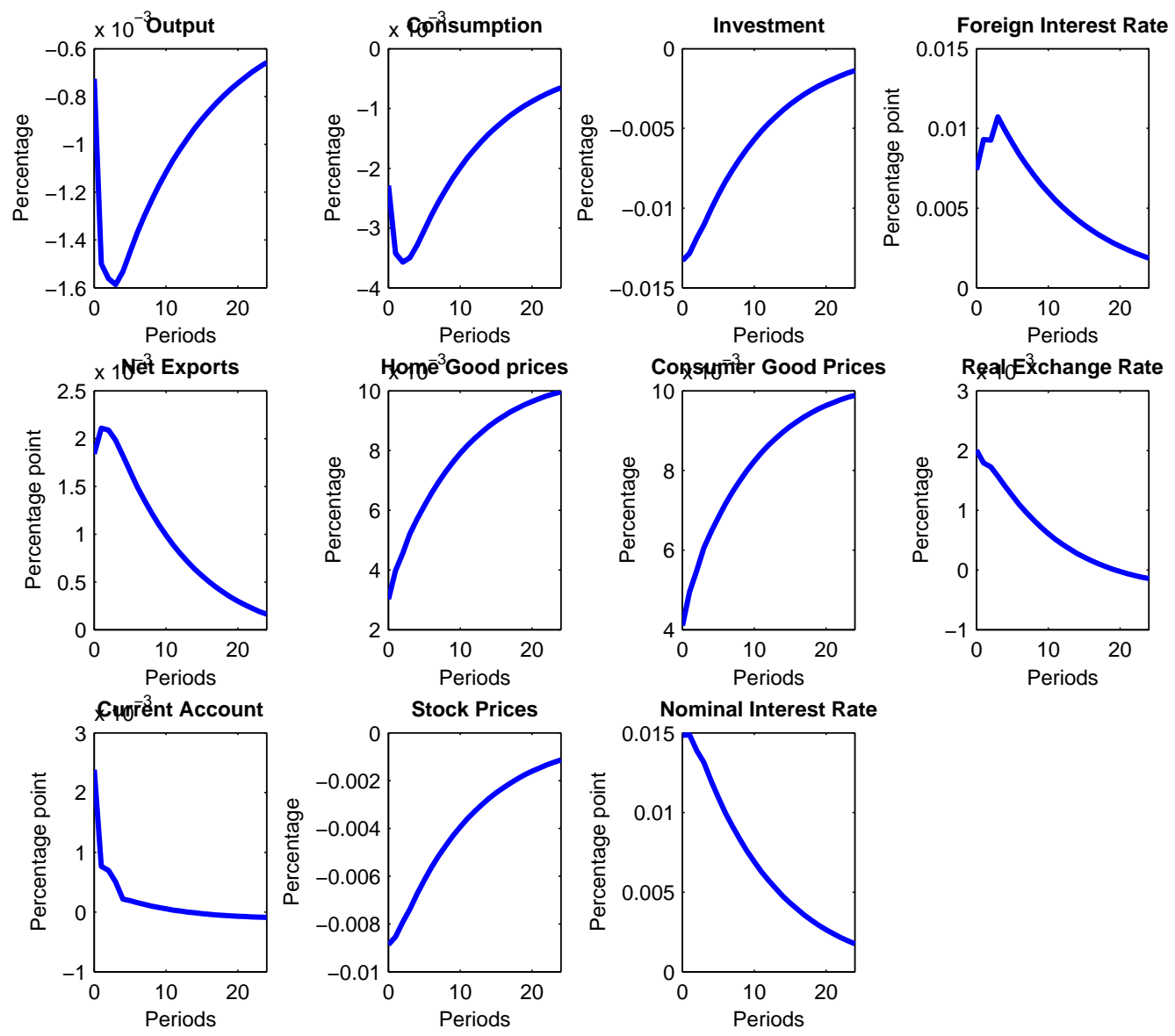

Figure B.13: Impulse responses of the small open economy model to a shock to the foreign interest rate spread with lower trade elasticity than baseline

Notes: Compared to the baseline in Figure 4, the trade elasticity is lower. Also, see the notes in Figure 4. 

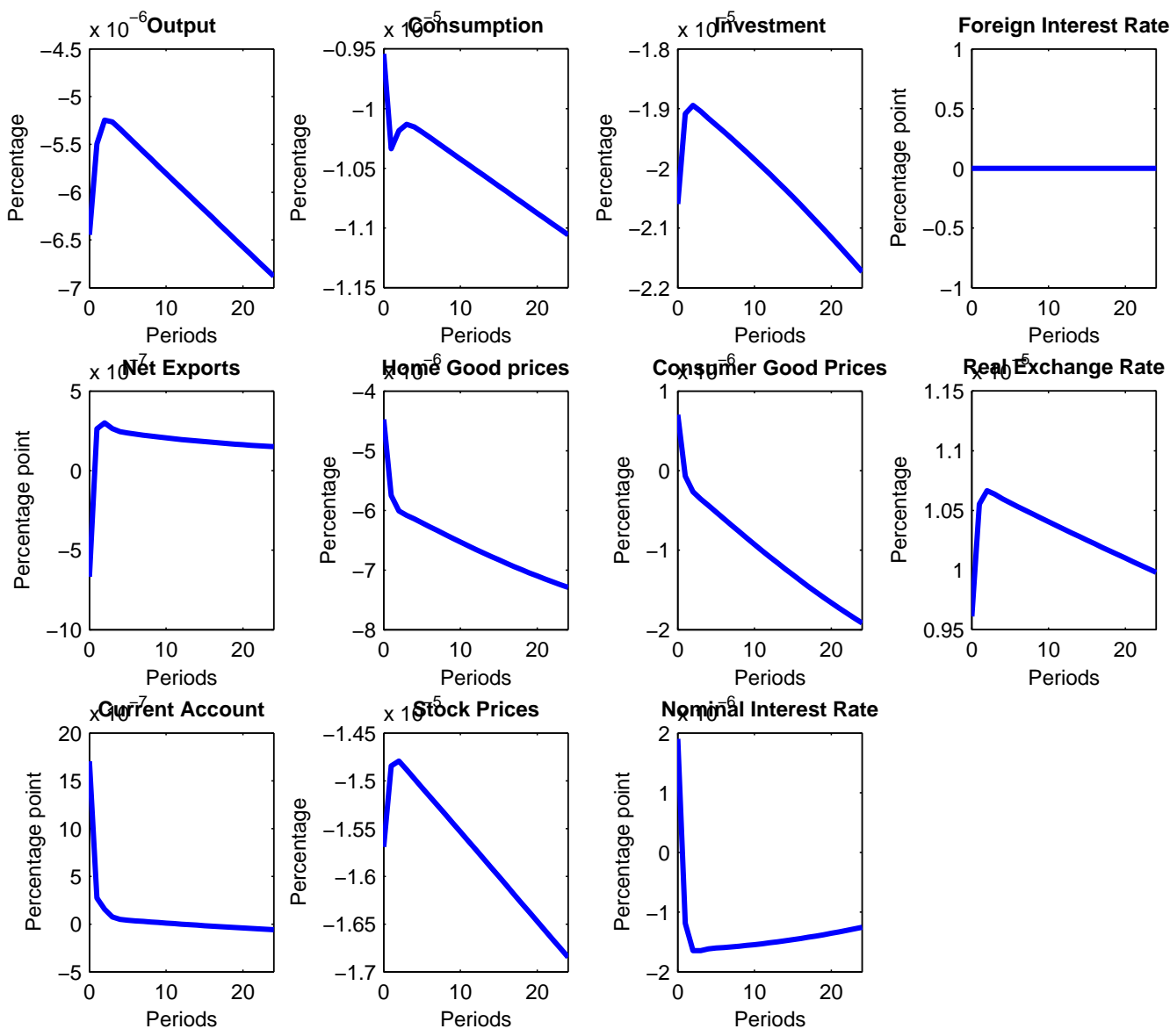

Figure B.14: Impulse responses of the small open economy model to a shock to foreign income

Notes: These are non-linear impulse responses to a shock to foreign income/demand. Also, see the notes in Figure 4 .

\section{B.3 US monetary policy spillovers}

We present results on spillovers to a standard monetary policy shock. 

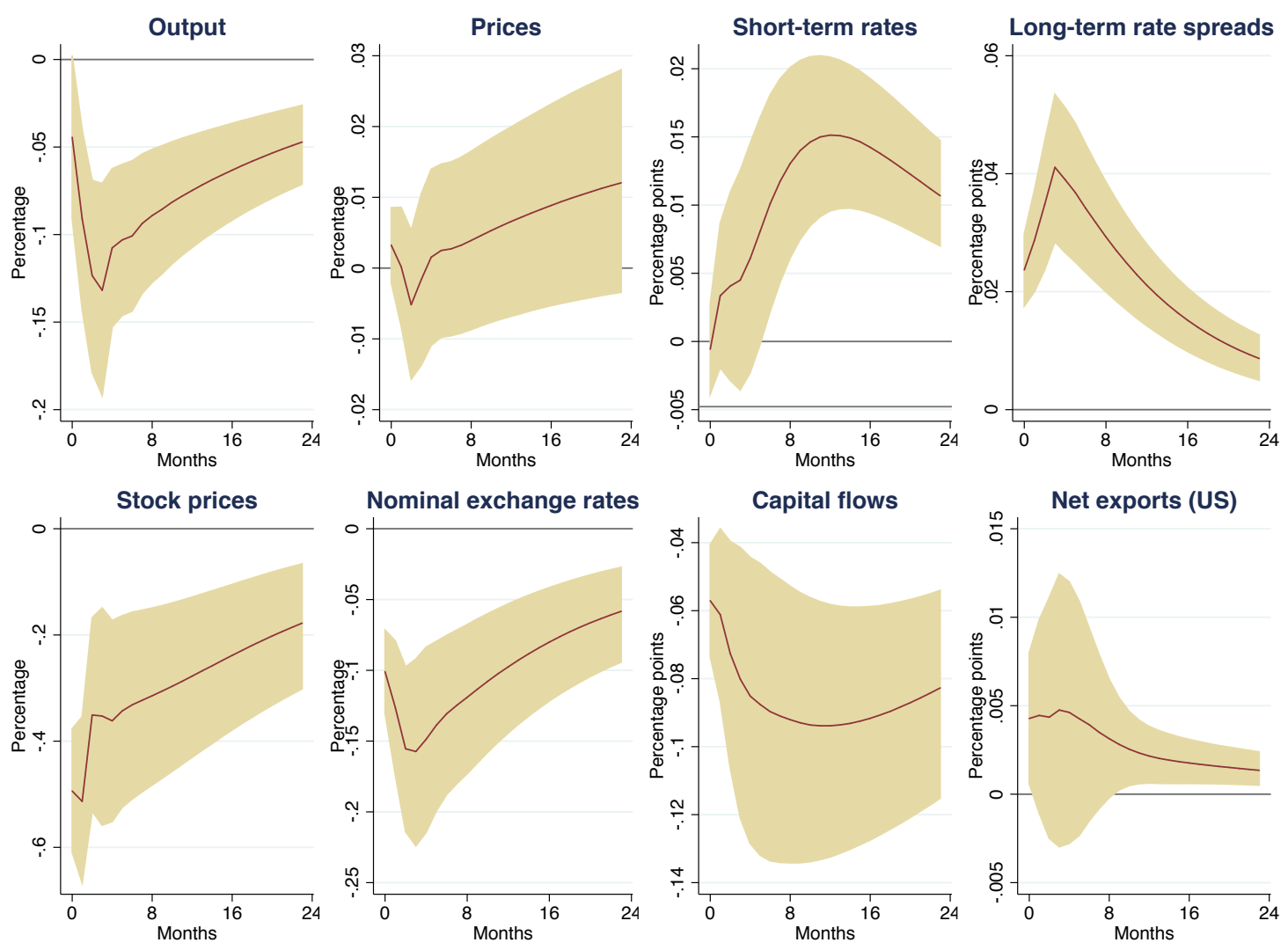

Figure B.15: Impulse responses of the EM panel VAR to the US monetary policy shock: macroeconomic and financial variables

Notes: Each plot presents the posterior median of the impulse responses to a one standard deviation (contractionary) US monetary policy shock along with the $68 \%$ error band in the baseline specification that includes the both macroeconomic and financial variables. A one standard deviation increase constitutes an increase of $0.262 \%$ points in the US short-term interest rate. Output is the industrial production and consumer prices are the CPI in each of the EM countries. Net exports are the ratio of the net exports from the EM countries to the US and GDP of the EM countries. The long-term rate spread is the spread between the 10-year Treasury yields in the US and the long-term interest rate in the EM countries. Both US and EM interest rates are nominal. The stock price is the MSCI. The nominal exchange rate is the nominal effective exchange rate of the local currency so a decrease in the exchange rate implies depreciation of the local currency. The capital flow is the ratio of the cumulative sum of the equity and bond inflows to GDP of the EM countries. 
Output
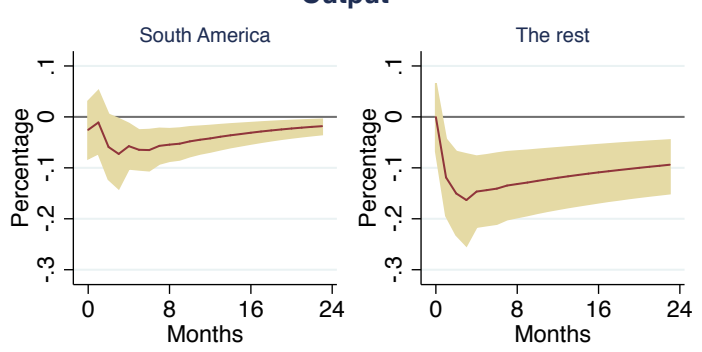

Short-term rates
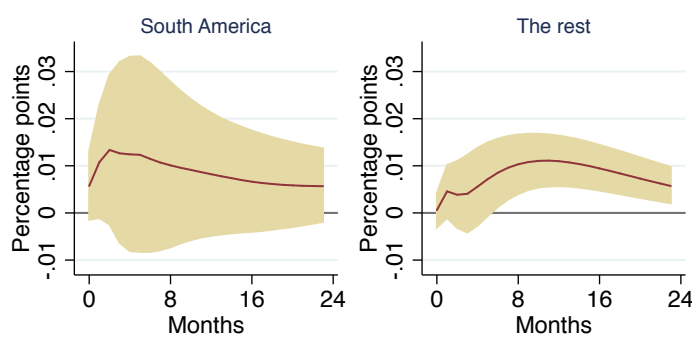

Stock prices
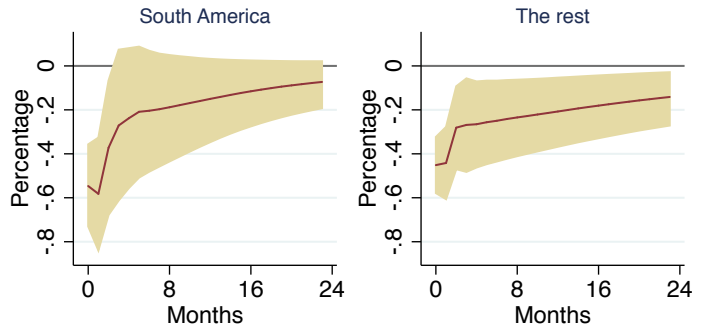

Capital flows
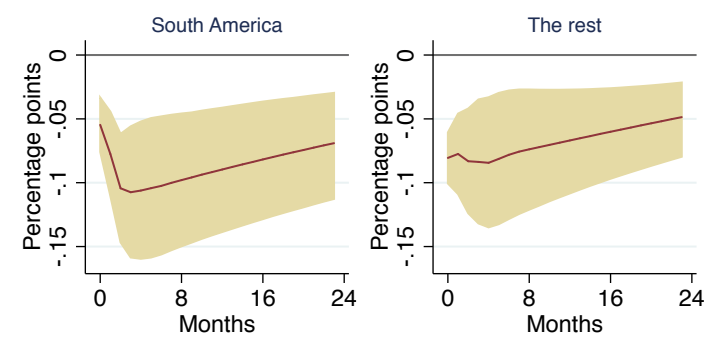

Prices
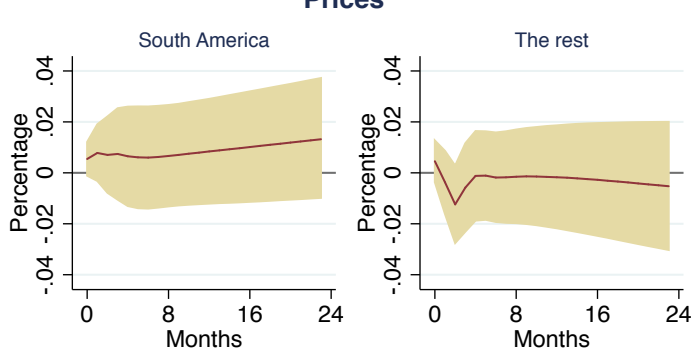

Long-term rate spreads

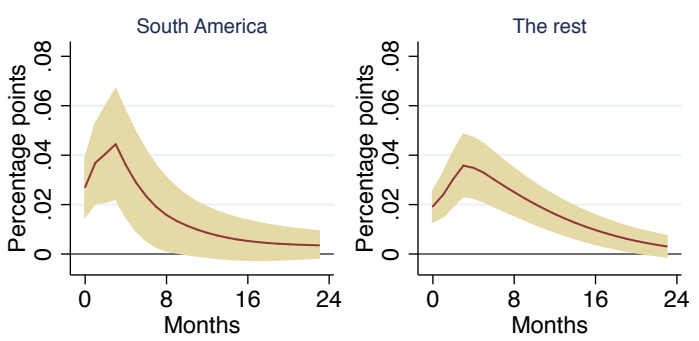

Nominal exchange rates
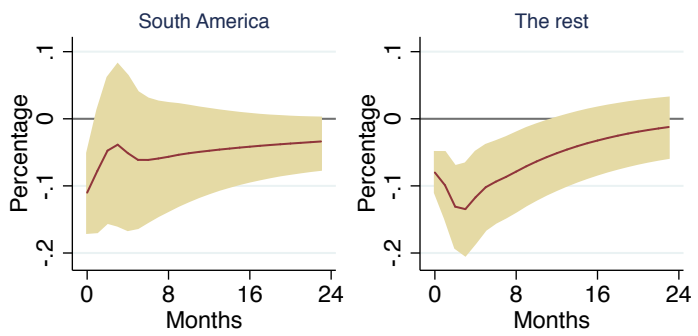

Net exports (US)
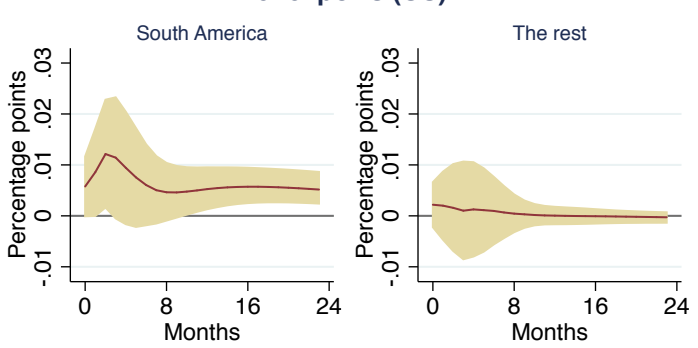

Figure B.16: Impulse responses of the EM panel VAR to the US monetary policy shock: macroeconomic and financial variables; South America vs. The rest

Notes: Each plot presents the posterior median of the impulse responses to a one standard deviation (contractionary) US monetary policy shock along with the $68 \%$ error bands in the specification for subgroup analysis that includes both the macroeconomic and financial variables. Subplots are arranged by variables and shown for two groups of countries: South America including Brazil, Chile, Colombia, Mexico, Malaysia, and Peru and the rest of the EM economies. See the notes in Figure B.15. 


\section{B.4 Capital control indices}

We present results on capital control indices. Fernandez et al (2015) construct these indices based on the de jure information extracted from IMF's Annual Report on Exchange Arrangements and Exchange Restrictions (AREAER). The indices are made available through the NBER. The construction of the indices involves using the narrative description in the AREAER to determine whether or not there are restrictions in international asset transactions (with 1 representing restriction and 0 not).

Table B.4: Capital control indices for the EMEs

\begin{tabular}{cccc}
\hline Sub-group & Aggregate Flows & Inflows & Outflows \\
\hline \hline South America & 0.46 & 0.46 & 0.46 \\
Rest & 0.66 & 0.60 & 0.72 \\
\hline
\end{tabular}

Notes: The capital control indices are from Fernandez et al (2015), where a higher value represents a greater degree of capital control measures used by the countries. We report the averages across the sub-groups for three different indices, those pertaining to aggregate capital flows, only capital inflows, and only capital outflows. Median across the sub-groups show a similar pattern. The time-period of the data is from 20042013, over which we take averages for a country.

\section{B.5 Textual analysis of central bank minutes}

We present below results from analyzing the entire text of monetary policy meeting minutes of Turkey and Peru from 2006-2016. In particular, we measure capital flow concerns as the number of times monetary policy minutes contain words in the group \{ capital flow, capital outflow, international capital market, international market\} and contrast this to the output stabilization concern measured as word count in the group \{output, economic conditions, employment, unemployment\}. 


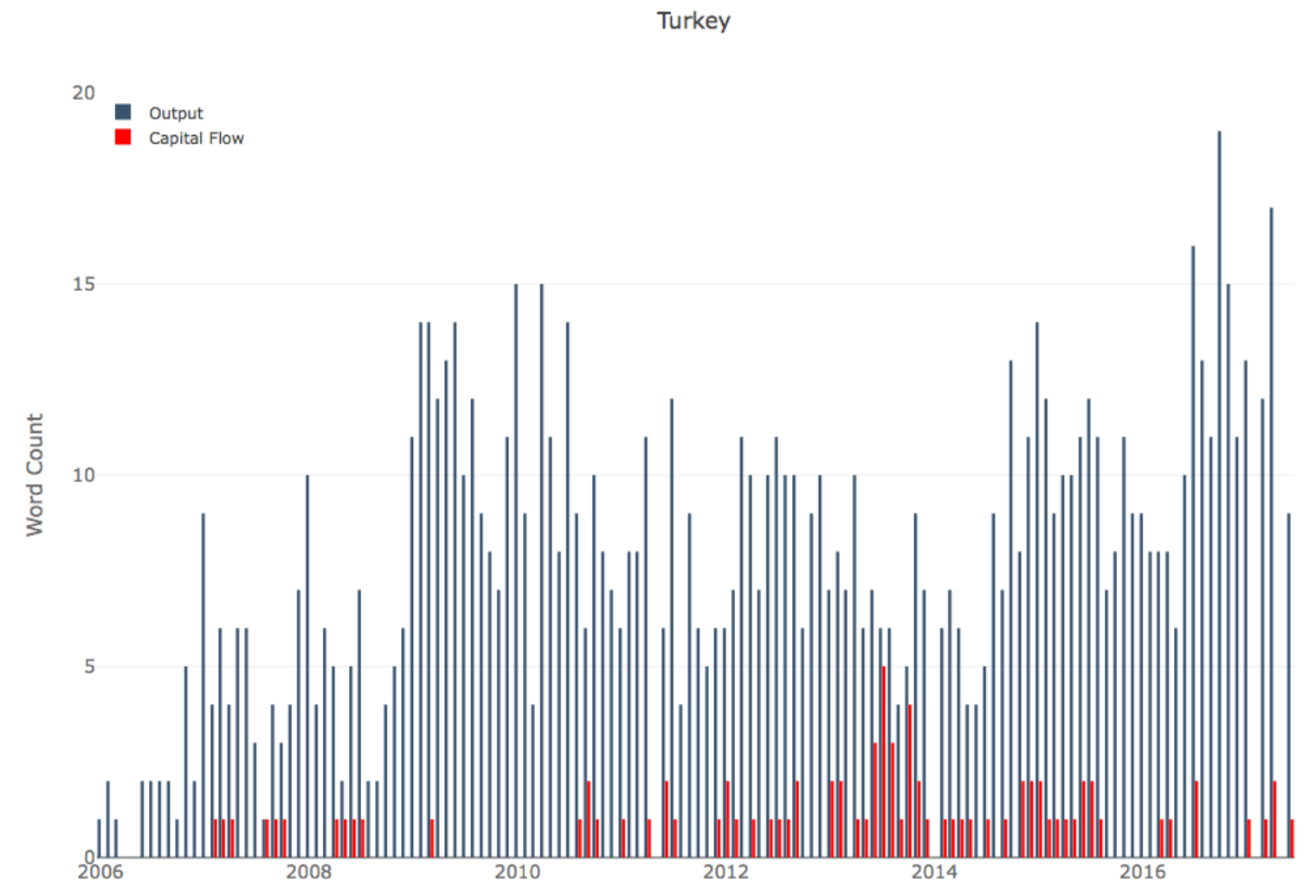

Figure B.17: Word counts reflecting concerns about output vs. capital flows in monetary policy minutes for Turkey

Notes: We use the policy minutes as given in the document "Summary of the Monetary Policy Committee Meetings." We report the number of times the monetary policy minutes contain words in two groups: \{capital flow, capital outflow, international capital market, international market\} and \{output, economic conditions, employment, unemployment\}. 


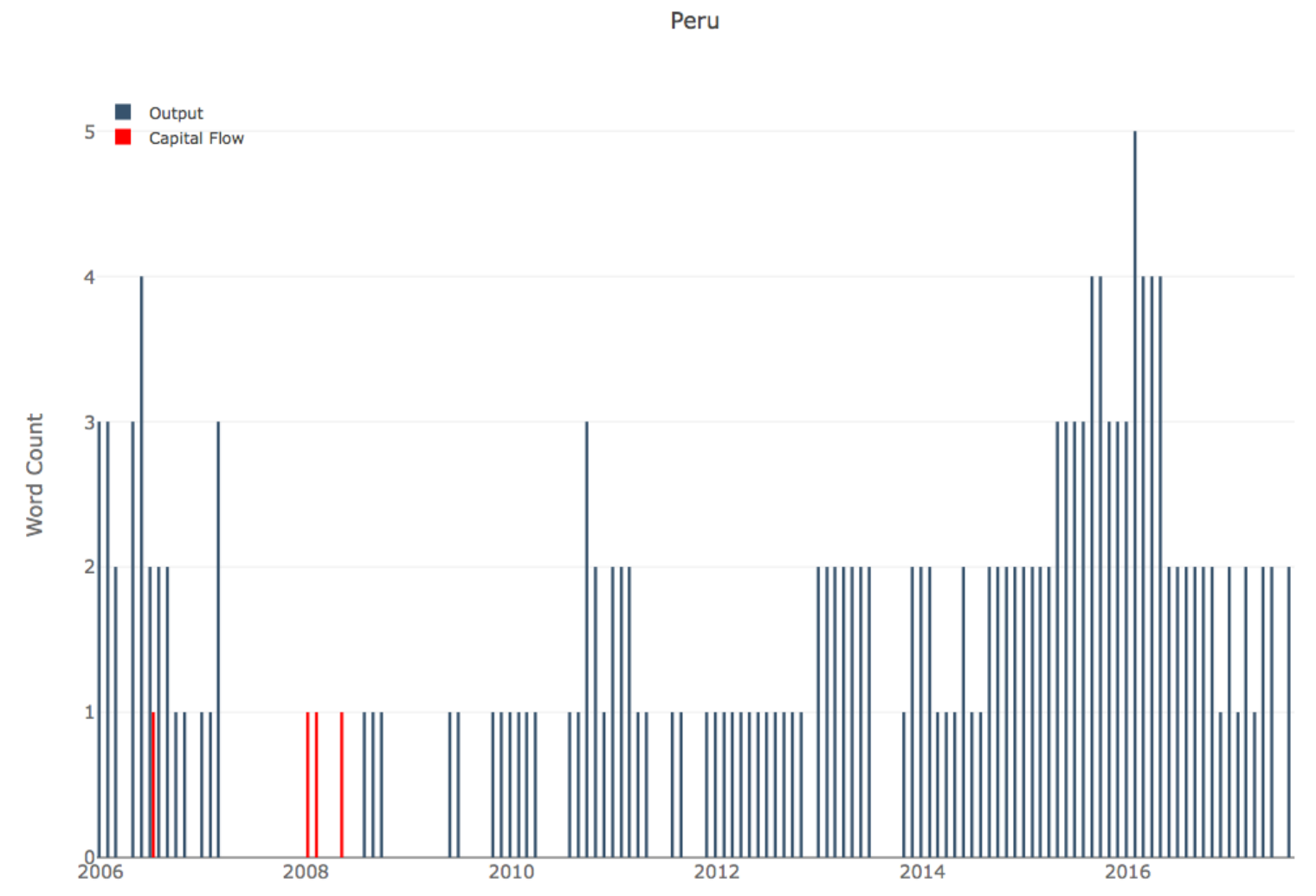

Figure B.18: Word counts reflecting concerns about output vs. capital flows in monetary policy minutes for Peru

Notes: We use the policy minutes as given in the document "Monetary Policy Notes." We report the number of times the monetary policy minutes contain words in two groups: \{capital flow, capital outflow, international capital market, international market\} and \{output, economic conditions, employment, unemployment\}. 